International Scientific-Technical and Production Journal

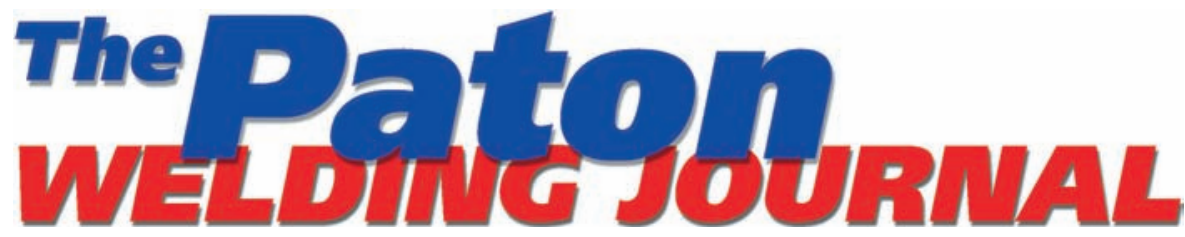

EDITORIAL BOARD

Editor-in-Chief B.E. Paton

Scientists of PWI, Kyiv S.I. Kuchuk-Yatsenko (vice-chief ed.), V.N. Lipodaev (vice-chief ed.)

Yu.S. Borisov, G.M. Grigorenko, A.T. Zelnichenko, V.V. Knysh,

I.V. Krivtsun, Yu.N. Lankin, L.M. Lobanov, V.D. Poznyakov, I.A. Ryabtsev, K.A. Yushchenko

Scientists of Ukrainian Universities V.V. Dmitrik, NTU «KhPl», Kharkov v.V. Kvasnitsky, NTUU «KPI», Kyiv

E.P. Chvertko, NTUU «KPl», Kyiv

Foreign Scientists

N.P. Alyoshin

N.E. Bauman MSTU, Moscow, Russia Guan Qiao

Beijing Aeronautical Institute, China M. Zinigrad

Ariel University, Israel V.I. Lysak

Volgograd STU, Russia Ya. Pilarczyk

Welding Institute, Gliwice, Poland U. Reisgen

Welding and Joining Institute, Aachen, Germany G.A. Turichin

St. Petersburg SPU, Russia

Founders

E.O. Paton Electric Welding Institute, NASU

International Association «Welding» Publisher

International Association «Welding» Translators

A.A. Fomin, O.S. Kurochko, I.N. Kutianova Editor

N.G. Khomenko

Electron galley

D.I. Sereda, T.Yu. Snegiryova Address

E.O. Paton Electric Welding Institute,

International Association «Welding»

11 Kazimir Malevich Str. (former Bozhenko Str.), 03150, Kyiv, Ukraine

Tel.: (38044) 20060 16, 2008277

Fax: (38044) 20082 77, 2008145

E-mail: journal@paton.kiev.ua

www.patonpublishinghouse.com

State Registration Certificate

KV 4790 of 09.01 .2001

ISSN 0957-798X

DOI: http://dx.doi.org/10.15407/tpwj Subscriptions

$\$ 384,12$ issues per year

air postage and packaging included. Back issues available.

All rights reserved.

This publication and each of the articles contained herein are protected by copyright.

Permission to reproduce material contained in this journal must be obtained in writing from the Publisher.

\section{CONTENTS}

\section{SCIENTIFIC AND TECHNICAL}

Kuchuk-Yatsenko S.I., Milenin A.S., Velikoivanenko E.A., Antipin E.V. and Didkovsky A.V. Mathematical modeling of the process of metal heating in continuous flash-butt welding

Poznyakov V.D., Zavdoveev A.V., Zhdanov S.L. and Maksimenko A.V. Influence of thermal cycle of welding on structure and mechanical properties of HAZ metal in high-strength steel produced by controlled rolling

Anoshin V.A. and Ilyushenko V.M. Effect of surface-active elements on the formation of solidification cracks

\section{INDUSTRIAL}

Elagin V.P., Tsaryuk A.K., Dunaevska N.I. and Peretyatko V.A.

Peculiarities of technology of repair welding of HPP turbounits after long-term operation

Polukhin V.V., Prokofiev A.S., Romashko D.V., Rymar S.V. and

Gubatyuk R.S. Influence of activators on the quality of spirally-welded pipes, produced with aplication of high-frequency welding

Kuskov Yu.M., Soloviov V.G., Lentyugov I.P. and Zhdanov V.A. Electroslag surfacing of layers of different thickness in stationary current-supplying mould

Borisov Yu.S., Voinarovych S.G., Kyslytsia O.M., Kaliuzhnyi S.M. and Kuzmych-lanchuk le.K. Application of thermal spraying methods for manufacture of resistive coatings (Review)

\section{NEWS}

IX International Conference «Mathematical Modelling and Information Technologies in Welding and Related Processes»

\section{INFORMATION}

LLC «TM.WELTEK»: 25 years in the world of flux-cored wires 43 


\title{
MATHEMATICAL MODELING OF THE PROCESS OF METAL HEATING IN CONTINUOUS FLASH-BUTT WELDING
}

\author{
S.I. KUCHUK-YATSENKO, A.S. MILENIN, E.A. VELIKOIVANENKO, \\ E.V. ANTIPIN and A.V. DIDKOVSKY \\ E.O. Paton Electric Welding Institute of the NAS of Ukraine \\ 11 Kazimir Malevich Str., 03150, Kyiv, Ukraine. E-mail: office@paton.kiev.ua
}

\begin{abstract}
In the last decade, an urgent and practically significant problem has been producing of high-quality joints of highstrength steels and alloys. For its solution the technologies are required which are distinguished by a high-concentration heating at a minimum energy input, including in continuous flash-butt welding of railway rails. To solve this problem, a mathematical model of the process of metal heating in continuous flash-butt welding was developed. The model allows avoiding labor-consuming and expensive experiments and significantly expanding the range of searching the ways of optimizing at a multifactor control of welding parameters, affecting, in particular, the formation of the temperature field in continuous flash-butt welding of rails. 8. Ref., 12 Figures.
\end{abstract}

Ke y words: continuous flashing, single contact, mathematical modeling, flash-butt welding, current density, efficiency coefficient, crater depth, spark gap, rail

Continuous flash-butt welding (CF) is widely used in the leading branches of industry for joining of parts from steels and alloys with different cross-section area. In accordance with acting reference documents [1] this type of welding is recommended for the parts with limited thickness of section elements, which does not exceed $12-15 \mathrm{~mm}$. These recommendations are based on the experience of commercial application of flash-butt welding using existing technologies, which do not often allow providing heating of the larger thickness parts, necessary for quality joints. Besides, in order to excite continuous flashing of such parts without resistance heating it is necessary additionally to increase source supply power. Therefore, in flash-butt welding of the larger thickness parts it is recommend to use flash-butt welding with resistance preheating.

In scopes of investigations, which were carried out at the E.O. Paton Electric Welding Institute of the NAS of Ukraine in the previous years, there were determined the main parameters of CF process, effecting the heating and formation of temperature field in a welding zone [2]. The methods for increase of energy efficiency of CF processes were proposed, in particular, allowing reduction of consumed power and rise of heating [3]. Based on these investigations there was developed a technology of CF welding of the parts with large cross-section (more than $1000 \mathrm{~mm}^{2}$ ) and thickness of more than $200 \mathrm{~mm}$. It is successfully used in industry for welding of different thickness parts of low-alloy and high-temperature steels, aluminum alloys.

In the last decade, an urgent and practically significant problem has been producing of high-quality joints of high-strength steels and alloys. For its solution the technologies are required which are distinguished by a high-concentration heating at a minimum energy input [4], including based on CF. Optimizing such processes applicable to specific production cycles is a long, labor-consuming and expensive process, therefore, it is reasonable to use together with it different methods of mathematical and computer modeling of the processes determining weldability of the parts and structure elements.

Such an approach allows significantly expanding a range for searching the optimizing ways in multifactor regulation of welding parameters, effecting, in particular, formation of temperature field.

Aim of the present paper is development of a mathematical model of temperature field kinetics in CF taking into account multifactor effect on heating intensity of high-speed processes of formation and breakdown of single contacts (SC) forming in welding applicable to typical technological cycle of CF of rails.

The mathematical model of heating process in $\mathrm{CF}$ is based on modeling of heating of SC forming in interaction of the parts being welded approaching 


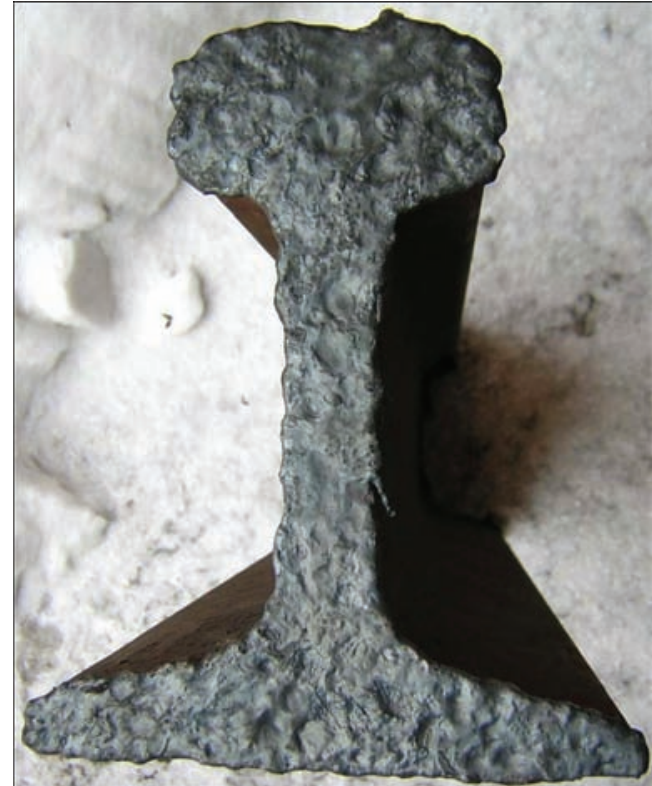

Figure 1. Appearance of rail fused surfaces

with set speed $v_{\text {apr }}$. At their interference in the areas, having microirregularities, there is formation of contacts with heating centers, where metal is melted and local heating of edges of the welded parts takes place. Heating and melting of each SC on the fusion surface provokes formation of deepening-craters generating a relief differing by nonuniform distribution of projections and deepenings (Figure 1).

Figure 2 shows a record of the welding parameters, including values of current and voltage at continuous flashing of rails in a mode accepted in production during welding using K1000 machine. As can be seen from given data at flashing excitation current $I_{w}$ in the welding circuit rapidly changes its value. The relief determined by area of SC and craters, appearing after their melting [5], is formed in fusion of the several layers of the contact surfaces.

A spark gap $\Delta_{\mathrm{g}}$, having nonconstant value (Figure 3), is formed between the contact surfaces. Amount of contacts simultaneously existing in the flashing process significantly reduces, thus, the total area of the contacts and current passing through them are decreased. An average value of resistance $R_{c}$ in the contact between the parts and value of current $I_{w}$ passing through them in flashing are kept at sufficiently stable level (see Figure 2). At that instantaneous current values $I_{\max }$ considerably differ form the average indices $I_{\mathrm{av}} I_{\max } / I_{\mathrm{av}}$ relationship describing stability of the heating process reaches the maximum values in the initial period of process excitation and is stabilized in the final. Also $I_{\max } / I_{\text {av }}$ value is specifically lower in welding of the parts with lower section thickness. In turn, presence of pulses of welding current rise relatively to its average value is caused by forma-

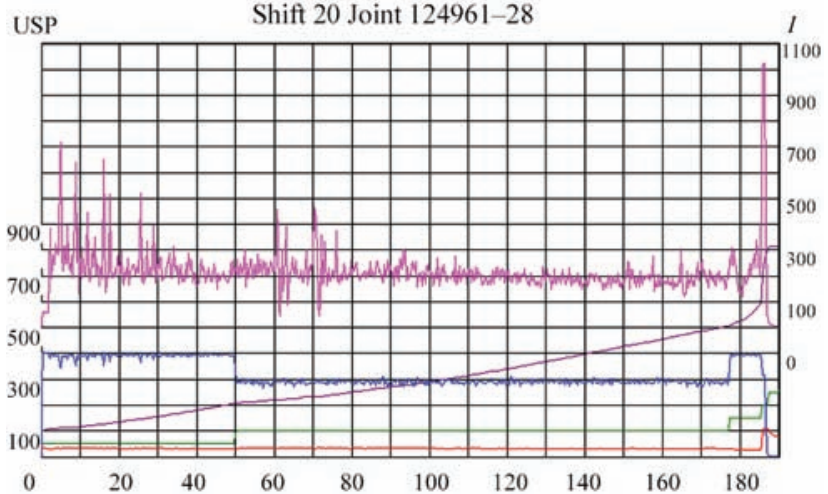

Figure 2. Example of record of the parameters of continuous flash-butt welding process of rails on stationary rail welding machine K1000

tion of the large area contacts. Indicated dependencies of formation of the large area contacts are related with specifics of flashing appearing in a phenomenon of its self-regulation. Increase of SC area and its conductivity promotes rise of generated in it heat energy that facilitates its melting and reduction of area. However, this condition is fulfilled at unlimited power of source. Under real conditions the value of instantaneous power, generated in the spark gap, is determined by accepted voltage value $U_{2 x x}$ and short-circuit resistance of the machine welding circuit that limits a range of change of contact resistance.

Relatively smooth areas are formed in the process of melting of small irregularities on the contact surfaces. This develops the conditions for formation of large area SC. Before the electric contact is formed over the whole area of these surfaces there is filling of the gap between the layers by the metal melt, formed in heating and melting of the contacts on the neighbor areas. Through this melt at sufficiently small gap formation and melting of the separate contacts, area of which is less than possible area of a new contact, are started. Phenomenon of the secondary melting, as it is shown in work [6], has considerably significant effect on heat balance at continuous flashing of the thick-wall parts.

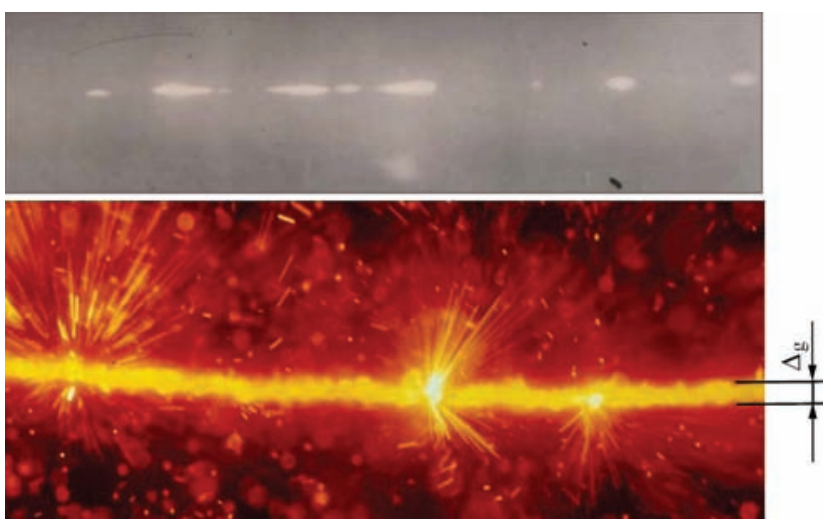

Figure 3. X-ray pattern of spark gap in rail welding 


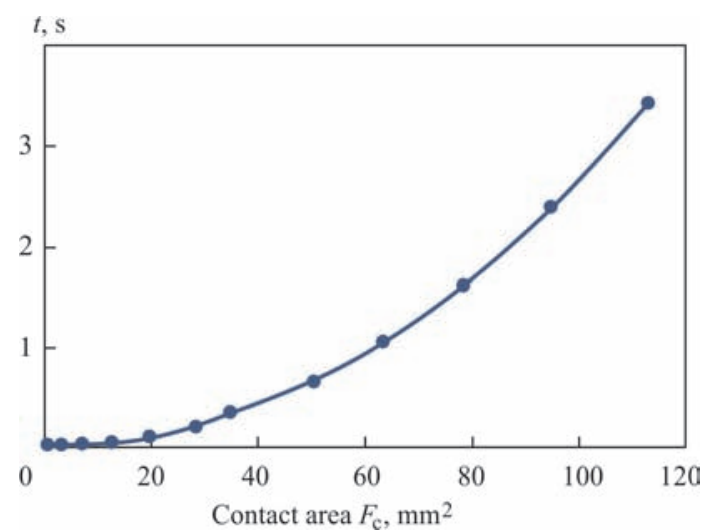

Figure 4. Time of SC existence depending on its area

Value $\Delta_{\mathrm{g}}$ is changed in every period of flashing time from 0 to $\Delta_{\mathrm{g} \max }$. Increase of contacts area rises the value of gap forming at their melting, and in this area formation of the new contacts is stopped and total number of simultaneously existing contacts is reduced. Thus, current drops to value $I_{\text {flash.av }}$, which is kept at relatively constant level and determined by feed rate in flashing. Therefore, the fusion surface relief is continuously changed, and average value $\Delta_{\mathrm{g}}$ is kept on the constant level as the average current in flashing, which is determined by amount of the simultaneously existing contacts. A distinguishing feature of this process is formation of craters of the maximum size. Depth of the craters $\Delta_{\mathrm{g}}$ remains the same for each elemental area of the fusion surface. It is determined by thickness of welded parts and voltage $U_{2 x x}$.

As can be seen from Figures 2 and 3, the contacts of different diameters can be formed at the edges of thick-wall parts in process of flashing. The duration of heating of such contacts considerably depends on their area and value of current passing through them (Figure 4). Current value $I=10 \mathrm{kA}$ and temperature $T=1800{ }^{\circ} \mathrm{C}$ as a final stage of SC heating were taken for calculation of time of existence of 1-12 mm diameter single contacts with contact area from 0.79 to $133 \mathrm{~mm}^{2}$. Following from the analysis of fusion surfaces it can be determined that the contacts of 20 to $50 \mathrm{~mm}^{2}$ area are mostly formed in the flashing pro-

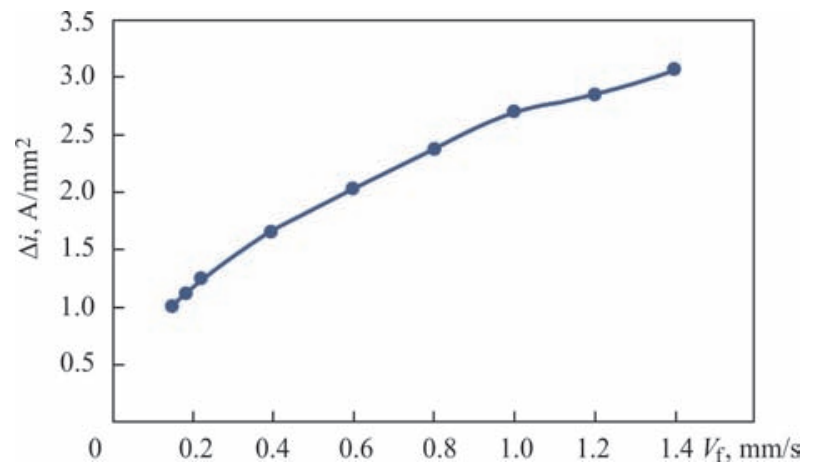

Figure 5. Dependence of value of current density on feed rate of fused surfaces cess. At that current density in them (Figure 2) is kept in the limits of $200-300 \mathrm{~A} / \mathrm{mm}^{2}$.

It was experimentally stated that the average value of current density $\Delta i_{\mathrm{w}}$ passing through the part in flashing is determined by feed rate (Figure 5) and depends on structure thickness. Rise of $v_{\mathrm{f}}$ provokes increase of $\Delta i_{\mathrm{w}}$ value at similar feed rates and secondary voltage $U_{2 x x}$ applied to the parts, and current density passing in the welding circuit is reduced with increase of part thickness. It is caused by increase of SC area and forming craters after their melting and, respectively, the average value of spark gap $\Delta_{\mathrm{g}}$ rises and number of the simultaneously existing contacts reduces. This dependence has linear nature at increase of thickness of welded parts from 5 to $30 \mathrm{~mm}$, whereas, it becomes less apparent at larger thickness of the parts. Therefore, the contacts of 5 and $8 \mathrm{~mm}$ diameters have been accepted for selection of typical sizes of simulated SC corresponding to the thicknesses of the parts being welded in 10-30 mm limits, for which CF has the widest application. The total value of current in the secondary welding circuit in CF welding of such part using machines designed at the E.O. Paton Electric Welding Institute of the NAS of Ukraine makes $20-30 \mathrm{kA}$ at 4-7 $\mathrm{V}$ voltages.

It was experimentally stated that the duration of $\mathrm{SC}$ heating is determined by the area and value of current passing through it. The analysis of current and voltage oscillograms shows that a period of time of contact existence falls at heating in a liquid state accompanied by its melting, boiling with rapid changes of resistance. Therefore, for qualitative and quantitative estimation of the heat balance in addition to the total duration of contact heating $t_{c}$ it is also reasonable to consider the heating duration in solid phase till melting temperature $t_{\mathrm{c} 1}$ of its central part at $T=$ $=1550{ }^{\circ} \mathrm{C}$ and explosion-forming breakdown at $T=$ $=1800{ }^{\circ} \mathrm{C}$.

In the most of cases there is a gap $\Delta_{\mathrm{g}}$ at the contacts boundary, the value of which can very depending on thickness of fused parts. The central part of the contact being heated to the melting temperature represents itself an ellipsoid limited by $T_{\mathrm{ml}}$ isotherms. In SC melting the part of liquid melt at the core boundary is kept by surface tension forces and remains on the crater surface after the contact breakdown. The contact being a current conductor in the welding circuit is subjected to effect of the electromagnetic forces creating in it compression and interacting with the powerful electromagnetic field of the welding machine. The compression forces can keep liquid metal in the contact area increasing the duration of its heating. They 
can also promote its displacement in the spark gap that is observed unders specific flashing conditions [7]. Effect of these forces rises with increase of $\Delta_{g}$ adjacent to the contact area. In the most cases flashing provokes explosion-like breakdown of the SC. It is experimentally determined that temperature of metal outbursted in contact breakdown can vary from 1550 to $1800{ }^{\circ} \mathrm{C}$ that corresponds to a core heating temperature. It is also determined that the lower metal temperatures correspond to heating of large area SC $\left(F_{\mathrm{c}}=50 \mathrm{~mm}^{2}\right)$ at low voltages $U_{2 x x}$ and the extremely high were observed in heating of small contacts accompanied by intensive evaporation. These data make the basis for taking into account in the calculations that the SC central part in heating to $T_{\mathrm{ml}}$ temperature will be in a solid state, and its breakdown can start at the temperatures exceeding $T_{\mathrm{ml}}$.

A section of $L_{x}, L_{y}$ size (Figure 6) was considered in development of a mathematical model of kinetics of temperature field change $T(x, y, t)$ in the SC area.

Since the main physical mechanism of heat transfer in the considered case is a heat conductivity process, then the kinetics of temperature field is described by the following relationship [8]:

$$
\frac{\partial}{\partial x}\left(\lambda \frac{\partial T}{\partial x}\right)+\frac{\partial}{\partial y}\left(\lambda \frac{\partial T}{\partial y}\right)=c \gamma \frac{\partial T}{\partial t},
$$

where $c \gamma, \lambda$ are the volumetric heat capacity and heat conductivity of material, respectively.

A convective heat exchange with the environment can be described using Newton equation, i.e. boundary conditions for considered problem (1) are the following:

$$
\lambda \frac{\partial T}{\partial n}=-\alpha\left(T-T_{0}\right)+q_{s},
$$

where $n$ is the normal line to the surface; $T_{0}$ is the ambient temperature; $\alpha$ is the coefficient of surface heat emission; $q_{\mathrm{s}}$ is the specific heating power on the contact surface.

An uniform distribution of the ambient temperature $T_{0}$ over the whole considered volume was taken as an initial condition:

$$
T(x, y, t)=T_{0} \text { at } t=0 .
$$

When reaching in the contact place some critical temperature $T_{\text {obt }}$, part of liquid metal was removed (outburst took place).

The solution (1) is based on the finite element method grounded on successive tracing in time with step $\Delta t$ of temperature distribution in the welded structure. For each tracing step (at the moment of time $t$ ) there was a solution of system of algebraic equations

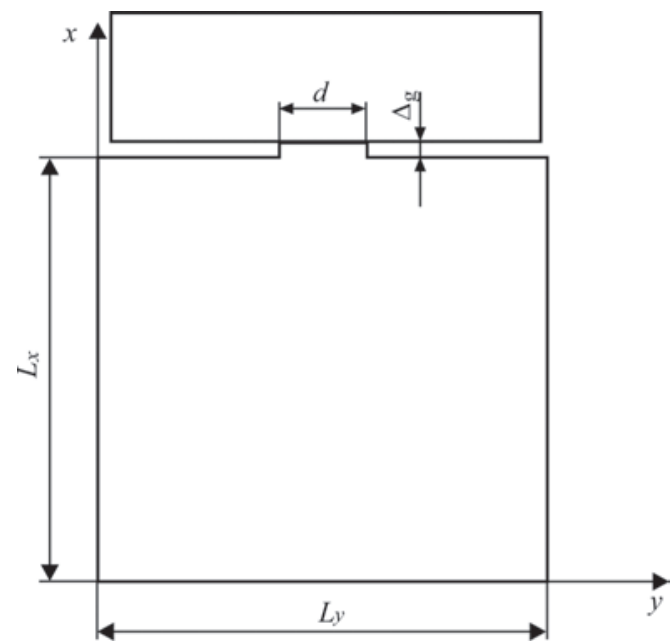

Figure 6. Typical scheme of heating of 5 and $8 \mathrm{~mm}$ diameter single contacts

obtained as a result of minimization of functional $E_{T}$ on temperatures in the nodes of finite element partition mesh (Lagrange variation principle):

$$
\begin{aligned}
& E_{\dot{O}}=-\frac{1}{2} \int_{S}\left[\frac{\partial}{\partial x}\left(\lambda \frac{\partial T}{\partial x}\right)+\frac{\partial}{\partial y}\left(\lambda \frac{\partial T}{\partial y}\right)-\right. \\
& \left.-\frac{c \gamma}{\Delta t}\left(T-T_{*}\right)\right] d S+\frac{1}{2} \int_{\Gamma}\left[\alpha\left(T-T_{0}\right)-q_{\mathrm{s}}\right] d \Gamma,
\end{aligned}
$$

where $T^{*}=T(x, y, t-\Delta t)$ is the temperature field at the moment $t-\Delta t$; $S$ is the considered total area of section in SC region; $G$ is the outer boundary of calculation area.

Derivatives $\partial T / \partial x, \partial T / \partial y$ are expressed for each finite element through the temperatures is the nodes.

Therefore, area integral $S$ is replaced with sum of area finite element integrals $\Delta S$. Minimization of (4) means equality to zero of $\partial E_{T} / \partial T_{i j}$ derivative, $i=$ $=1, \ldots, M ; j=1, \ldots, N$, where $M$ is the number of partition elements on axis $0 x, N$ is the amount of elements on $0 y$ axis.

Figure 7 shows the dependencies of time of existence of different area SCs, from the moment of appearance and to their explosion, on density of the

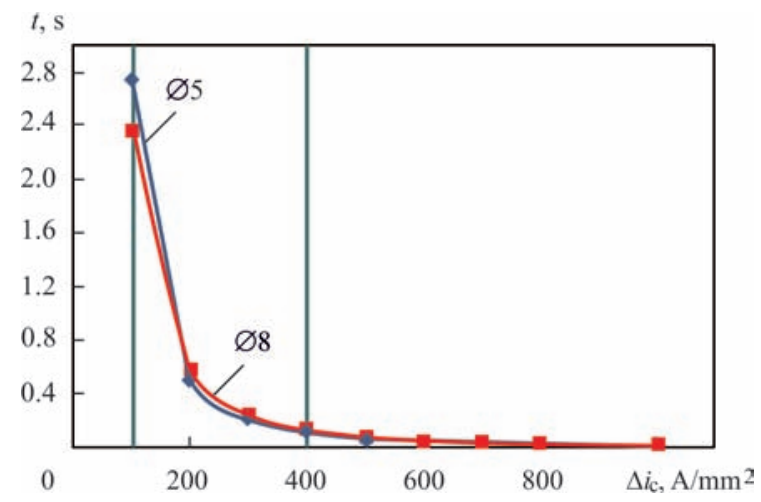

Figure 7. Dependence of time of 5 and $8 \mathrm{~mm}$ diameter SC existence on current density $\Delta i_{c}$ 
passing current. A range of change of $\Delta i_{c}$ was selected within the limits of the experimental data given in work [3], temperature of edges of the contacting parts in the initial period of heating $T_{0}=20^{\circ} \mathrm{C}$. Provided data allow making a conclusion on nonlinear effect of the current density on contact existence time, since change of the SC area does not significantly change time of its existence. It can be explained by locality of the heating process before the outburst temperature. Duration of existence of the different area contacts is reduced with rise of the current density. At the current density more than $400 \mathrm{~A} / \mathrm{mm}^{2}$ the duration of contact heating makes centiseconds and breakdown of heated volume is accompanied by intensive vapor formation. At lower current densities there is increase of the contact duration existence that demonstrates larger effect of the heat transfer processes into the edges of the contacting parts and decrease of the heating rate. At the current densities less than $100 \mathrm{~A} / \mathrm{mm}^{2}$ the duration of contacts heating rise so that successive melting of the forming contacts with a set rate of part edges approaching becomes impossible. The melting process turns to resistance heating, at which area of the contacting sections demonstrates progressive increase and propagates along the whole area of the contacting parts. Therefore, values of $\Delta i_{\mathrm{c}}$ less than $100 \mathrm{~A} / \mathrm{mm}^{2}$ for the indicated welding power sources shall be considered as minimum ones, at which excitation of CF without heating of the part edges is possible. Thus, flashing in current density range $100-400 \mathrm{~A} / \mathrm{mm}$ at the contacts can be considered the most perspective from point of view of welding heating intensification without additional effect on approaching rate of the parts. It is traditionally used mean for regulation of heating in flashing. Increase of the duration of contacts existence in preservation of their total amount and area results in rise of welding current and termination of melting, transfer of heating into a short-circuit mode. Therefore, a field of current density values, noted in Figure 7, can be determined as the field of unstable

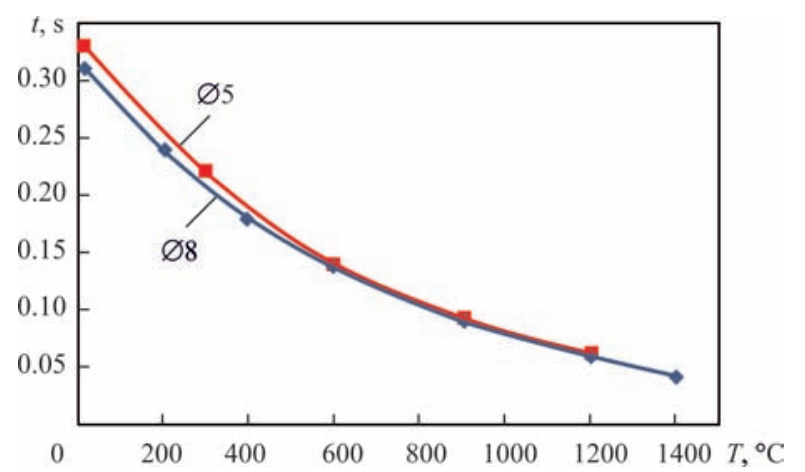

Figure 8. Dependence of time of 5 and $8 \mathrm{~mm}$ diameter SC existence on temperature of fused edges flashing in the absence of the system for automatic regulation of resistance in the contact between the parts, in particular, in initial period of flashing, when temperature of part edges is low. For given conditions of contact heating this zone corresponds to current densities $150-200 \mathrm{~A} / \mathrm{mm}^{2}$.

Provided calculation was carried out for the initial conditions of flashing, when unheated edges of the welded parts are in contact. Increase of their temperature changes the conditions of contacts heating and less energy is necessary for their heating, therefore, duration of contacts existence reduces (Figure 8). In heating of part edges to $800-900{ }^{\circ} \mathrm{C}$ the range of working current densities in the welding circuit can be reduced from 150 to $200 \mathrm{~A} / \mathrm{mm}^{2}$. This method is successfully used in selection of the optimum programs of voltage decrease in continuous flashing. Program development is based on the principle of flashing at minimum possible voltage in each period of welding. This provides flashing at current densities in a range of $200-300 \mathrm{~A} / \mathrm{mm}^{2}$ and in separate cases at the final period of flashing at $150 \mathrm{~A} / \mathrm{mm}^{2}$ density.

The developed approach can be used for solution of the practical tasks for optimizing the industrial welding cycles, in particular, at estimation of efficiency coefficient of the process. For this it is additionally necessary to estimate heat loss $q_{\text {los }}$ in a process of welding. The main mechanisms of heat loss are dissipation of heat energy into environment according to (2) as well as heat content of outbursted liquid metal. i.e.

$$
q_{\mathrm{nom}}=V_{\mathrm{obt}} \int_{T_{0}}^{T_{\mathrm{obt}}} c \gamma d T+\iint_{\Gamma \Gamma} \alpha\left(T-T_{0}\right) d \Gamma d t,
$$

where $V_{\text {obt }}$ is the sum outbursted volume of metal.

Thus, the efficiency of heat source $\eta$ in the process of welding is calculated as

$$
\eta=\frac{q_{\text {sour }}-q_{\text {nom }}}{q_{\text {sour }}},
$$

where $q_{\text {sour }}=\int_{t} W \mathrm{~d} t, W$ is the heat power of source in the area of single contact, which was taken equal 0.035IU $\mathrm{W}$, that corresponds to observed modes in experimental investigations of temperatures during welding $(I, U$ are current and voltage supplied on welded structure).

For calculation of time of existence of 5 and $8 \mathrm{~mm}$ diameter SC there was taken a current density value of $\Delta i=250 \mathrm{~A} / \mathrm{mm}^{2}$ and temperature $T=1800{ }^{\circ} \mathrm{C}$ as a final heating stage. The heating modes in 100 $400 \mathrm{~A} / \mathrm{mm}^{2}$ ranges are of significant interest from point of view of intensification of heating in flashing 


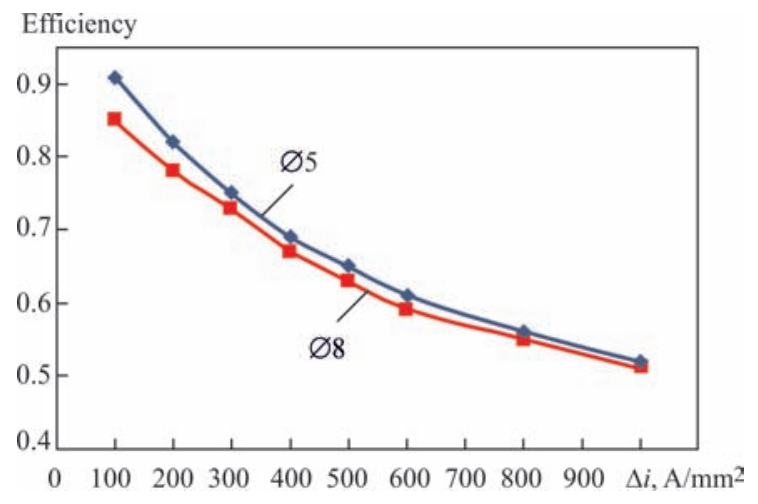

Figure 9. Dependence of thermal efficiency of heating of 5 and $8 \mathrm{~mm}$ diameter contacts on $\Delta i$ passing through SC

since they allow rising welding current and process thermal efficiency. Figure 9 shows the dependencies of thermal efficiency of flashing process according to (6) in variation of current density in the contacts. The highest values of thermal efficiency can be reached in $\Delta i=100-400 \mathrm{~A} / \mathrm{mm}^{2}$ value range independent on the contact area.

Besides, effect of temperatures of edges being fused on the value of thermal efficiency of welding process was investigated using numerical analysis of temperature distribution in the welding process. For this the SC with passing through it current of $250 \mathrm{~A} / \mathrm{mm}^{2}$ density was considered. As it is shown in Figure 10, increase of temperature of a near-contact metal layer, where SC appears, provokes decrease of thermal efficiency of the process. It is caused by the fact that the energy transferred into the part edges continuously decreases with temperature increase, and lost with melted metal remains constant and even rises. Thermal efficiency in flashing heating respectively reduces.

Obtained results of the numerical analysis of temperature field kinetics in SC area can be used for consideration of a complex of problems on optimizing the specific industrial cycles, in particular, applicable to flash-butt welding of rails. Calculation of the temperature kinetics $T$ in continuous flash-butt welding of

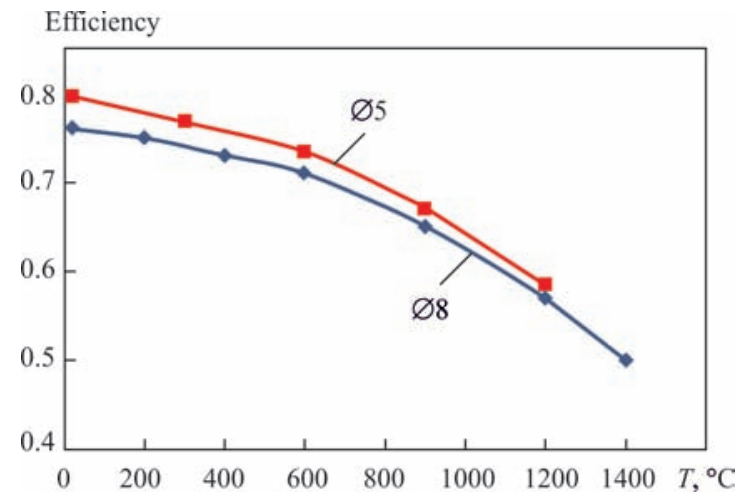

Figure 10. Dependence of thermal efficiency of heating of 5 and $8 \mathrm{~mm}$ diameter contacts on temperature of near-contact layer of metal adjacent to fusion surface

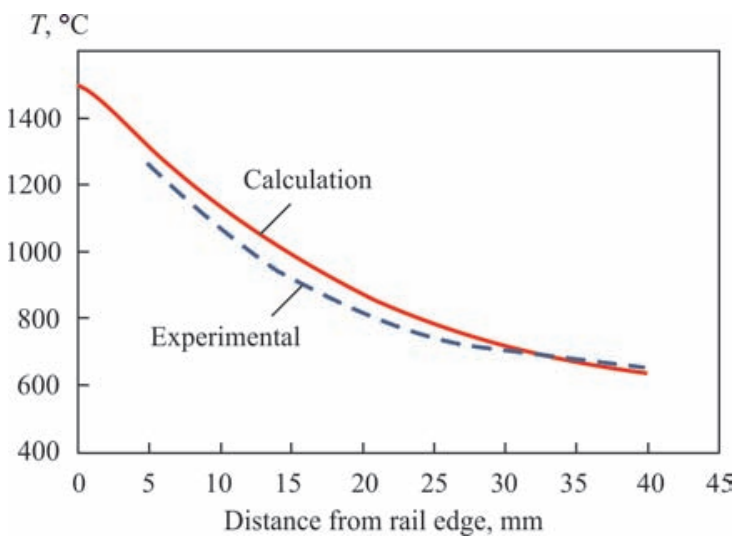

Figure 11. Distribution of temperature along rail axis in continuous flashing

rails, the same as for $\mathrm{SC}$, is based on the algorithm of numerical solution of $3 \mathrm{D}$ heat conductivity equation in Cartesian coordinate system $x, y, z$ :

$$
\frac{\partial}{\partial x}\left(\lambda \frac{\partial T}{\partial x}\right)+\frac{\partial}{\partial y}\left(\lambda \frac{\partial T}{\partial y}\right)+\frac{\partial}{\partial z}\left(\lambda \frac{\partial T}{\partial z}\right)=c \gamma \frac{\partial T}{\partial t} .
$$

Convective heat exchange with the environment and initial conditions were taken the same as in SC calculation according to relationships (2) and (3). The functional, minimizing of which allows forming the necessary system of linear algebraic equations in scope of finite element solution of heat conductivity problem, for this case will be presented in the next form:

$$
\begin{aligned}
E_{T}= & -\frac{1}{2} \int_{V}\left[\frac{\partial}{\partial x}\left(\lambda \frac{\partial T}{\partial x}\right)+\frac{\partial}{\partial y}\left(\lambda \frac{\partial T}{\partial y}\right)+\frac{\partial}{\partial z}\left(\lambda \frac{\partial T}{\partial z}\right)-\right. \\
& \left.-\frac{c \gamma}{\Delta t}\left(T-T_{*}\right)\right] d V+\frac{1}{2} \int_{\Gamma}\left[\alpha\left(T-T_{0}\right)-q_{s}\right] d \Gamma,
\end{aligned}
$$

where $V$ is the considered volume in the welded structure.

The real data, obtained in continuous flash-butt welding of rails on stationary rail welding machine K1000 was used for calculation of the temperature field. Besides, measurement of the temperature field

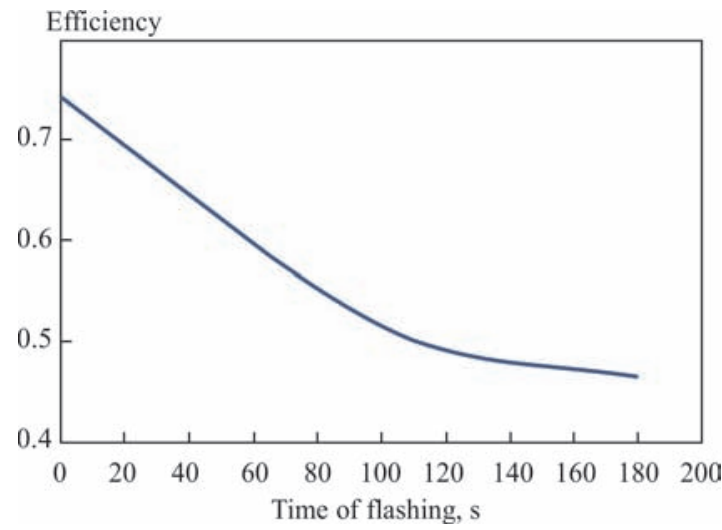

Figure 12. Change of thermal efficiency in process of continuous flashing of rails 
using thermocouples was carried out in welding of this joint.

As can be seen from Figure 11, the developed model allows with sufficiently high accuracy predicting the kinetics of temperature field in the considered case that permits its later on application for selection of the optimum temperature modes without performance of expensive experiments. In particular, calculation of efficiency for continuous flashing of rails was carried out based on (6). The results of numerical prediction (Figure 12) show that welding efficiency is sufficiently high in the initial period, but it drops in process of flashing.

It is caused by the fact that the temperature of edges of fused surfaces rises, and thermal efficiency varies as in the case of SC heating (see Figure 10). Application of this model allows significantly expanding the range of searching the ways for intensification of heating in multifactor regulation of the welding parameters, effecting formation of the temperature field as well as make easier search of the optimum thermal cycles in continuous flashbutt welding of thick-wall parts.

\section{Conclusions}

1. Analysis of the records of welding parameters and rail fusion surfaces showed that continuous flashing of thick-walled parts can provoke formation of the contacts of different diameters, but their maximum area does not exceed area corresponding to 5 and $8 \mathrm{~mm}$ diameter contacts.

2 Duration of heating of different area contacts with continuous flashing depends on the value of current density passing through the contact.
3 There is noticeable dependence of the time of contacts heating on the value of current density in $100-400 \mathrm{~A} / \mathrm{mm}^{2}$ current density range.

4. Increase of temperature of the contact surface provokes significant reduction of the duration of its heating.

5. There were determined the general dependencies of thermal efficiency at continuous flashing on current density passing through the contact, and temperature in the contact zone. It is determined that increase of the current density and temperature of the contact promotes decrease of thermal efficiency.

The temperature field in continuous flash-butt welding of R65 type rails at optimum mode was determined by calculation. The calculation result is close to the experimental one.

1. (2011) GOST R ISO 15614-13-2009: Specification and qualification of welding procedures for metallic materials. Welding procedure test. Pt 13: Resistance butt and flash welding. Moscow, Standartinform [in Russian].

2. TU U 27.1-40081293-002:2016: New welded rails for railways. Dnipropetrovske NKTB, NDKTI PJSC Ukrzaliznytsya [in Ukrainian].

3. Kuchuk-Yatsenko, S.I. (1992) Continuous flash-butt welding. Kiev, Naukova Dumka [in Russian].

4. Weingrill, L. Enzinger, N. (2017) Temperature fields evolution during flash-butt welding of railway rails. Mater. Sci. Forum, 879, 2088-2093.

5. Orlov, B.D., Chakalev, A.A., Dmitriev, Yu.V. (1986) Technology and equipment for resistance welding. Moscow, Mashinostroenie [in Russian].

6. Kuchuk-Yatsenko, S.I. (1976) Flash-butt welding. Kiev, Naukova Dumka [in Russian].

7. Yan Guo Li, Fu Cheng Zang (2010) Numerical simulation of flash-butt welding of high-manganese steel crossing with carbon steel rail. Adv. Mater. Research, 123-125, 571-574.

8. (2005) Processes and mechanisms of welding residual stress and distortion. Ed. by Zhili Feng. Sawston, Woodhead Publishing. 


\title{
INFLUENCE OF THERMAL CYCLE OF WELDING ON STRUCTURE AND MECHANICAL PROPERTIES OF HAZ METAL IN HIGH-STRENGTH STEEL PRODUCED BY CONTROLLED ROLLING
}

\author{
V.D. POZNYAKOV, A.V. ZAVDOVEEV, S.L. ZHDANOV and A.V. MAKSIMENKO \\ E.O. Paton Electric Welding Institute of the NAS of Ukraine \\ 11 Kazimir Malevich Str., 03150, Kyiv, Ukraine. E-mail: office@paton.kiev.ua
}

\begin{abstract}
At present there is a tendency to develop high-strength alloyed steels with yield limit of more than $590 \mathrm{MPa}$, in which heat treatment (quenching and tempering) is replaced by the process of controlled rolling with subsequent accelerated cooling. Application of technologies of welding such steels is now based only on recommendations of the manufacturer of metal and welding consumables, as well as on carbon equivalent. Considering that the new generation of steels, including alform $620 \mathrm{M}$, was produced due to complex application of both microalloying and thermomechanical treatment with subsequent accelerated cooling, the obtained properties can be lost as a result of softening during processing stages, associated with steel heating. As the level of the change of mechanical properties of HAZ metal determines steel weldability, the influence of thermal cycles of welding on the properties and structure of HAZ metal in high-strength steel alform $620 \mathrm{M}$ is considered at the first stage of investigations. Performed investigations revealed that optimum combinations of mechanical properties and structure can be achieved at the rate of cooling of welded joint HAZ metal higher than $25^{\circ} \mathrm{C} / \mathrm{s} .10$ Ref., 2 Tables, 4 Figures.
\end{abstract}

Keywords: high-strength steel, controlled rolling, thermal cycles of welding, heat-affected zone, structure, properties

Lowering the specific weight of structures under the condition of ensuring their required service reliability is one of the main tasks solved daily by the developers of machines, mechanisms and metal structures. Successful fulfillment of this task is largely determined by the properties of steels, applied for their manufacture. First of all, we are talking about the strength of steel, both at static and at dynamic loads. One of the directions for increasing the strength of rolled steel is producing quenching structures by thermal refining of low-carbon metal (quenching and tempering) and limited alloying with manganese, chromium, nickel and molybdenum, in combination with the carbideand nitride forming elements [1]. Alongside the high values of strength $\left(\sigma_{0.2} \geq 590 \mathrm{MPa}\right)$ alloyed steels such as $14 \mathrm{Kh} 2 \mathrm{GMR}, 12 \mathrm{GN} 2 \mathrm{MFAYu}, 14 \mathrm{KhN} 2 \mathrm{MDAFB}$, etc., have a sufficient margin of ductility, good brittle fracture resistance and weldability. This is indicated by half a century experience of operation of welded structures, made from them: powerful mine excavators, heavy-duty vehicles, construction and road machinery.

At present there are tendencies for development of high-strength alloyed steels with $\sigma_{0.2} \geq 590 \mathrm{MPa}$, in which thermal treatment is replaced by the process of controlled rolling with subsequent accelerated cool- ing. Such steels began to enter the metal market of Ukraine, and can be applied in mechanical engineering, metallurgy, mining and processing industries. For instance, radial blowers [2] (exhausters) of H7500 type of riveted design are used in metallurgical works of Ukraine for pumping out the combustion products of open-hearth furnaces, sinter and converter gases. Replacement or repair of exhausters requires stopping the production line for the period from several hours up to several days that affects the productivity of sinter, open-hearth and converter process. The process of repair of the exhauster proper is a very long and labour-consuming one, as mostly exhausters with riveted impellers are operating (repair involves replacement of blades or blades and central disc). In connection with a short operating time and need for frequent scheduled repair of H7500 impeller, a fundamentally new welded structure was developed with the assistance of PWI specialists [2]. As is known, the most heavy-duty part of the impeller is its central disc. The main requirements at selection of material for manufacture of exactly this part were as follows: certain percent of carbon content (to ensure good weldability), as well as calculated values of yield limit (more than $600 \mathrm{MPa}$ ), (for preservation of structure integrity at operation in the higher temperature range) 
Table 1. Chemical composition of steel alform 620M, wt.\%

\begin{tabular}{|c|c|c|c|c|c|c|c|c|c|c|c|c|}
\hline $\mathrm{C}$ & $\mathrm{Si}$ & $\mathrm{Mn}$ & $\mathrm{P}$ & $\mathrm{S}$ & $\mathrm{Al}$ & $\mathrm{Cr}$ & $\mathrm{Mo}$ & $\mathrm{Ni}$ & $\mathrm{V}$ & $\mathrm{Nb}$ & $\mathrm{Ti}$ & $\mathrm{B}$ \\
\hline 0.08 & 0.37 & 2.0 & 0.005 & 0.01 & 0.027 & 0.38 & 0.21 & 0.02 & 0.01 & 0.043 & 0.017 & 0.001 \\
\hline
\end{tabular}

and relative elongation (to ensure structure ductility). Proceeding from these data, high-strength low-alloyed steel alform 620M, microalloyed by niobium and vanadium, was selected, which is produced by an Austrian company, and supplied in the condition after controlled rolling and accelerated cooling.

By the data of EN10025-2 standard, this steel is characterized by the following mechanical properties: increased strength properties $\left(\sigma_{\mathrm{y}}>620 \mathrm{MPa}\right.$; $\left.\sigma_{\mathrm{t}}=730 \mathrm{MPa}\right)$; high ductility $\left(\delta_{5}=23 \%\right)$ and impact toughness $\left(K C V_{-40}>34 \mathrm{~J} / \mathrm{cm}^{2}\right)$. Such mechanical properties are due to finely dispersed structure, produced by controlled rolling and subsequent accelerated cooling. These steels have predominantly bainite structure [3-5]. Vanadium, niobium and titanium additives promote metal reaustenitization, preventing austenitic grain growth. Dispersion hardening is effectively controlled by vanadium content. One of the most important mechanical characteristics is impact toughness, which also has differences both in niobium and in niobium-vanadium steels [6,7]. Maximum impact toughness of steel with niobium corresponds to cooling rate of $20^{\circ} \mathrm{C} / \mathrm{s}$, whereas for steel with vanadium additive this temperature shifts to $60{ }^{\circ} \mathrm{C} / \mathrm{s}$. With lowering of the cooling rate to $6^{\circ} \mathrm{C} / \mathrm{s}$, an essential decrease in impact toughness of both the steels is observed, that is associated with formation of granular bainite. Lowering of ductility of these steels is associated with precipitation of brittle inclusions along the bainite grains, coarsening of the austenitic grain during welding and changing of bainite morphology from lamellar to granular one.

Today application of the technologies of welding high-strength steels produced by the methods of controlled rolling is based only on the recommendations of the manufacturer of metal $[8,9]$ and welding consumables, as well as on carbon equivalent. This is obviously not enough for development of critical welded structures, using processing involving heating from 300 up to $1500^{\circ} \mathrm{C}$, which are exposed to dynamic and alternating loading. Considering that the new generation of steels, including alform 620M, are produced due to complex use of both microalloying, and themomechanical treatment with subsequent accelerated

Table 2. Mechanical properties of steel alform 620M

\begin{tabular}{|c|c|c|c|}
\hline$\sigma_{\mathrm{y}}, \mathrm{MPa}$ & $\sigma_{\mathrm{t}}, \mathrm{MPa}$ & $\delta_{5}, \%$ & $\psi, \%$ \\
\hline 667 & 731 & 24 & 77 \\
\hline
\end{tabular}

cooling, the obtained properties can be lost as a result of softening during processing operations associated with steel heating. It is known that the metal structure and mechanical properties can change significantly under the impact of welding thermal cycles (WTC). The influence of welding thermal cycles on the properties and structure of HAZ metal was established by the results of studies performed on high-strength steel S460M [10], produced by controlled rolling with subsequent accelerated cooling. It is shown that with increase of HAZ metal cooling rate $w_{6 / 5}$ from 3 up to $25{ }^{\circ} \mathrm{C} / \mathrm{s}$ the ferrite-pearlite structure transforms into bainite structure that results in hardness increase from $H V 190$ up to $H V 280$, as well as increase of strength characteristics [10]. However, the question of studying the weldability of steel of a higher strength class remains urgent. As the level of change of mechanical properties of the HAZ metal determines the steel weldability, the first stage of studies is devoted to consideration of the influence of welding thermal cycles on the properties and structure of HAZ metal in high-strength low-alloyed steel alform plate $620 \mathrm{M}$, microalloyed by niobium and vanadium.

Experimental procedure. Structural steel alform $620 \mathrm{M}$ which is supplied in the condition after controlled rolling was used for the experiments. Chemical composition of this steel is given in Table 1, and its mechanical properties are shown in Table 2.

As was already mentioned, the structure and properties of rolled steel HAZ metal can change under the impact of welding thermal cycles. Therefore, this impact on alform $620 \mathrm{M}$ steel was studied at the initial stage of the work. Rate of cooling of metal, heated up to temperatures of $1200-1300{ }^{\circ} \mathrm{C}$, in the temperature range of $600-500{ }^{\circ} \mathrm{C}\left(w_{6 / 5}\right)$, was taken as WTC criterion. Investigation results were used to determine the limit cooling rates $\left(w_{6 / 5 \min }\right.$ and $\left.w_{6 / 5 \max }\right)$, below and above which lowering of strength and ductility values of HAZ metal occurs, compared to the specified requirements to welded joints. Change of mechanical property values, depending on the cooling rate of $\mathrm{HAZ}$ metal in the temperature range of $600-500{ }^{\circ} \mathrm{C}$ was studied with application of model samples of $120 \times 12 \times 12 \mathrm{~mm}$ size, which were heat-treated in MSR-75 unit, in keeping with welding thermal cycles. Heat treatment process was as follows. First the samples were heated by passing current up to temperatures of $1200-1300{ }^{\circ} \mathrm{C}$, which are characteristic 

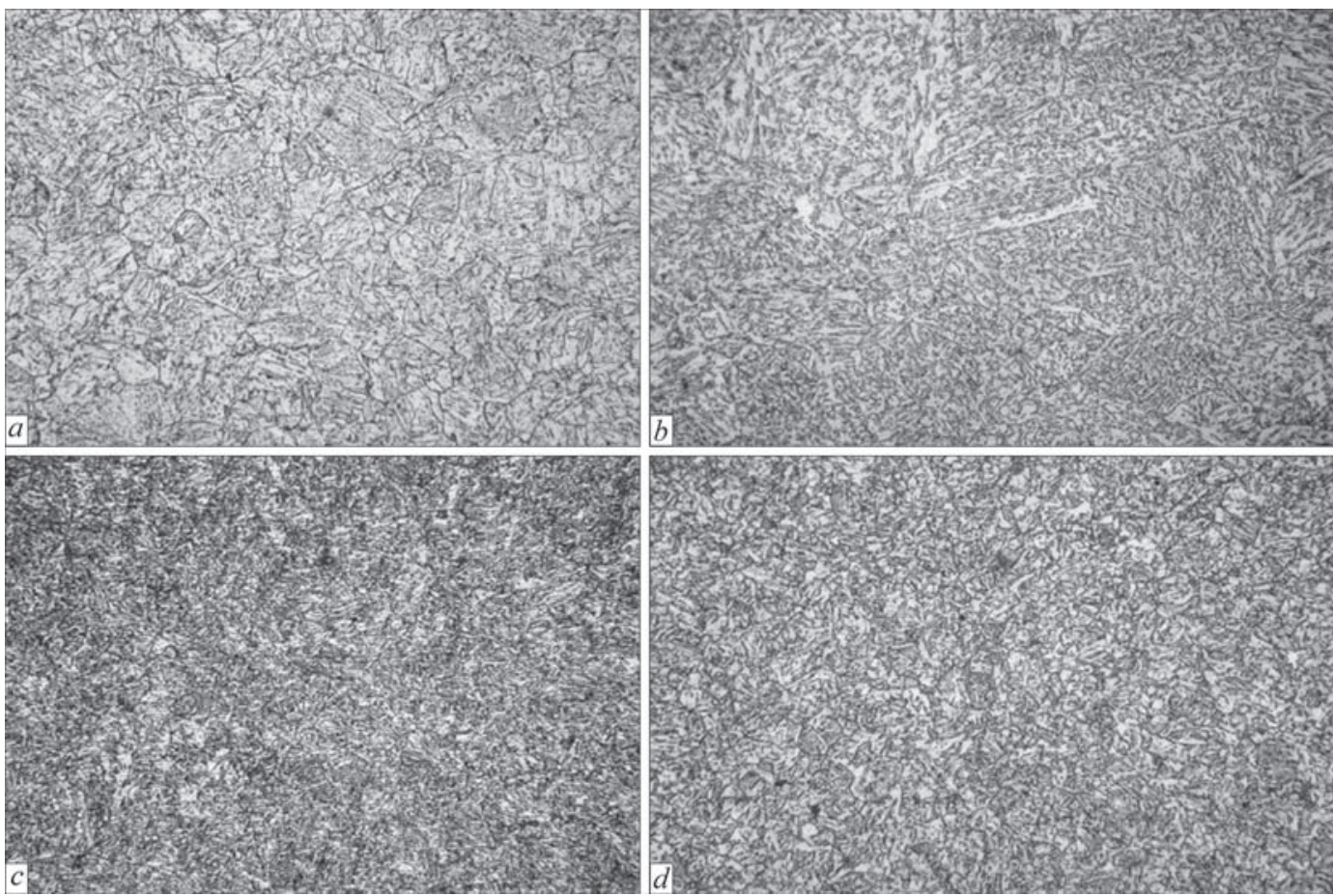

Figure 1. Microstructure $(\times 500)$ of steel alform $620 \mathrm{M}$, depending on cooling rate $w_{6 / 5}: a-$ base metal; $b-3 ; c-12 ; d-25^{\circ} \mathrm{C} / \mathrm{s}$

for the overheated zone of welded joint HAZ. Sample heating rate was equal to $150-170{ }^{\circ} \mathrm{C} / \mathrm{s}$ that corresponds to the conditions of metal heating in the heat-affected zone at arc welding processes. At this temperature, the samples were soaked approximately for two seconds, and then were cooled forcedly. The rate of sample heating-cooling was controlled by chromel-alumel thermocouple of $0.5 \mathrm{~mm}$ diameter. Samples of type II to GOST 6996-96 were mechanically cut out of the steel for static tensile testing (three samples for each cooling rate). Testing was performed to GOST 6996-66 at the temperature of $20^{\circ} \mathrm{C}$.

Results and discussion. Structure and mechanical properties of thermomechanically strengthened steel alform 620M were studied in this work. Thermomechanical rolling in the temperature range of $900-700{ }^{\circ} \mathrm{C}$ with controlled cooling leads to formation in steel alform $620 \mathrm{M}$ of a bainite structure (predominantly lower bainite - $90 \%$ ) with grain size of the order of $40 \mu \mathrm{m}$ and hardness $H V 280$.

Impact toughness values of steel alform 620M are essentially higher than the normative values and are equal to $K C V_{-40}=307 \mathrm{~J} / \mathrm{cm}^{2}$. Therefore, by the values of static strength, ductility and impact toughness steel alform $620 \mathrm{M}$ can be considered to be promising from the viewpoint of its application for blower fans of the equipment of ore-dressing complex.

In their turn, the dependencies characterizing the change of strength and ductility values in modeled HAZ metal of steel alform $620 \mathrm{M}$ under the impact of WTC are given in Figure 2. Results of the conduct- ed investigations are indicative of the fact that at the cooling rate $w_{6 / 5}=3{ }^{\circ} \mathrm{C} / \mathrm{s}$ in the temperature range of $600-500{ }^{\circ} \mathrm{C}$, the values of yield limit of HAZ metal decrease, compared to the initial state, namely $\sigma_{0.2}$ from 667 to $553 \mathrm{MPa}$; with $w_{6 / 5}$ increase up to $12{ }^{\circ} \mathrm{C} / \mathrm{s}$ the yield limit rises up to 580, and up to $585 \mathrm{MPa}$ at $w_{6 / 5}=25^{\circ} \mathrm{C} / \mathrm{s}$. Ultimate strength $\sigma_{\mathrm{t}}$ decreases slightly to $723 \mathrm{MPa}$ at $w_{6 / 5} 3^{\circ} \mathrm{C} / \mathrm{s}$, and then rises up to $790 \mathrm{MPa}$ at $w_{6 / 5}=25^{\circ} \mathrm{C} / \mathrm{s}$. At the same time, ductile properties of modeled HAZ metal compared to the initial state change only slightly (changes do not exceed 5-10\%).
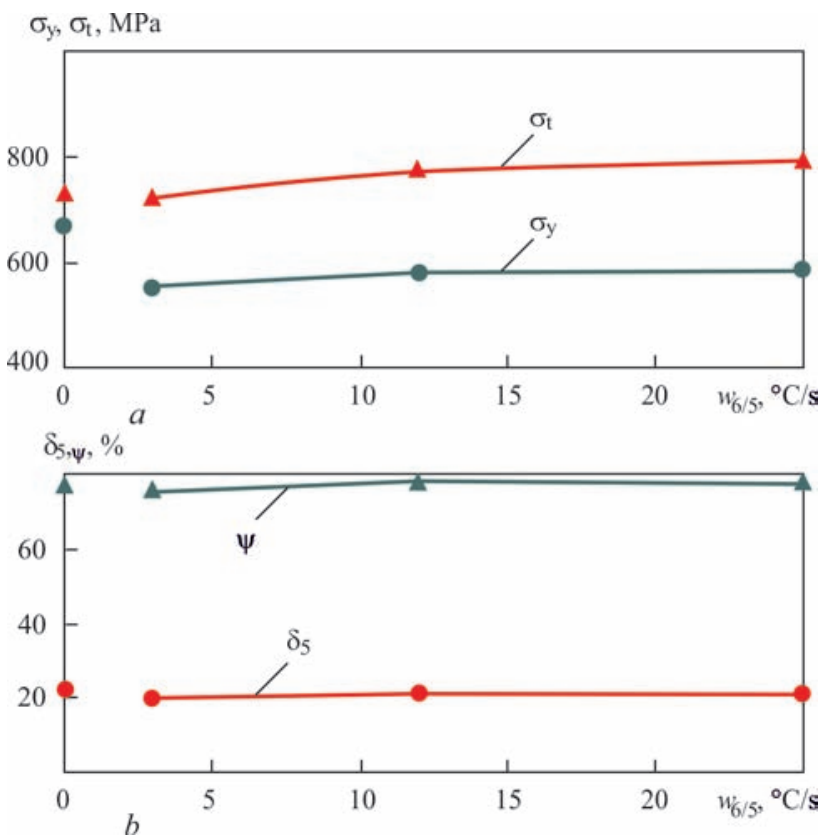

Figure 2. Mechanical properties of steel alform 620M, depending on cooling rate $w_{6 / 5}$ 


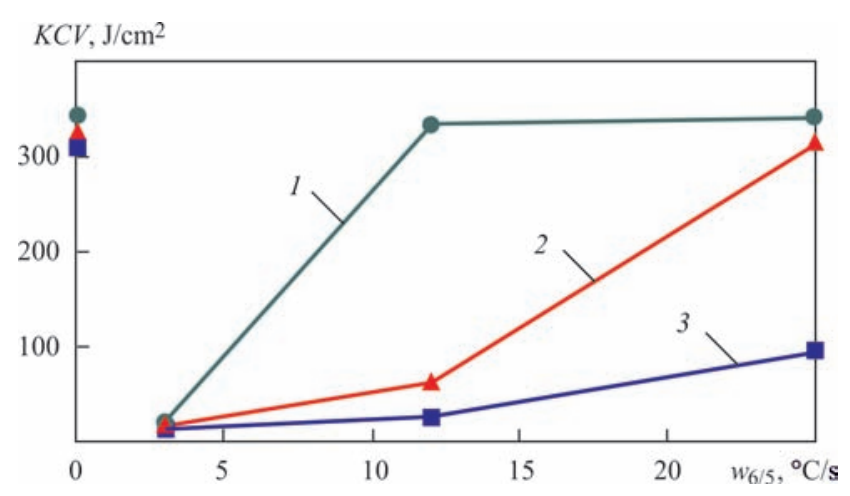

Figure 3. Impact toughness of steel alform $620 \mathrm{M}$, depending on cooling rate $w_{6 / 5}\left(1-20 ; 2--20 ; 3--40^{\circ} \mathrm{C}\right)$

At impact bend testing of samples with a sharp $\mathrm{V}$-shaped notch it was established that impact toughness of HAZ metal of steel alform 620M decreases relative to base metal (Figure 3). The most significant lowering of $K C V$ values is observed in samples, which cooled down at the rate of $w_{6 / 5}=3{ }^{\circ} \mathrm{C} / \mathrm{s}$ (from 341 to $21.2 \mathrm{~J} / \mathrm{cm}^{2}$ at testing temperature of $20^{\circ} \mathrm{C}$, from 329 to $19.5 \mathrm{~J} / \mathrm{cm}^{2}$ at the temperature of $-20^{\circ} \mathrm{C}$ and from 307 to $14.3 \mathrm{~J} / \mathrm{cm}^{2}$ at the temperature of $-40{ }^{\circ} \mathrm{C}$ ). With increase of cooling rate up to $12^{\circ} \mathrm{C} / \mathrm{s}$, they increase somewhat for impact toughness values at negative temperatures and increase significantly for testing at room temperature: $K C V_{20}=332 \mathrm{~J} / \mathrm{cm}^{2}, K C V_{-20}=$ $=62 \mathrm{~J} / \mathrm{cm}^{2}$ and $K C V_{-40}=27 \mathrm{~J} / \mathrm{cm}^{2}$. With increase of cooling rate to $25^{\circ} \mathrm{C} / \mathrm{s}$, they rise up to the following values: $K C V_{20}=340 \mathrm{~J} / \mathrm{cm}^{2}, K C V_{-20}=312 \mathrm{~J} / \mathrm{cm}^{2}$ and $K C V_{-40}=94 \mathrm{~J} / \mathrm{cm}^{2}$.

Such changes of mechanical properties of HAZ metal of steel alform $620 \mathrm{M}$ are due to different structural transformations in the range of the studied cooling rates. This is evidenced by the results of metallographic studies. These studies showed that a structure consisting of different morphological forms of lower and upper bainite with prevalence of the latter (Figure $2, b$ ), with average grain size of the order of 65 $\mu \mathrm{m}$, formed in the overheated zone of the HAZ metal of steel alform $620 \mathrm{M}$ at the cooling rate $w_{6 / 5}=3^{\circ} \mathrm{C} / \mathrm{s}$. Hardness of such metal is equal to HV220.

At $w_{6 / 5}$ increase up to $12{ }^{\circ} \mathrm{C} / \mathrm{s}$ an equiaxed bainite structure forms with lower bainite content of $60 \%$. Grain size decreases and corresponds to $15-25 \mu \mathrm{m}$, hardness increasing up to HV250.

At further increase of the cooling rate up to $w_{6 / 5}=$ $=25{ }^{\circ} \mathrm{C} / \mathrm{s}$, a structure consisting of a mixture of upper $(20 \%)$ and lower $(80 \%)$ bainite forms in the modeled HAZ metal. Due to that metal hardness rises up to $H V 270$ that, in its turn, leads to increase of the values of its static strength and decrease of its ductile properties.

Analysis of fractographic data obtained after impact bend testing of the samples, showed that with increase of cooling rate (from $w_{6 / 5}=3{ }^{\circ} \mathrm{C} / \mathrm{s}$ up to $w_{6 / 5}=$ $\left.=25^{\circ} \mathrm{C} / \mathrm{s}\right)$ at negative testing temperatures $\left(T_{\text {test }}=-20\right.$ and $-40^{\circ} \mathrm{C}$ ), the nature of fracture in the zone of the main crack propagation changes from $100 \%$ of brittle fracture (Figure 4,a) to mixed mode: $70-75 \%$ of quasibrittle and $25-30 \%$ of ductile fracture $\left(T_{\text {test }}=\right.$ $=-20{ }^{\circ} \mathrm{C}$, Figure $\left.4, b\right)$. With increase of the cooling rate, the size of elements of fracture surface decreases more than 2 times from $50 \mu \mathrm{m}\left(w_{6 / 5}=3{ }^{\circ} \mathrm{C} / \mathrm{s}\right)$ to $25 \mu \mathrm{m}$ $\left(w_{6 / 5}=25^{\circ} \mathrm{C} / \mathrm{s}\right)$. This circumstance is indicative of the fact that from the viewpoint of mechanical properties a cooling rate of $w_{6 / 5}=25{ }^{\circ} \mathrm{C} / \mathrm{s}$ provides an optimum combination of strength, ductility and impact toughness, the closest to those values for base metal.

Thus, it was found that lowering of the strength and impact toughness of HAZ metal of steel alform $620 \mathrm{M}$ at cooling rate $w_{6 / 5}=3^{\circ} \mathrm{C} / \mathrm{s}$, is due to an essential grain growth (up to $65 \mu \mathrm{m}$ ) and formation of predominantly upper bainite structure. Increase of cooling rate $w_{6 / 5}=12{ }^{\circ} \mathrm{C} / \mathrm{s}$ leads to reduction of average grain size to $15-25 \mu \mathrm{m}$, increase of specific fraction

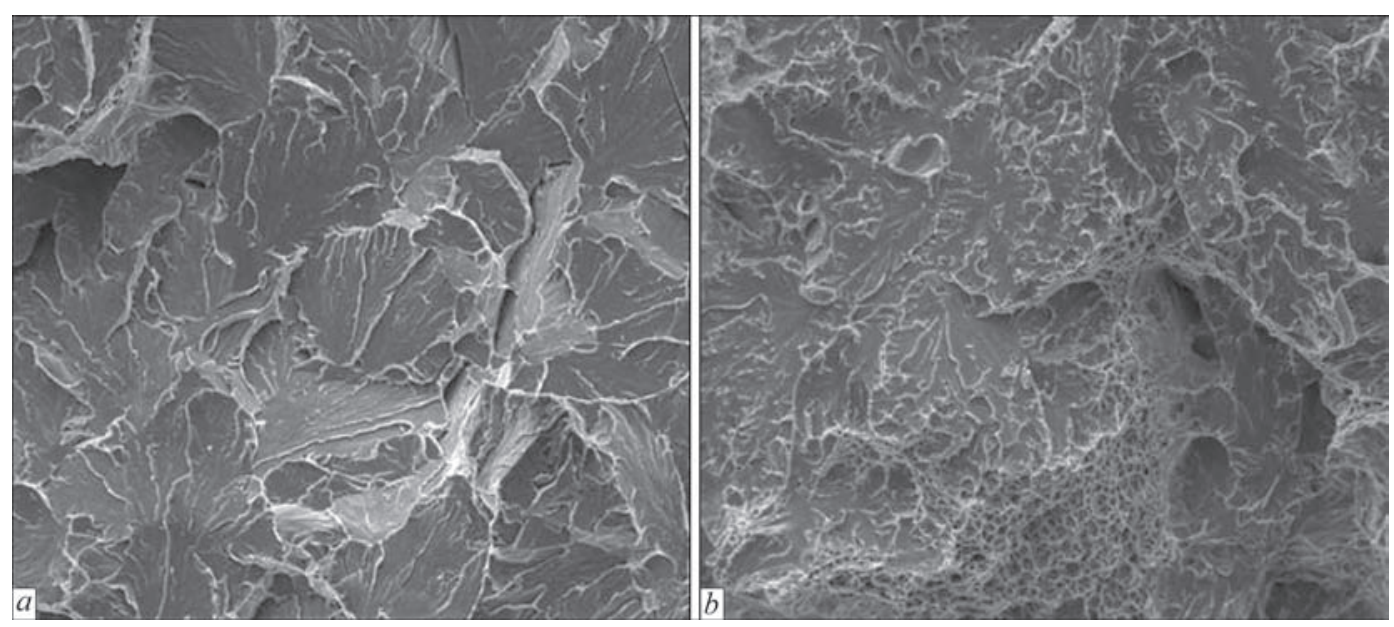

Figure 4. Fractograms of fracture surface of samples of steel alform plate $620 \mathrm{M}$ after impact bend testing $(\times 810): a-T_{\text {test }}=-20{ }^{\circ} \mathrm{C}$, $w_{6 / 5}=3^{\circ} \mathrm{C} / \mathrm{s} ; b-T_{\text {test }}=-20^{\circ} \mathrm{C}, w_{6 / 5}=25^{\circ} \mathrm{C} / \mathrm{s}$ 
of lower bainite to $60 \%$ and, consequently, to increase of strength values. However, the values of cold resistance (impact toughness at negative temperatures) are at an unsatisfactory level. The latter fact is attributable to a high content of upper bainite (40\%) in the produced structure. Cold resistance values can be increased by increasing the cooling rate of HAZ metal to $w_{6 / 5} \geq 25^{\circ} \mathrm{C} / \mathrm{s}$. This is achieved due to formation of a finely-dispersed structure $(15 \mu \mathrm{m})$, consisting predominantly of lower bainite ( $80 \%)$.

\section{Conclusions}

Performed studies of the influence of welding thermal cycles on the structure and properties of steel alform $620 \mathrm{M}$ showed the following:

- at the cooling rate of modeled HAZ metal $w_{6 / 5}=$ $=3{ }^{\circ} \mathrm{C} / \mathrm{s}$ (characteristic for submerged-arc welding processes) an essential lowering of the yield limit to $554 \mathrm{MPa}$, and of impact toughness to values not meeting the Euronorm standards (less than $34 \mathrm{~J} / \mathrm{cm}^{2}$ ) is observed, that is due to a significant coarsening of grains of the structure, produced at such cooling conditions;

- the values of strength and impact toughness can be increased by increasing the cooling rate of the modeled HAZ metal $w_{6 / 5}$ to $25{ }^{\circ} \mathrm{C} / \mathrm{s}$. Here, a finely dispersed structure forms in the HAZ metal with grain size of the order of 15-25 $\mu \mathrm{m}$, and the fracture surface of the samples, tested for impact bending, has a mixed structure of brittle-ductile fracture.

Thus, it is found that optimum combinations of mechanical properties and structure can be achieved at the cooling rate of welded joint HAZ metal $w_{6 / 5} \geq$ $\geq 25^{\circ} \mathrm{C} / \mathrm{s}$.
1. Musiyachenko, V.F., Mikhoduj, L.I. (1987) Arc welding of high-strength alloyed steels. Moscow, Mashinostroenie [in Russian].

2. Gavrilov, D.S., Makhnenko, O.V. (2016) Prediction of welding strains of rotor wheel of blower HP-7500 in arc and laser technologies of welding. In: Proc. of 7th Int. Conf. on Laser Technologies in Welding and Materials Processing (14-18 Sept. 2015, Odessa, Ukraine), 14-20.

3. Ragu Nathan S., Balasubramanian, V., Malarvizhi, S., Rao, A.G. (2015) Effect of welding processes on mechanical and microstructural characteristics of high strength low alloy naval grade steel joints. Defence Technology, 11, 308-317.

4. Ufuah, E., Ikhayere, J. (2013) Elevated temperature mechanical properties of butt-welded connections made with high strength steel grades S355 and S460M. In: Proc. of the Int. Conf. on Design, Fabrication and Economy of Metal Structures (24-26 Apr. 2013, Miscols, Hungary). Ed. by K. Jarmai, J. Farkas, Springer, 407-412.

5. Nazarov, A., Yakushev, E., Shabalov, I. et al. (2014) Comparison of weldability of high-strength pipe steels microalloyed with niobium, niobium and vanadium. Metallurgist, 7, 9-10, 911-917.

6. Zhixiong Zhu, Jian Han, Huijun Li, Cheng Lu (2016) High temperature processed high $\mathrm{NbX} 80$ steel with excellent heataffected zone toughness, Materials Letters, 163, 171-174.

7. Dongsheng Liu, Qingliang Li, Toshihiko Emi (2011) Microstructure and mechanical properties in hot-rolled extra highyield-strength steel plates for offshore structure and shipbuilding. Metallurgical and Materials Transactions A, 42, 1349-1361.

8. Natschläger M., Egger R., Kapl S.A. (2015) Thermomechanically rolled heavy plates for penstocks. Hydropower, 1, 114-118.

9. (2011) Technical terms of delivery for heavy plates. Highstrength and ultra-highstrength thermomechanically rolled fine-grain steels. Voestalpine Grobblech GmbH, Austria.

10. Zavdoveev, A., Pozniakov, V., Rogante, M. et al. (2017) Weldability of S460M high strength low-alloyed steel. In: Proc. of 7th Int. Conf. on Mechanical Technologies and Structural Materials MTMS2017 (21-22 Sept. 2017, Split, Croatia). Ed. by S. Jozić, B. Lela. Croatian Society for Mechanical Technologies, Split, Croatia, 163-166. 


\title{
EFFECT OF SURFACE-ACTIVE ELEMENTS ON THE FORMATION OF SOLIDIFICATION CRACKS
}

\author{
V.A. ANOSHIN and V.M. ILYUSHENKO \\ E.O. Paton Electric Welding Institute of the NAS of Ukraine \\ 11 Kazimir Malevich Str., 03150, Kyiv, Ukraine. E-mail: office@paton.kiev.ua
}

\begin{abstract}
Based on analysis of physicochemical properties of harmful impurities, the concepts of the mechanism of their effect on formation of solidification cracks in different metals are summarized, which consist, firstly, in enrichment of crystallite boundaries with them (residual liquid) at the last stages of solidification, and, secondly, in revealing the effect of adsorption-induced decrease of strength and ductility. The difference in the nature of solidification of single-phase and two-phase (with eutectic) alloys was established as regards enrichment of crystallite boundaries with harmful impurities. It is shown that the specific surface energy at solid metal - melt interface and on grain boundaries has the greatest effect on crack formation. It was established that also the surface-active alloying elements, characterized by the same physicochemical properties as harmful impurities, can influence the increased tendency to solidification cracking. The formula for subcritical crack growth, proposed by E.E.Glikman et al., can serve as a criterion for evaluation of the effect of surface-active elements on the formation of solidification cracks. 36 Ref., 2 Tables, 9 Figures.
\end{abstract}

Ke y words : solidification cracks, harmful impurities, physicochemical properties, effect of adsorption-induced decrease of ductility and strength, distribution coefficient, enrichment of grain boundaries, state diagram, solidification nature, eutectic

Solidification cracks are one of the most common defects in welding and casting of various metals and alloys. Generalized postulates of the current theory of solidification cracking (technological strength of metals) were discussed already in 1960s [1].

According to this theory technological strength of metals depends on:

- brittleness temperature range (BTR);

- deformability in BTR;

- deformation rate (intensity of elastoplastic deformation increase with temperature lowering), i.e. solidification cracking is affected by two factors: metallurgical (BTR and deformability in it) and force (deformation rate).

A necessary condition for solidification cracking is presence of solid and liquid phases in metal. However, there are still differences in the views on the amount and form of the liquid phase, leading to cracking. A fairly comprehensive review of this subject was made by V.V. Podgaetsky [2].

At the same time, there is no unambiguous opinion about the mechanism of the influence of intercrystalline liquid interlayers (residual liquid phase) on solidification cracking.

N.N. Prokhorov [3], as a result of theoretical analysis of the process of alloy deformation in the solid-liquid state came to the conclusion that deformability depends mainly on the sizes of crystallites and thickness of the liquid phase, i.e. it does not take into

(C) V.A. ANOSHIN and V.M. ILYUSHENKO, 2018 account the physicochemical interaction of the solid and liquid phases. A number of authors (B.I. Medovar, V.V. Podgaetsky, I.I. Novikov, A.E. Runov, I.R. Patskevich) have suggested that the liquid phase can influence solidification cracking, as a result of manifestation of the effect of adsorption-induced lowering of ductility and strength (ALDS).

As noted by V.V. Podgaetsky [2], the influence of surface properties of the residual liquid on solidification cracking was taken into account by J.Borland in his generalized theory of hot cracking. He, however, makes the following comments on this theory [2]: «The statement of the significant influence of the area of contact between the crystallites on the possibility of cracking is questionable... in the presence of the liquid phase on the crystallite boundaries initiation of intercrystalline crack filled with the melt is more beneficial in terms of energy than in other regions, even at higher angle $\theta$ (as noted in the work by I.I. Novikov [5]). Conditions of initiation of cracks of sulphide origin are not consistent with the above theory, either. Even though the chemical composition of intercrystalline sulphide films differs greatly from that of the weld metal, this does not prevent solidification cracking». However, I.I. Novikov [5] believes that the change of the composition of commercial alloys by additional alloying should not change the brittleness, resulting from ALDS effect, as the value of surface energy on the boundary of the solid and liquid phases is so small in the majority of alloys that be the energy 
Table 1. Some physical properties of the considered metals and impurities [10]

\begin{tabular}{|l|c|c|c|c|c|c|c|c|}
\hline \multirow{2}{*}{ Physical properties } & \multicolumn{4}{c|}{ Alloying elements } & \multicolumn{5}{c|}{ Impurities } \\
\cline { 2 - 11 } & $\mathrm{Fe}$ & $\mathrm{Ni}$ & $\mathrm{Cu}$ & $\mathrm{Al}$ & $\mathrm{P}$ & $\mathrm{SS}$ & $\mathrm{Bi}$ & $\mathrm{TNa}$ \\
\hline Surface tension, $\sigma_{\mathrm{m}}, \mathrm{MJ} / \mathrm{cm}^{2}$ & 1840 & 1810 & 1350 & 914 & 69.7 & 42 & 90 & 91 \\
\hline Specific heat of sublimation $P, \mathrm{MJ} / \mathrm{cm}^{3}$ & 46.0 & 55.7 & 43.9 & 27.8 & 18.5 & 4.4 & 8.8 & 4.3 \\
\hline Melting temperature, K & 1811 & 1728 & 1357 & 932 & $\begin{array}{c}317.4 \text { (for white) } \\
870 \text { (for red) }\end{array}$ & 392 & 545 & 371 \\
\hline
\end{tabular}

somewhat larger or smaller is practically of no importance for the mechanical properties of the alloy in the solid-liquid state. We believe, this is a mistaken opinion. Such a difference in the views is indicative of insufficient theoretical and experimental studies of the process of solidification crack formation.

Considering that for real structures the range of force factor regulation is small (structure rigidity is preset in most of the cases, and is determined by service requirements, and the ranges of welding mode parameter variation for specific products are also limited), the most effective impact on cracking can be produced by metallurgical methods. Therefore, let us consider the influence of metallurgical factor on cracking.

As is known, the influence of metallurgical factor on solidification cracking at a constant welding mode is determined mainly by chemical composition of the metal, and, primarily, presence of harmful impurities [2, 5-9]. These impurities are:

- sulphur, phosphorus in iron and its alloys;

- sulphur, phosphorus in nickel and its alloys;

- bismuth, lead, sulphur, phosphorus in copper and its alloys;

- sodium in aluminium and its alloys.

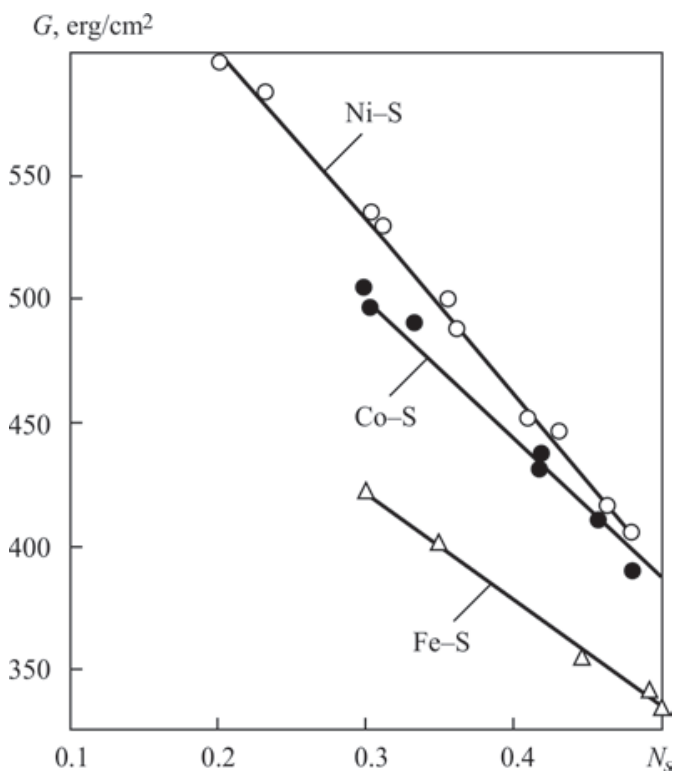

Figure 1. Sulphur effect on surface tension of iron, nickel and cobalt [11]
The above-mentioned elements, apparently, feature some common physicochemical properties, determining their similar specific influence on solidification cracking.

As is known, the physicochemical properties of impurities are largely determined by the state diagram of metal-impurity system. Analysis of these diagrams shows that all of them belong predominantly to the eutectic type with limited (low) solubility of the impurity in the solid metal, and the melting temperature of the eutectic or chemical compound in metal-impurity system is lower than the melting temperature of metal-solvent. All the considered impurities are characterized by high surface (adsorption) activity. Its theoretical evaluation is usually performed by the totality of several criteria [10]:

$$
\begin{gathered}
\Delta \sigma=\sigma_{\text {solv }}-\sigma_{\text {imp }}>0 ; \\
\Delta P=P_{\text {solv }}-P_{\text {imp }}>0 \text { where } P=\frac{L}{V} ; \\
\Delta T_{\mathrm{m}}=T_{\text {solv }}^{\mathrm{m}}-T_{\text {imp }}^{\mathrm{m}},
\end{gathered}
$$

where $\sigma_{\text {solv }}, \sigma_{\text {imp }}$ are the surface tensions of the solvent and the impurity, respectively; $P_{\text {solv }} P_{\text {imp }}$ is the specific heat of sublimation of the solvent and impurity, respectively; $L$ is the heat of sublimation in the melting point $(\mathrm{J} / \mathrm{g} \cdot \mathrm{atom}) ; V$ is the atomic volume at melting temperature $\left(\mathrm{cm}^{3} / \mathrm{g} \cdot\right.$ atom $) ; T_{\text {solv }}^{\mathrm{m}}, T_{\mathrm{imp}}^{\mathrm{m}}$ is the melting

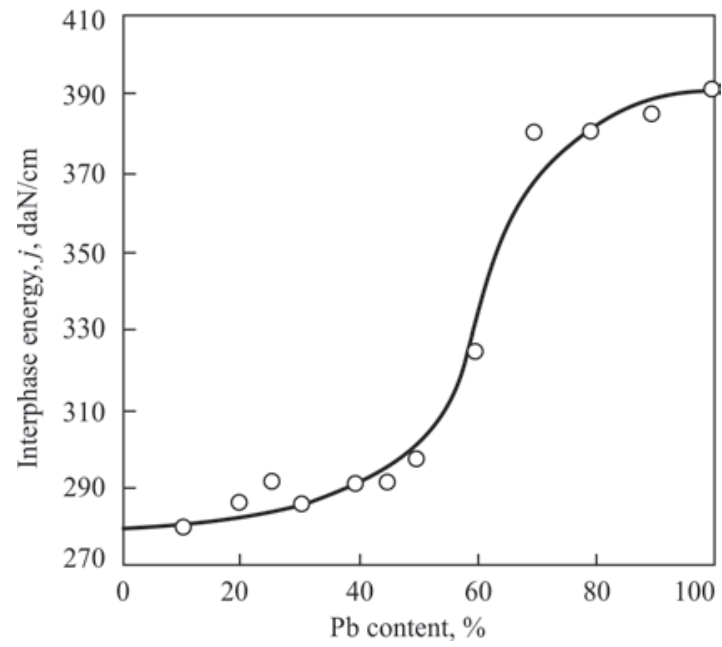

Figure 2. Interphase energy $j$ on the boundary of copper with $\mathrm{Bi}-$ $\mathrm{Pb}$ melts at $350^{\circ} \mathrm{C}[12]$ 
Table 2. Equilibrium coefficient of distribution $K_{0}$ of impurities in the considered metals

\begin{tabular}{|c|c|c|c|c|c|c|c|}
\hline \multicolumn{2}{|c|}{$\mathrm{Fe}$} & \multicolumn{2}{c|}{$\mathrm{Ni}$} & \multicolumn{2}{c|}{$\mathrm{Cu}$} & $\mathrm{Al}$ \\
\hline $\mathrm{S}$ & $\mathrm{P}$ & $\mathrm{S}$ & $\mathrm{P}$ & $\mathrm{Bi}$ & $\mathrm{Pb}, \mathrm{S}$ & $\mathrm{P}$ & $\mathrm{Na}$ \\
\hline $0.003-0.03$ & 0.13 & $\approx 0.0001$ & 0.02 & 0.0001 & 0.01 & 0.11 & 0.0014 \\
\hline
\end{tabular}

temperature of the solvent and the impurity, respectively.

If inequalities (1)-(3) are satisfied, the impurity is surface active relative to this solvent. As one can see from Table 1, evaluation of the considered impurities by the above criteria is indicative of their surface activity relative to iron, nickel, copper and aluminium, respectively (Figures 1-4).

Another common property of the above impurities is their small coefficient of distribution (Table 2), that promotes an increase of their concentration along the crystallite boundaries, and enhances their harmful impact even at small concentrations of the impurity in the metal.

Numerical values of the coefficient of distribution in Table 2, are given by the data of works $[14,15]$, and were also calculated by us by the respective binary state diagrams [16].

Thus, all the considered impurities have the following common specific physicochemical and thermodynamic properties:

- state diagram of metal-impurity system of eutectic type with limited (small) mutual solubility;

- melting temperature of the impurity, eutectic or chemical compound in metal-impurity system is below the melting temperature of metal-solvent;

- high surface (adsorption) activity of the impurity;

- small coefficient of impurity distribution.
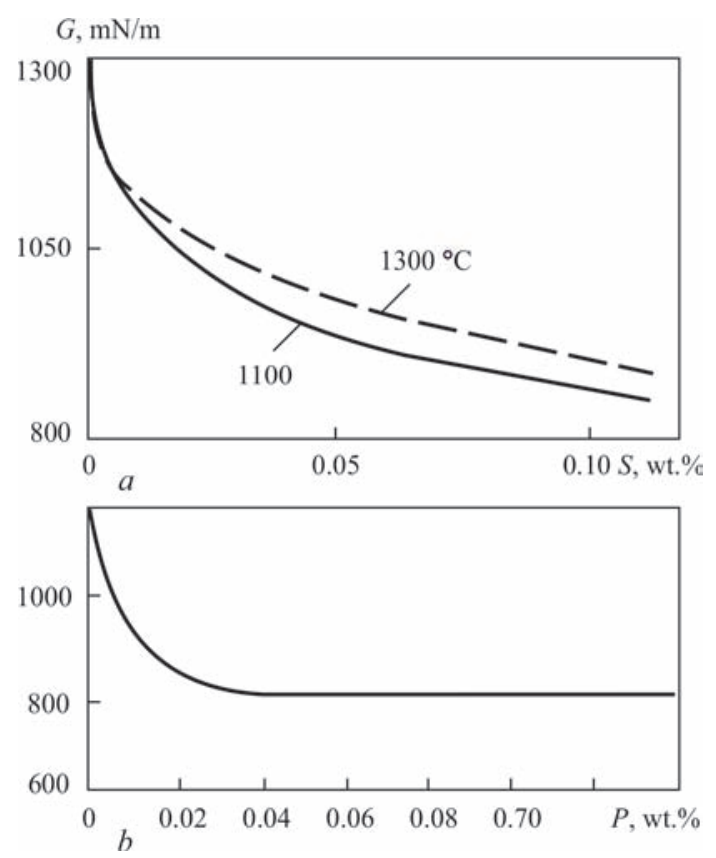

Figure 3. Effect of sulphur $(a)$ and phosphorus $(b)$ on surface tension of copper [13]
As is known from physicochemical mechanics of metals [17], the above-mentioned specific properties of impurities are indicative of the fact that in the system of solid metal-liquid phase, containing surface-active elements, the effect of adsorption-induced lowering of ductility and strength (special case of Rebinder effect) or, as it is sometimes called, the effect of liquid metal brittleness (LMB) can be manifested.

And indeed, solidification cracks form during deformation of weld metal, which is in solid-liquid state. Therefore, the specifics of physicochemical interaction of the solid body with the liquid phase (manifested in different adsorption activity of the latter), should have a certain influence on weld metal deformability.

In terms of physicochemical mechanics of metals [14] lowering of metal deformability can be presented as follows:

- in thermodynamic aspect: surface-active elements reduce the free surface energy of the solid and thus facilitate crack initiation;

- in molecular-kinetic aspect: during physicochemical interaction of the solid with atoms of surface-active elements restructuring and breaking of interatomic bonds are facilitated.

E.E. Glikman with associates [18] conducted a cycle of experimental and theoretical studies to clarify the micromechanism of embrittling action of surface-active melts (Rebinder effect). As a result, mo-

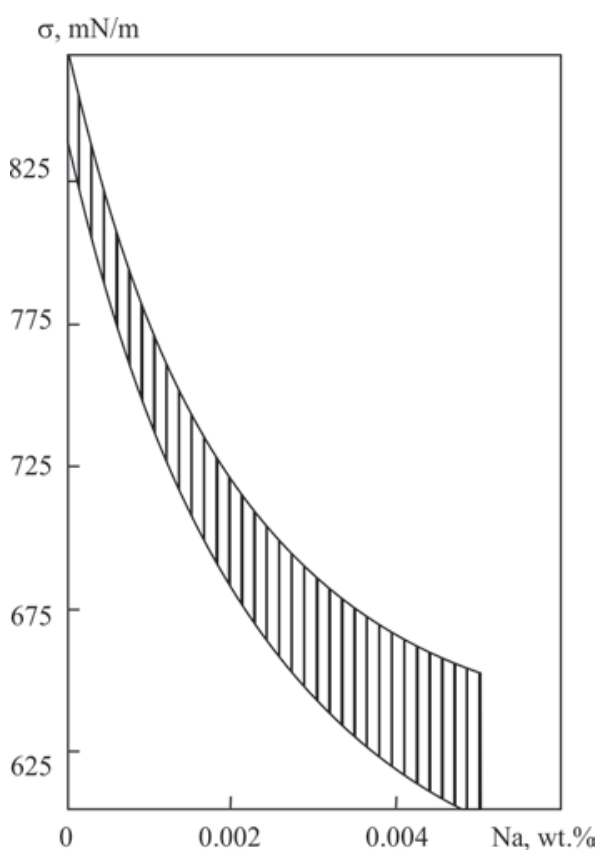

Figure 4. Effect of sodium on surface tension of aluminium [13] 
lecular-kinetic model of fracture under the impact of surface-active melt was proposed.

The controlling stage of fracture is that of subcritical crack growth. Its duration determines the time to fracture at creep and limit deformation to rupture (under tension). After the crack has reached a certain length, the subcritical growth stops and rapid fracture takes place. An abrupt acceleration of crack growth is related to achievement of a certain critical deformation in the plastically deformed region at the tip, the measure of which is the so-called critical crack opening displacement $\delta_{c}$.

Quantitative expression of the rate of subcritical crack growth in the proposed mechanism of embrittling action of surface-active melts is given by the following formula [18]:

$$
V=A \frac{\left(\sigma-\sigma^{*}\right) \exp \left(\frac{Q}{K T}\right)}{T},
$$

where $Q$ is the activation energy of subcritical crack growth

$$
Q=\left(S_{S L}+S_{c}\right) \gamma_{S L}-S_{b} \gamma_{b}+H_{l}-S_{c} \gamma_{O S L},
$$

where $\sigma$ is the deforming stress; $\sigma^{*}$ is the threshold stress, at achievement of which the embryo microcrack, filled with the melt, starts growing; $\gamma_{S L}$ is the specific surface energy on solid metal-melt interface; $\gamma_{b}$ is the specific surface energy of grain boundaries; $A$ is the constant: $A=\left(\omega^{5 / 3} D_{0} C_{0}\right) /\left(R^{2} h K\right)$ (for designations see work [18]).

The greatest influence on the rate of subcritical crack growth is produced by value $Q$ and, in particular, specific surface energy on solid metal-melt boundary $\left(\gamma_{S L}\right)$ and specific surface energy of grain boundaries $\left(\gamma_{b}\right)$. With reduction of $\gamma_{S L}$ and increase of $\gamma_{b}$ the crack growth rate increases exponentially. So, $\gamma_{S L}$ decrease by $25 \%$ leads to 30 times increase of crack growth rate [18]. Such an abrupt dependence of fracture rate on the specific fracture energy on «crystal-melt» boundary is an important experimental result, which confirms on the microscopic level the main postulate of the hypothesis of adsorption-induced lowering of strength (ALDS) about the determinant role of surface energy lowering in facilitating restructuring and breaking of interatomic bonds at the crack tip.

In our opinion, the proposed molecular-kinetic model, explaining the embrittling impact of surface-active melts, the most fully reflects the available experimental data on the influence of various physicochemical conditions on manifestation of ALDS effect.

Summarizing the above-said, the mechanism of the influence of surface-active elements on cracking susceptibility, in our opinion, can be presented as follows:

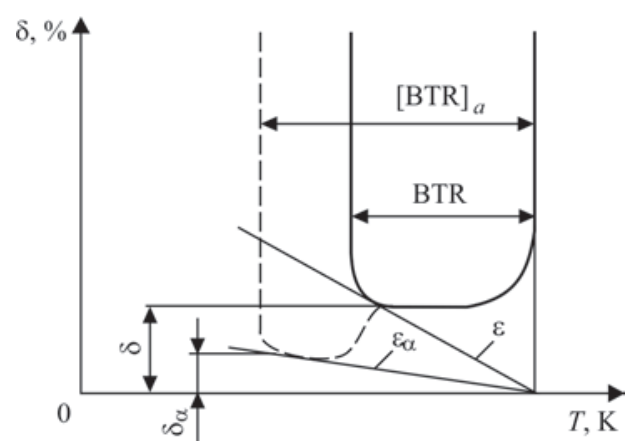

Figure 5. Dependence of relative elongation on solidification temperature (scheme)

- during weld metal solidification, the composition of the liquid phase along the crystallite boundaries will change in the direction of its enrichment by surface-active elements, as a result of their low coefficient of distribution. Maximum achievable concentration of the surface-active element in the liquid interlayer will be equal to value $C_{0} / K_{0}$, where $C_{0}$ is the average concentration of the element in the weld pool; $K_{0}$ is the equilibrium coefficient of distribution;

- as a result of manifestation of the effect of adsorption-induced ductility and strength lowering, the surface-active elements lower the deformability of the solidifying metal, and also expand its brittleness temperature range.

This is graphically presented in Figure 5, and the experimental data are given in Figure 6.

B.A. Movchan also notes that at solidification «an exceptionally high concentration of impurity forms on the crystallite boundary» [19].

Available experimental data confirm the above concepts. So, by the data of Auger spectroscopy [20], in copper containing $\approx 0.003 \% \mathrm{Bi}$, its concentration on grain boundaries reaches $\approx 50 \%$. By the data of work [21], sulphur content on the crack surface in ingots of oxygen-free copper was equal to $\approx 0.75 \%$ at its concentration in the metal equal to $0.002 \%$. Sulphur concentration in welds on steel is equal to

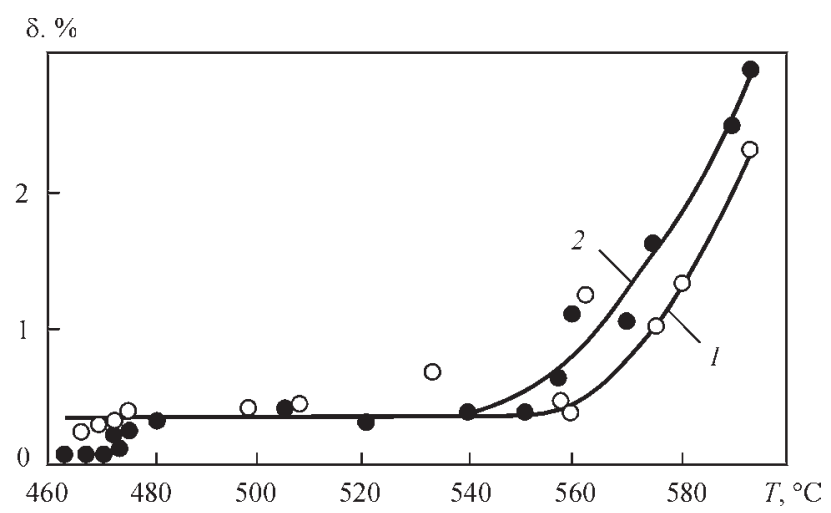

Figure 6. Effect of sodium content in aluminium alloy V95 on relative elongation in solidification temperature range [5]: 1 - alloy V95; 2 - alloy V95 + 0.0034 wt. \% Na 
$10-12 \%$ along crystallite boundaries at its average content of $\approx 0.03 \%$ [2].

Investigation of the morphology and composition of surface layer of hot cracks forming in monel welding, which was performed by the methods of electron fractographic and X-ray emission analyses, also confirms the above-said: the crack surface is mainly enriched in sulphur (27 times) [22].

Experimental data on manifestation of ALDS effect, caused by various surface-active elements in welding, were presented for the first time in works $[23,24]$. These data are indicative of the fact that abrupt embrittling action on metals can be produced not only by impurities, but also by alloying elements at certain concentrations, which are applied as effective deoxidizers, desulphurizers, modifiers, etc., and which are characterized by the above physicochemical properties.

Such an alloying element is cerium, causing solidification cracking in monel welding [25].

Proceeding from the above mechanism of the impact of surface-active elements on solidification cracking, the main metallurgical measures for their prevention are as follows:

1. Lowering of surface activity of the solidifying liquid phase $\left(\gamma_{S L}\right.$ increase) by:
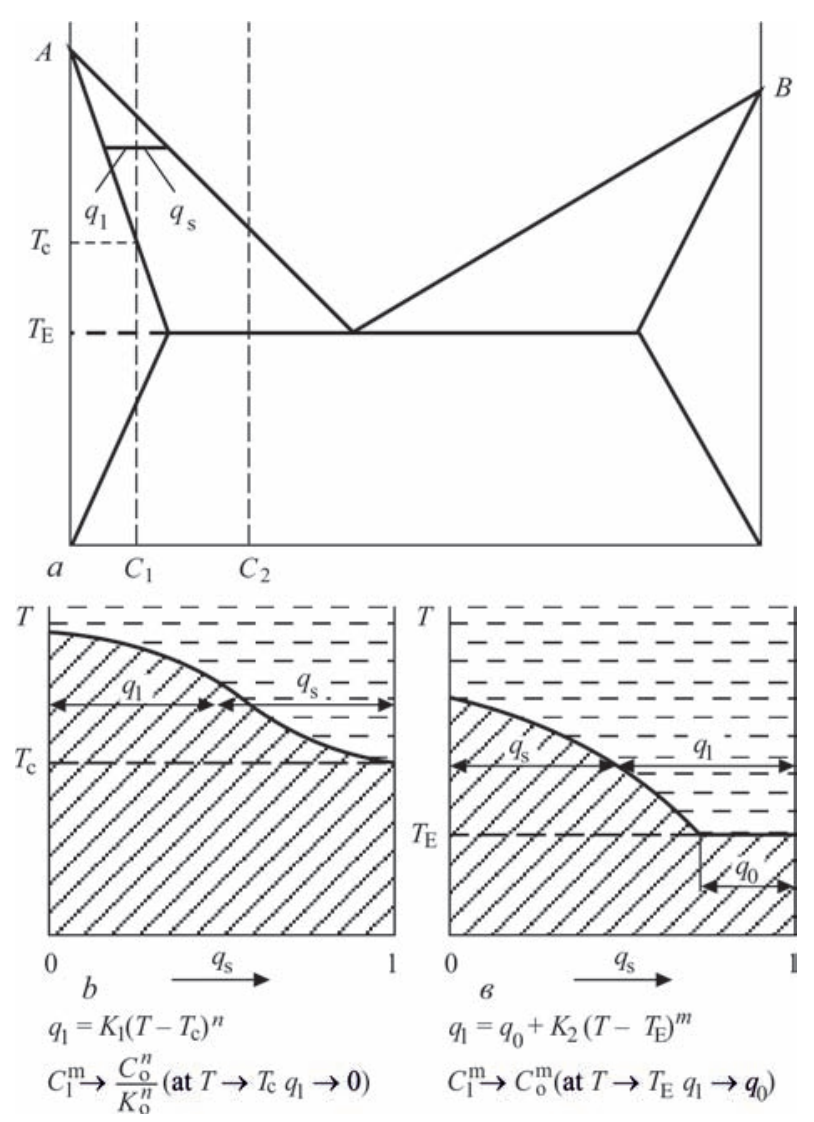

Figure 7. Schematic of the state diagram of two-component alloy (a) and features of solidification of single-phase $C_{1}(b)$ and twophase $C_{2}(c)$ alloys
- reduction of impurity concentration;

- binding the impurities into refractory or low surface-inactive compounds.

2. Reduction of surface energy of grain boundaries by:

- alloying by surface-active elements;

- changing the strength properties and crystalline structure of the solid phase.

It should be noted that the above factors (item 1) not only increase the surface energy of the liquid phase $\gamma_{S L}$, but also reduce the BTR.

Let us consider the examples of application of the above-mentioned measures of solidification cracking prevention in welding various metals.

\section{1. $\gamma_{S L}$ increase}

Concentration of impurities along the crystallite boundaries can be reduced both through application of refining fluxes (that is not always effective), and by changing the nature of alloy solidification. So, the amount of the liquid phase at solidification of single-phase alloys tends to zero, when approaching the solidus temperature (by the main components) (Figure 7), and the concentration of the impurity along the crystallite boundaries tends to value $C_{0}^{\text {imp }} / K_{0}[26]$ (where $C_{0}^{\text {imp }}$ is the initial impurity concentration in the metal, and $K_{0}$ is the equilibrium coefficient of distribution). Impurity concentration in this case can be high even at a low initial content in the metal that, in its turn, can lead to solidification cracking, as a result of ALDS effect manifestation. At solidification of two-phase alloys (of eutectic type), when approaching the solidus temperature (eutectic), the amount of the liquid phase is not equal to zero, but has finite values (Figure 7). As a result, impurity concentration on crystallite boundaries at the final stage of solidification will be equal to the initial value ( $\left.C_{0}^{\text {imp }}\right)$, i.e. enrichment of crystallite boundaries will practically be absent, and, thus, solidification cracking resistance will be enhanced.

This, in our opinion, can account for higher technological strength of two-phase aluminium bronzes and brasses, as well as chromium-nickel bronze, compared to single-phase alloys and metals.

Binding impurities into even though low-melting, but low surface-active compounds also allows increasing the resistance to solidification cracking. So, for instance, presence of oxygen in low-carbon steel reduces surface activity of sulphur as a result of its binding into oxysulphides, and, although the melting temperature of oxysulphide phase is below the iron sulphide melting temperature, the embrittling action of sulphur decreases, and metal cracking resistance increases, respectively. V.V. Podgaetsky et al. [2], experimentally showed an increase of interphase tension 
of oxysulphide phase (lowering of surface activity), which is expressed in changing of the film form of the sulphide phase to globular form at oxygen addition to the weld.

In low-carbon steel manganese is also used for binding sulphur into a refractory compound $(\mathrm{MnS})$, due to its low equilibrium coefficient of distribution $K_{0 \mathrm{Mn}}^{\mathrm{Fe}}[14]$.

As was noted in [27], L. Riv, when studying the influence of the composition of metal of welds made by electrodes, determined that electrodes the least susceptible to cracking produce the most oxidized weld metal (total oxygen content of 0.17 to $0.20 \%$ ). The electrodes the most susceptible to cracking produced welds with minimum oxygen content $(0.05-0.06 \%)$. This can be explained by the fact that at oxygen content of $0.05 \%$ the surface activity of sulphur increases 5 to 10 times [28].

\section{Reduction of grain boundary energy $\left(\gamma_{b}\right)$}

Metal alloying by elements, lowering the surface energy of grain boundaries, at a certain concentration will reduce the probability of solidification cracking. So, for instance, monel alloying by surface-active element - cerium reduces $\gamma_{b}$, and, thus, increases the cracking resistance of welds.

Considering the relation between grain boundary surface energy $\gamma_{b}$ and solid surface energy $\gamma_{S}$ $\left(\gamma_{b} \approx 0.27 \gamma_{\mathrm{S}}\right.$ [29]), as well as the correlation dependence between $\gamma_{S}$ of a solid and its mechanical properties (ultimate strength, hardness) [30], one can note that metal alloying by strengthening elements will increase and, other conditions being equal, will strengthen the harmful effect of the impurities, and, the probability of cracking, respectively. This is also noted in works $[12,17]$.

The experiments performed by us on copper-nickel alloys confirm the above-said [31]. Increase of aluminium content in the alloy led to increase of its hardness and of solidification cracking susceptibility, accordingly, both in the weld metal and in the HAZ.

\section{BTR reduction}

The most effective reduction of BTR will be observed at metal alloying with elements, firstly, increasing the liquid phase solidus temperature, and, secondly, having a small coefficient of distribution that will ensure an increase of the solidus temperature at small concentrations of the element and at practically unchanged liquidus temperature, i.e. BTR is reduced.

Presence of a region of solid solutions of base metal and alloying element and surface inactivity of the latter will be indicative of absence of liquid metal brittleness in this system.

It should be also noted that elements with a small coefficient of distribution have the metal-alloying el-

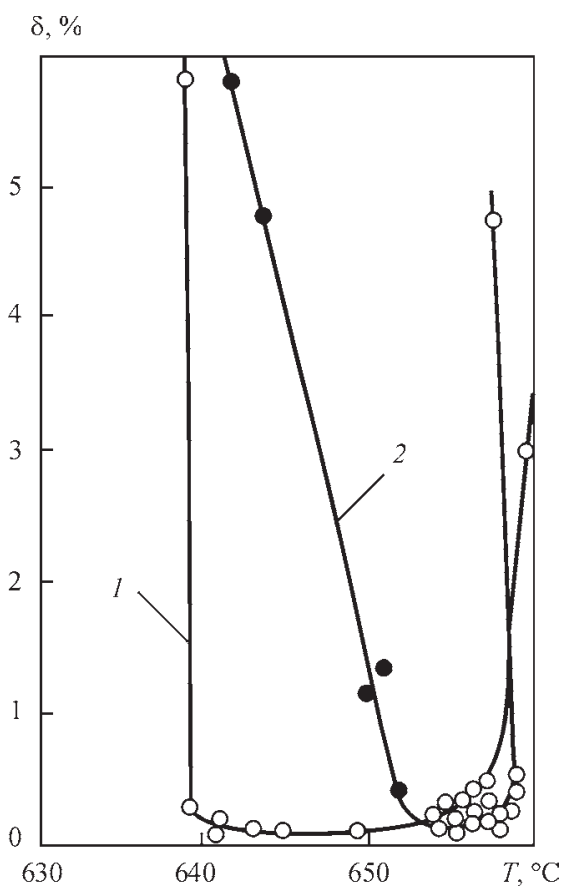

Figure 8. Effect of iron content on relative elongation of aluminium alloy $(\mathrm{Al}+1.5 \mathrm{wt} . \% \mathrm{Mn})$ in the solidification range ([5]): $1-\mathrm{Al}+1.5 \% \mathrm{Mn} ; 2-\mathrm{Al}+1.5 \% \mathrm{Mn}+0.25 \% \mathrm{Fe}$

ement state diagram of eutectic type, i.e. at metal alloying with such an element, at concentration higher than its maximum solubility at $T_{\text {eut }}$ (when the eutectic starts appearing), impurity concentration along the crystallite boundaries will be also lowered, and surface activity of the residual liquid phase will decrease, respectively. Optimum concentration of the alloying element is determined experimentally.

Such elements, for instance, in aluminium alloys and commercial aluminium, are iron (Figure 8), as well as nickel, cerium and scandium.

State diagrams of aluminium with these elements are given in works [32, 33].

Thus, analyzing the influence of various alloying elements on the change of surface energies of the liquid phase $\gamma_{S L}$ and grain boundaries $\gamma_{b}$, including also

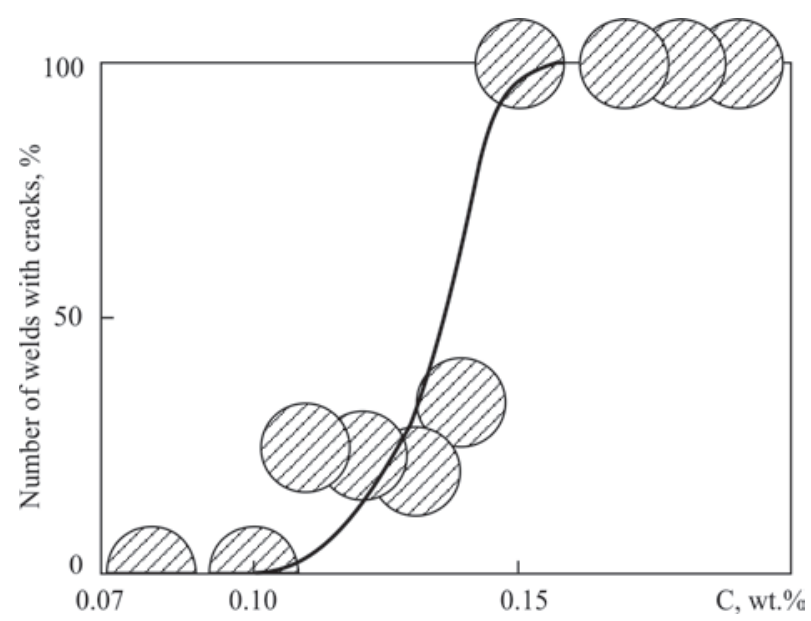

Figure 9. Dependence of frequency of solidification cracking on carbon content for fillet welds of tee joints of low-carbon steel [2] 
the nature of metal or alloy solidification, we can assess their influence on the probability of solidification cracking.

So, for instance, the harmful influence of carbon in welding low-carbon steel can be explained as follows:

- firstly, carbon increases the surface activity of sulphur in iron (lowers $\gamma_{S L}$ ), both as a result of its physicochemical properties, and due to steel deoxidation, i.e. lowering of positive influence of oxygen;

- secondly, carbon enhances the strength properties of the solid phase, and increases its surface energy, accordingly.

An abrupt increase of cracking susceptibility at increase of carbon content in steel above $0.16 \%$ (Figure 9,a) [2] is associated, in our opinion with the change of the nature of solidification, namely: at carbon concentration of $\approx 0.10-0.16 \%$ the amount of the liquid phase at the last stage of solidification has a final value, and no significant enrichment in sulphur occurs along the crystallite boundaries, and solidification is over at $T=1499{ }^{\circ} \mathrm{C}$ (Figure 9, b) [34]. At the content of $\mathrm{C}>0.16 \%$ the amount of the liquid phase at the final stage of solidification tends to zero, and enrichment of the crystallite boundaries with sulphur become markedly greater $\left(\gamma_{S L}\right.$ decreases $)$, and BTR increases, respectively. More over, appearance of austenite grains leads to increase of surface energy of grain boundaries $\left(\gamma_{b}\right)$. All that is exactly what causes an abrupt increase of cracking susceptibility of low-carbon steel at carbon concentration higher than $0.16 \%$.

The given arguments provide an explanation also for the following fact. Dr. Vera, Hungarian metal scientist, studied the hot brittleness of Al-Si alloy [5]. He established that maximum hot brittleness is observed at $1.6 \% \mathrm{Si}$ content. At the same time, at $1.88 \% \mathrm{Si}$ content the hot brittleness is practically zero. Vera explains this fact by crack healing by the melt. This is possible at achievement of a critical amount of the eutectic (12-13\%) [5]. At $1.88 \%$ Si concentration, only of $\approx 2 \%$ eutectic can form, according to Al-Si state diagram. Therefore, this explanation is unconvincing, the more so that Vera did not have any direct proof of crack healing by the melt [4]. In our opinion, this fact can be explained as follows: proceeding from Figure 7, as well as Al-Si state diagram at $1.6 \% \mathrm{Si}$ content, Na saturation will be maximum $\mathrm{Na}\left(K_{0}^{\mathrm{Na}}=0.0014\right)$, and $\mathrm{Na}$ concentration will be equal to $C_{0} / K_{0}^{\mathrm{Na}}$, and at $1.88 \% \mathrm{Si}$ content the eutectic already is in place (according to Al-Si state diagram [32] the eutectic starts appearing already at $1.65 \% \mathrm{Si}$ ), and no enrichment occurs (Na concentration is equal to the initial one $C_{0}$ ).
It should be noted that sodium is the main cause for solidification cracking in aluminium and its alloys, because of the small coefficient of distribution $\left(K_{0}^{\mathrm{Na}}=0.0014\right)$.

In [35] it is noted that $100 \%$ rejection of ingots because of cracks is observed at the $\mathrm{Na}$ content $>0.001 \%$ in aluminium alloy 1920. In our opinion in aluminium and its alloys, particularly highstrength ones, sodium content should be limited and controlled. At the same time, it is not controlled in GOST 4784-97 (Aluminium and wrought aluminium alloys), although its content in aluminium alloys can be within $0.001-0.03 \%$ [36].

Summarizing the above said, one can note that the formula of subcritical crack growth, in our opinion, can be the criterion of evaluation of the element effect on solidification cracking, and taking it into account can reduce the time and metal consumption in development of new welding and welded materials.

\section{Conclusions}

1. Based on analysis of physicochemical properties of impurities, the concepts of the mechanism of their effect on solidification crack formation were summarized. They consist in the following: firstly, enrichment of crystallite boundaries with them at the last stages of solidification, secondly, manifestation of the effect of adsorption-induced lowering of ductility and strength. The graphic interpretation of this mechanism was proposed, illustrating the lowering of deformatiblity of the solidifying metal and increase of BTR under the impact of surface-active impurities.

2. Difference in the nature of solidification of single- and two-phase (with eutectic) alloys was established as regards enrichment of crystallite boundaries with impurities.

3. Application of molecular-kinetic model of solid fracture under the impact of a surface-active melt (proposed by E.E. Glikman et al.) enables explaining from a single point of view the available experimental data on the influence of various metallurgical factors on solidification cracking. It is shown that specific surface energies on solid metal-melt boundary $\left(\gamma_{S L}\right)$ and on grain boundaries $\left(\gamma_{b}\right)$ have the strongest impact on crack formation.

4. It is also shown that surface-active alloying elements having the same physicochemical properties as those of the impurities can also influence the higher susceptibility to solidification cracking.

5. The formula of subcritical crack growth can be a criterion for evaluation of the influence of surface-active elements on deformability of the solidifying metal (on solidification cracking). 
1. (1962) Decision of the meeting on hot cracks in welded joints, castings and ingots. Svarochn. Proizvodstvo, 11, 41-43 [in Russian].

2. Podgaetsky, V.V., Parfesso, G.I. (1977) Cracks of sulfide origin in welding of steel. Kiev, Naukova Dumka [in Russian].

3. Prokhorov, N.N. (1976) Physical processes in metals during welding. Vol. 2: Internal stresses, strains and phase transformations. Moscow, Metallurgiya [in Russian].

4. Drezet, J.M., Allehaux, D. (2008) Application of the RappazDrezet-Gremaud hot tearing criterion to welding of aluminium alloys. Ed. by T. Boellinghaus et al. In: Hot Cracking Phenomena in Welds II. Springer-Verlag Berlin Heidelberg, 19-37.

5. Novikov, I.I. (1966) Hot brittleness of nonferrous metals and alloys. Moscow, Nauka [in Russian].

6. Brooks, J.A., Lambert, F.J. (1978) The effects of phosphorus, sulfur and ferrite content on weld cracking of type 309 stainless steel. Welding Res. Suppl., May, 139-143.

7. Nishimoto, K., Saida, K., Kiuchi, K., Nakayama, J. (2011) Influence of minor impurity elements on hot cracking susceptibility of extra high-purity type 310 stainless steels. Ed. by T. Boellinghaus et al. In: Hot Cracking Phenomena in Welds. Springer-Verlag Berlin Heidelberg, 183-207.

8. Bernaovsky, P. (2005) Contribution to HAZ liquation cracking of austenitic stainless steels. Ed. by T. Boellinghaus et al. In: Hot Cracking Phenomena in Welds II. Springer-Verlag Berlin Heidelberg, 84-103.

9. Anoshin, V.A., Ilyushenko, V.M., Bondarenko, A.N. et al. (2014) Integrated evaluation of effect of main impurities on weldability of copper. The Paton Welding J., 11, 24-27.

10. Nizhenko, V.I., Eremenko, V.N. (1964) On surface activity of additives in liquid metals. Poroshk. Metallurgiya, 2(20), 11-18 [in Russian].

11. Vajsburd, S.E. (1965) Surface properties of binary metallic melts Fe-S, Co-S, Ni-S. Surface phenomena in melts and solid phases appearing from them. Nalchik, Kabardino-Balkarskoe Kn. Iz-vo, 333-337 [in Russian].

12. Rostoker, U., Mac-Kogi, Dis, Markus, G. (1962) Brittleness under action of liquid metals. Moscow, Inostrannaya Literatura [in Russian].

13. Nizhenko, V.I., Floka, L.I. (1981) Surface tension of liquid metals and alloys. Moscow, Metallurgiya [in Russian].

14. Tiller, U.A. (1968) Chapter IV: Solidification. Physical metals science. Ed. by Kan. Issue II: Phase transformations. Metallography. Moscow, Mir, 155-226 [in Russian].

15. Bartel, I., Burig, E., Khajn, K. et al. (1987) Crystallization from melts. In: Refer. book. Moscow, Metallurgiya [in Russian].

16. Khansen, M., Anderko, K. (1962) Structure of binary alloys. Moscow, Metallurgizdat [in Russian].

17. Likhtman, V.I., Shchukin, E.D., Rebinder, P.A. (1962) Physical-chemical mechanics of metals. Moscow, AN SSSR [in Russian].

18. Glikman, E.E., Goryunov, Yu.V., Dyomin, V.M., Sarychev, K.Yu. (1976) Kinetics and mechanism of fracture of copper at deformation in surface-active melts. Izv. Vuzov SSSR, Fizika, 5, 7-23 [in Russian].
19. Movchan, B.A. (1970) Boundaries of crystallites in cast metals and alloys. Kiev, Tekhnika [in Russian].

20. Powell, B.D., Mukura, H. (1973) Segregation of bismuth to grain boundaries in copper-bismuth alloys. Acta Met., 21, 1151-1156.

21. Karmanchuk, V.I. et al. (1979) On causes of crack initiation in oxygen-free copper continuous casting ingots. Tsvetnye Metally, 6, 58-59 [in Russian].

22. Anoshin, V.A., Ilyushenko, V.M., Lukyanchenko, E.P. (2018) Effect of main impurities on formation of cracks in welding of copper-nickel alloys and surfacing of monel on steel. The Paton Welding J., 4, 11-13.

23. Anoshin, V.A., Ilyushenko, V.M., Rudenko, V.N. (1973) Influence of sulfur on crack formation in welding of monel and nickel. Avtomatich. Svarka, 11, 74-75 [in Russian].

24. Anoshin, V.A., Gurevich, S.M., Ilyushenko, V.M., Baranova, V.N. (1981) Influence of surface-active elements on deformability of nickel and monel. Ibid., 7, 46-48 [in Russian].

25. Gurevich, S.M., Anoshin, V.A., Ilyushenko, V.M., Vitman, D.V. et al. (1970) Influence of cerium on susceptibility of monel to crack formation. Ibid., 1, 72-73 [in Russian].

26. Chalmers, B. (1968) Theory of solidification. Moscow, Metallurgiya [in Russian].

27. Rabkin, D.M., Frumin, I.I. (1950) Causes of hot crack formation in welds. Avtomatich. Svarka, 2, 3-43 [in Russian]

28. Popel, S.I., Tsarevsky, B.V., Pavlov, V.V. et al. (1976) On mutual effect of oxygen and sulfur on their surface activity in iron. In: Physical chemistry of contact phase interface. Kiev, Naukova Dumka [in Russian].

29. Zadumkin, S.N., Karashaev, A.A. (1965) Relation between surface energies of metals in solid and liquid phases. In: Surface phenomena in melts and solid phases appearing from them. Nalchik, Kabardino-Balkarskoe Knizhn. Izd-vo [in Russian].

30. Kuznetsov, V.D. (1954) Surface energy of solids. Moscow, Gosizdat [in Russian].

31. Ilyushenko, V.M., Anoshin, V.A., Bondarenko, A.N. et al. (1980) Some problems of weldability of complexly-alloyed copper alloys. In: Proc. of 1st All-Union Conf. on Current Problems of nonferrous metals. Kiev, Naukova Dumka, 225229 [in Russian].

32. Mondolfo, L.F. (1979) Structure and properties of aluminium alloys. Moscow, Metallurgiya [in Russian].

33. Drits, M.E. et al. (1973) About nature of interaction of scandium with part of Al-Sc system rich in aluminium. Izv. $A N$ SSSR. Metally. Moscow, Nauka, 213-217 [in Russian].

34. Benz, M.G., Elliot, J.F. (1961) The austenitite solidus and revised iron-carbon diagram. Trns. Metallurg. Soc. AIME, 221(2), 232-331.

35. Shadrin, G.G. (1980) Effect of sodium content on hot brittleness of 1920 alloy of Al-Mg-Zn system. Tekhnologiya Lyogkikh Splavov, 10, 12-14 [in Russian].

36. Ishchenko, A.Ya., Labur, T.M. (2013) Welding of modern structures from aluminium alloys. Kiev, Naukova Dumka [in Russian]. 


\title{
PECULIARITIES OF TECHNOLOGY OF REPAIR WELDING OF HPP TURBOUNITS AFTER LONG-TERM OPERATION
}

\author{
V.P. ELAGIN ${ }^{1}$, A.K. TSARYUK ${ }^{1}$, N.I. DUNAEVSKA ${ }^{2}$ and V.A. PERETYATKO ${ }^{3}$ \\ ${ }^{1}$ E.O. Paton Electric Welding Institute of the NAS of Ukraine \\ 11 Kazimir Malevich Str., 03150, Kyiv, Ukraine. E-mail: office@paton.kiev.ua \\ ${ }^{2}$ Coal Energy Technology Institute of the NAS of Ukraine \\ 19 Andriivska Str., 04070, Kyiv, Ukraine. E-mail: ilv.golenko@gmail.com \\ ${ }^{3}$ PJSC SEC «Centrenergo» \\ 120/4 e, Kazatska Str., 03680, Kyiv, Ukraine. E-mail: peretyatkovladimir@urk.net
}

\begin{abstract}
Long-term operation of turbine equipment promotes formation of cracks in the casings of valves, cylinders and steam lines under effect of various factors. Their appearance is caused to the significant extent by deterioration of structure and mechanical properties of metal. Aim of the work is the analysis of possibility to take into account the state of metal in a damaged part in the technology of repair welding for providing a reliable operation of welded joint. Review of literature showed that modem technologies of repair welding envisage technological measures for prevention of cold crack formation, but do not account for deterioration of base metal state and its effect on workability of the welded joint. Removal of damages in turbine equipment components after long-term operation require development of new technologies of repair welding using additional technological measures of thermal and deformation influence. 24 Ref., 1 Table, 2 Figures
\end{abstract}

Keywords : components of turbine equipment, cracks, heat-resistant steel, structure, metal state, welding repair technology, technological measures

A significant number of emergency stops of HPP units is caused by damage of stop and control valves, cylinders of pressure and steam pipeline, which are among the main components of turbine equipment [1]. The casings of valves and cylinders represent large-sized thick-walled cast parts of a complex structure of heat-resistant steels $\mathrm{Cr}-\mathrm{Mo}$ or $\mathrm{Cr}-\mathrm{Mo}-\mathrm{V}$ and have, as a rule, welded joints with branch pipes of steam lines. Their service conditions are characterized by high operating temperatures $\left(545^{\circ} \mathrm{C}\right)$ and steam pressure $(23.5 \mathrm{MPa})$. The service term of some of them has already amounted to more than 320 thou h, which significantly exceeds the estimated (100 thou $\mathrm{h}$ ) and fleet (220 thou h) life. A high service life of the parts

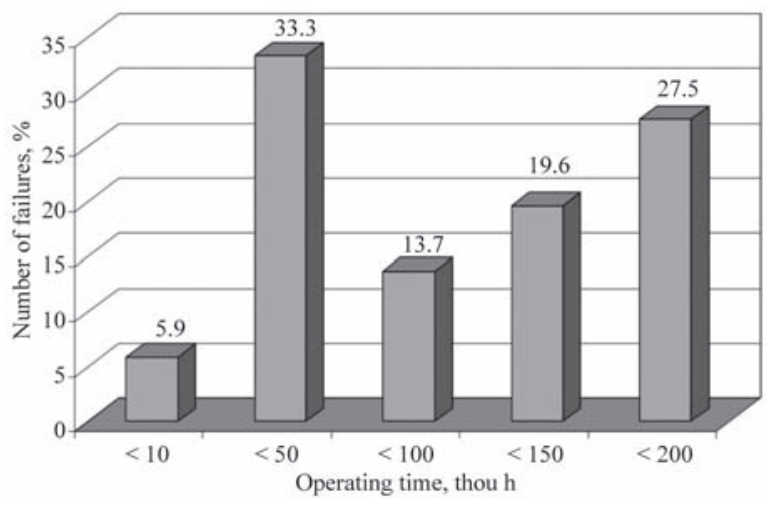

Figure 1. Number of failures in the HPP equipment, depending on the service life [4] is predetermined by the considerable «durability» of the metal, successful structure as well as repair with the use of welding for the serviceability restoration in case of damages [2, 3].

The most frequent type of damage to casing parts are cracks, and the place of their occurrence is welded joints [3]. They can be formed in different periods of operation under the action of technological, structural and operation factors $[3,4]$ according to the mechanism of cold brittleness (cold cracks) [5]; fatigue or corrosive fatigue fracture [2], dispersion embrittlement (cracks of reheating) [3, 6], creep [2, 3, 7]. Damage to equipment elements in the period from 10 to 50 thou $\mathrm{h}$ is predetermined by the defects of metal and assembly. The number of failures increases with the increase in operating hours (Figure 1). The main factor causing their increase is the deterioration of the metal structure and properties.

The cracks of cold brittleness are formed after operation of a period being less than 5 thou $\mathrm{h}$ and the cause is mainly a technological factor, i.e. violations or drawbacks of technology of welding, heat treatment and manufacturing of castings, from which the defects, the structures of quenching, hydrogen saturation of the metal, high levels of stresses were formed in the metal. During this period, the mechanical properties of the metal vary slightly, but the parameters 
of resistance to fracture, sensitive to local structural changes, decrease. After 5-20 thou h, the cracks from the dispersion embrittlement of metal can be formed after reheating as a result of welding, unsuccessful heat treatment mode or in the non-heat treated joints at the operation temperatures being higher than 510 ${ }^{\circ} \mathrm{C}[4,5]$. The precipitation of carbides both over the body and along the grain boundaries, leads to a decrease in cracks initiation [2,8].

The fatigue cracks initiate after 20-70 thou h under the influence of high cyclic stresses resulted from non-stationary mode of service, corrosion effect of the operating environment and the presence of stress concentrator. A deformation of the material under thermal influence is propagating by the mechanism of active tension-compression. At this period, the major changes in the metal structure occur at the level of redistribution of carbide components with the formation of a substructure, favourable for crack propagation [6].

The creep cracks can be formed from the arising of high long-term stresses, exceeding the design ones under the influence of each or in a complex of three factors: technological, structural and operational and are recognized as one of the main causes of damaging steam lines at the temperatures higher than $450{ }^{\circ} \mathrm{C}$ $[2,3]$. The development of creeping process occurs primarily at the reduced resistance to counteracting a long-term stress at a high temperature due to insufficient working section of a part, degradation of structure and action of corrosive environment [1, 9]. At the increased pressure and service life, the factor of degradation of the structure becomes the most frequent cause of arising cracks. The characteristic of changing the structure, causing degradation, is a gradual transformation of the ferrite-pearlite (steel $12 \mathrm{Kh} 1 \mathrm{MF}$ ) or the bainite-ferrite structure (steel 15Kh1M1F) (Figure 2, a) into ferrite (Figure 2,b) with the coarsening and formation of the carbide clustering along the grain boundaries, as well as the appearance of pores and creep microcracks $[6,9]$. At the same time, a significant change in the mechanical properties of the metal occurs in relation to the level of these characteristics for delivery conditions [10]. A part of steel $15 \mathrm{Kh} 1 \mathrm{M} 1 \mathrm{FL}$ is rejected if there was a decrease in the yield strength to $270 \mathrm{MPa}$, ultimate tensile strength to $470 \mathrm{MPa}$ and impact toughness to $130 \mathrm{~kJ} / \mathrm{m}^{2}$, as well as if the creep pore chains appear along the grain boundaries during examination at the microscope magnification of $\times 500$ [11].

For repair of parts of the power equipment, consumable electrode arc welding is used [12,13]. Development of the technology of welding is carried out for each repair, its method and technique of performance, welding mode, welding consumables, need in addi-

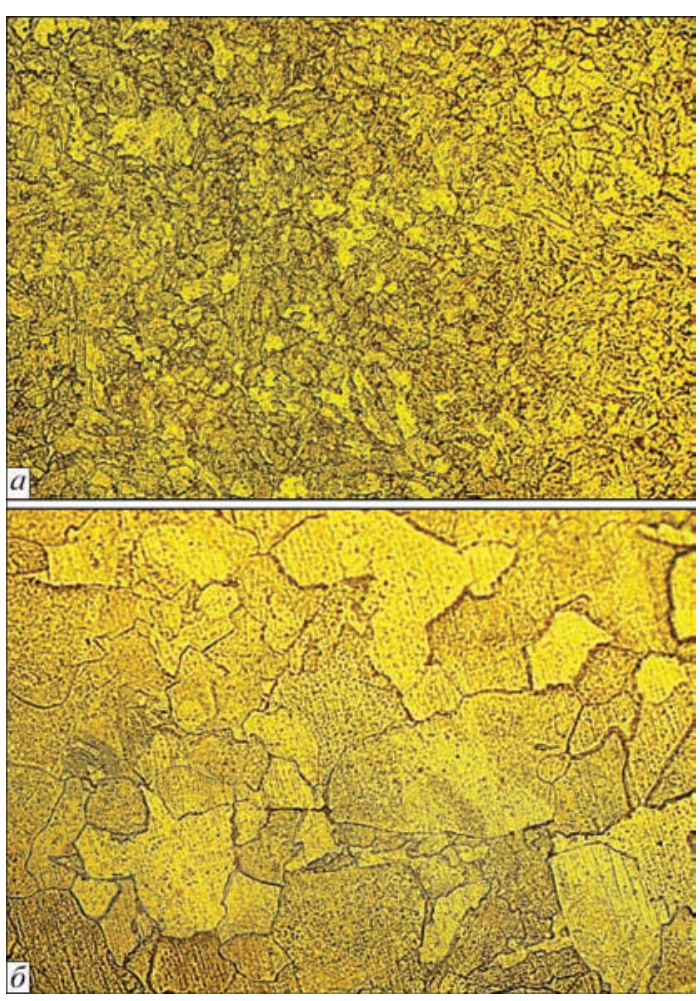

Figure 2. Microstructure $(\times 500)$ of metal of branch pipe of the stop valve in the condition: $a$ - before operation; $b$ - after operation at the temperature of $560{ }^{\circ} \mathrm{C}$, and pressure of $230 \mathrm{MPa}$, of 310 thou h duration $(b)$

tional technological measures of thermal and deformation influence for producing welded joint, equal to the base metal, are determined. The main provisions of the welding technology and the peculiarities of its application are determined on the basis of the requirements of the regulatory documents, depending on the initial parameters, such as: chemical composition and hardness of the base metal, dimensions of damage, regions of its location and of a part in general, operating conditions, etc. There are no recommendations for taking into account the service life and at the same time changing the structure and mechanical properties of the metal. The initial structure significantly influences the weldability of the base metal, the resistance to cracking and the properties of welded joints $[5,14]$ and its change should be taken into account while choosing or developing a repair welding technology.

The aim of the work is to analyze the possibility of taking into account the state of the part metal after long-term operation in the technology of repair welding to provide a reliable service of welded joint.

Many technologies of repair welding of parts of heat-resistant steels are known $[15,16]$. One of the very first technologies, which found a wide application for repair welding of large-sized massive parts, is welding using austenitic electrodes [17, 18]. It allows preventing the formation of cold cracks in welded joints without preheating and postweld heat 
Recommendations on using technological means in welding depending on base metal condition

\begin{tabular}{|c|c|c|c|c|c|c|c|c|}
\hline \multirow{2}{*}{$\begin{array}{c}\text { Condition of welded } \\
\text { metal }\end{array}$} & \multicolumn{7}{|c|}{ Technological measures of welding } \\
\cline { 2 - 9 } & $\begin{array}{c}\text { Welding } \\
\text { method }\end{array}$ & $\begin{array}{c}\text { Welding } \\
\text { materials }\end{array}$ & $\begin{array}{c}\text { Welding } \\
\text { mode }\end{array}$ & Preheating & $\begin{array}{c}\text { Deposition } \\
\text { of surfacing } \\
\text { layer }\end{array}$ & $\begin{array}{c}\text { Peening } \\
\text { of deposited } \\
\text { layers }\end{array}$ & $\begin{array}{c}\text { Thermal } \\
\text { rest }\end{array}$ & $\begin{array}{c}\text { High- } \\
\text { temperature } \\
\text { tempering }\end{array}$ \\
\hline Cold brittleness & + & + & + & + & + & + & + & + \\
\hline Dispersion hardening & - & - & - & - & - & - & - & - \\
\hline Thermal fatigue & - & - & - & - & - & - & - & - \\
\hline Creep & - & - & - & - & - & - & - & - \\
\hline
\end{tabular}

treatment, which is important for implementation of disassembly-free repair. The disadvantage of such technology is the embrittlement of metal in the fusion zone of austenitic metal with pearlite steel because of the formation and propagation of chemical and structural heterogeneity at a high temperature, which is caused by carbon diffusion [19]. Delamination of austenitic weld with a chemical composition based on iron is carried out after 4-8 years of operation, and based on nickel - after 15-20 years of operation. The term of destruction of a welded joint with austenitic high-nickel weld can decrease to 3-4 years, if a part was in service for over 150 thou $h$ before repair [16]. To prevent the embrittlement of the fusion zone of an austenitic weld with pearlite steel, the operation of such welded joints is limited to $480{ }^{\circ} \mathrm{C}$ [18].

The main method for elimination of defects in the casing parts of the power equipment is the manual arc welding using pearlite electrodes with preheating and postweld high-temperature tempering [13, 16]. The improvement of reliability of welded joints is achieved by bringing the structure of the metal into equilibrium state, reducing the level of welding stresses and diffusion hydrogen. However, an increased heat input contributes to the growth of grain and chemical heterogeneity, which will promote reducing the crack resistance to in degraded structure of base metal. Therefore, the welding conditions, temperature of preheating and postweld heat treatment at such a method are subjected to mandatory correction depending on the service life and condition of the metal of a part, which is subjected to repair.

The relatively new welding technologies with pearlite electrodes using of technological methods for control of thermodeformational welding cycle are known, for example, such as: technique of forming a weld using the «transverse hill» method [20]; application of low-temperature thermal rest instead of high-temperature tempering [21-23]; preliminary surfacing of edges welded [16], application of the minimum energy input and technique of welding by narrow annealing beads applied in a definite sequence; layer-by-layer peening of weld metal [16, 24]. A high resistance of welded joints to crack formation in these technologies is achieved due to a more efficient use of welding heating, preventing the formation of coarse grain and brittle structures in the near-weld zone, reducing the level of stressed state and the content of diffusion hydrogen in the metal. The greater opportunities for improving the structure and properties of welded joints make them challenging for using in repair of components of power equipment, having a long service life. But there are not so many technological measures, applied in these technologies and their parameters are not determined for repair of parts with different conditions of metal welded (Table).

Thus, taking into account the diversity of types and sizes of components of power equipment, operating conditions, type of damages and condition of metal during their repair, a specific welding technology should be applied. Determining its optimal parameters requires additional investigations, the relevance of which grows because of the further increase in the service life and degradation level of metal. The development and application of welding repair technology is an economically and organizationally effective measure, which provides a significant elongation in the service life of parts without significant financial costs as compared to replacement for the new ones.

\section{Conclusions}

1. The damages to the components of turbine equipment are formed in different period of operation under the influence of many factors and are always accompanied by the preliminary deterioration in the structure and properties of the metal.

2. The modern technologies of repair welding do not take into account the condition of the metal of a damaged part, which does not provide confidence in the reliability of the produced welded joints.

3. The elimination of damages of components of turbine equipment after a long-term operation requires the development of new technologies of repair welding with the use of additional technological measures of thermal and deformation influence. 
1. Chernousenko, O.Yu. (2013) Damage and residual service life of the CVD and CSD stop valves of the K-800-240 steam turbine at the Slavyansk TES. Visnyk NTU KhPI. Series: Power and heat engineering processes and equipment, 986(12), 100-106 [in Russian].

2. Izrailev, Yu.L., Khromchenko, F.A., Livansky, A.P. et al. (2002) The persistence of the steam pipes of aging thermal power plants. Ed. by Yu.L. Israilev and F.A. Khromchenko. Moscow: Torus Press [in Russian].

3. Khromchenko, F.A. (2003) Service life of welded joints of steam pipelines. Moscow, Mashinostroenie [in Russian].

4. Kushnarenko, V.M., Kandyba, N.E., Stepanov, E.P. et al. (2003) Analysis of damageability of steam generating equipment of TPP. Vestnik OGU, 6, 177-182 [in Russian].

5. Makarov, E.L. (1981) Cold cracks in welding of alloy steels. Moscow, Mashinostroenie [in Russian].

6. Gladshtein, V. I. (2014) Microdamage of metal of high-temperature parts of power equipment. Moscow, Mashinostroenie [in Russian].

7. Dmitrik, V.V., Glushko, A.V., Grigorenko, S.G. (2016) Features of pore formation in welded joints of steam lines in longterm operation. The Paton Welding J., 9, 51-54.

8. Kotrechko, S.A., Meshkov, Yu.Ya., Televich, R.V. (2004) The microstructure parameters controlling the brittle strength of low-carbon steels with the structure of tempering martensite. Metallofizika i Novejshie Tekhnologii, 26(1), 435-456 [in Russian].

9. Panteleenko, F.I., Snarsky, A.S., Krylenko, A.V. (2012) Features of the structure degradation and mechanical properties of the elements of the furnace and heat-power equipment components after long-term operation. Nauka i Tekhnika, 1, 16-20 [in Russian].

10. OST 108.96I.02-79: Castings of carbon and alloy steels for parts of steam stationary turbines with guaranteed strength characteristics at high temperatures. Specifications.

11. MPE Ukraine (2004) Metal control and life extension of the main components of boilers, turbines and pipelines of thermal power plants. In: Standard instruction: SOU-N MPE 40.17.401:2004 [in Ukrainian].

12. (2018) Rules of labor protection during equipment operation under pressure. Order of the Ministry of social policy of Ukraine, 05 March 2018, No. 333. NPAOP 0.00-1.81-18 [in Ukrainian].
13. Welding, heat treatment and control of pipe systems of boilers and pipelines during installation and repair of equipment of thermal power plants. Min. energy of the USSR. RD 34.17.101-89 (RD 34.15.027-89) [in Ukrainian].

14. Pokhodnya, I.K., Yavdoshchin, I.R., Paltsevich, A.P. et al. (2004) Metallurgy of arc welding. Interaction of metal with gases. Ed. by I.K. Pokhodnya. Kiev, Naukova Dumka [in Russian].

15. Anokhov, A.E., Korolkov, P.M. (2003) Welding and heat treatment of casing power equipment during repair. Kiev, Ekotekhnologiya [in Russian].

16. Khromchenko, F.A. (2005) Welding technologies for repair works. Moscow, Intermet Engineering [in Russian].

17. Zemzin, V.N., Bagramova, T.I., Titiner, Z.K. et al. (1974) Use of high-nickel electrodes for welding-up of defects in cast housing parts of steam turbines. Leningrad, LDNTP [in Russian].

18. (2013) NPO TsKTI 10.049-2013: Elimination of defects in cast parts of power equipment with the use of welding without subsequent heat treatment: Guidelines [in Russian].

19. Lipodaev, V.N., Snisar, V.V., Elagin, V.P. et al. (1991) Features of brittle fracture of dissimilar welded joint with high-nickel weld metal. Avtomaticheskaya Svarka, 10, 6-9 [in Russian].

20. Efimenko, N.G., Atozhenko, O.Yu., Vavilov, A.V. et al. (2014) Structure and properties of welded joints of $15 \mathrm{Kh} 1 \mathrm{M} 1 \mathrm{FL}$ steel at repair of casting defects by transverse hill method. The Paton Welding J., 2, 42-46.

21. Tsaryuk, A.K., Ivanenko, V.D., Skulsky, V.Yu. et al. (2012) Technology of repair welding of boiler unit assemblies without postweld heat treatment. The Paton Welding J., 9, 37-42.

22. Aloraierd, A. Al-Maznoueed, A., Price, J.W.H., Shehata, T. (2010) Weld repair practices without post weld heat treatment for ferritic alloys and their consequences on residual stresses: Review. Int. J. of Pressure Vessels and Piping, 87, 127-133.

23. Som Dutt Sharma, S.D, Saluja, R., Moeed, K.M. (2013) A review on effect of preheating and/or post weld heat treatment (PWHT) on hardened steel. Int. J. of Technical Research and Applications, (1-2), 5-7.

24. Delamarian, C. (1998) Manual for maintenance and retrofit of conventional power plants. Timisoara, Editura Sudura. Publishing House of the Romanian Welding Society.

Received 02.10.2018 


\title{
INFLUENCE OF ACTIVATORS ON THE QUALITY OF SPIRALLY-WELDED PIPES, PRODUCED WITH APLICATION OF HIGH-FREQUENCY WELDING
}

\author{
V.V. POLUKHIN, A.S. PROKOFIEV, D.V. ROMASHKO, S.V. RYMAR and R.S. GUBATYUK \\ E.O. Paton Electric Welding Institute of the NAS of Ukraine \\ 11 Kazimir Malevich Str., 03150, Kyiv, Ukraine. E-mail: office@paton.kiev.ua
}

\begin{abstract}
The paper deals with development of the high-frequency welding technology in manufacture of thin-walled spirally-welded pipes by adding activators to the weld zone and applying the pressure to improve the strength characteristics of welded joint metal. Investigations are based on scientific principles of theoretical fundamentals of welding, materials science and problems of metal strength. A specifics of the welding technology considered is the fact that during heating of edges to be joined by high frequency currents the activators, having lower melting temperatures, transition to the liquid state, bind surface contaminations and transport them to the surface at pressure applying. Edges of the cleaned metal are joined as a result of running of diffusion processes at temperatures close to base metal melting temperatures. In principle, the process of joining at the final stage proceeds with the weld metal being in the solid phase. The obtained weld width does not exceed 4-8 $\mu \mathrm{m}$. Weld metal consists of the base metal being welded, enriched in activator elements. Near-weld zone structure is close to that of the base metal. Thin-walled spirally-welded pipes can be produced with a high quality of welded joint at a high welding speed. 21 Ref., 3 Tables, 5 Figures.
\end{abstract}

Ke yw ords : thin-walled spirally-welded pipes, welding, high-frequency current, pressure application, activators

In modern conditions of the pipe market development, the production of thin-walled spirally-welded pipes [1-3], in which the ratio of the diameter $D$ to the wall thickness $S(D / S)$ is $80 / 1$ and higher, is remained actual. As a rule, the wall thickness of such pipes is determined by the thickness of the strip, from which such pipes are manufactured.

Thin-walled spirally-welded pipes are distinguished by a number of positive features. One of them is a high material utilization factor due to the reduced wall thickness and a large value of $D / S$ ratio. The other one is a highly efficient and economical way of their production. In high-frequency electric pipe-welded mills, designed at the E.O. Paton Electric Welding Institute, the manufacture of thin-walled spirally-welded pipes is performed per a single pass. The mills provide a wide regulation of the $D / S$ ratio by changing the diameter of the produced pipes, maintaining the wall thickness of the pipe $S$ constant. This makes it possible to manufacture pipes of a wide range. The mill is small-sized and assembled according to the block scheme, with the possibility of its arrangement at a small production site or in the body of a trailer, railway platform, barge, which makes the equipment mobile.

In terms of energy costs per a running meter of a weld, the method of high-frequency welding in the manufacture of thin-walled spirally-welded pipes is the most economical and highly-efficient.
The advantages of thin-walled spirally-welded pipes can also include the possibility of applying protective coatings on them, including nonmetallic ones, in the form of enamel, glass, synthetic and composite materials, both inside and outside the pipe. In the case of polyethylene coating, the pipes are similar in appearance to plastic pipes, but they are significantly stronger than the latter ones. At the same time, traditional welding technologies are applicable during assembly of pipes into pipelines and installation of flanges ones.

Thin-walled spirally-welded pipes are widespread in the manufacture of air ducts, ventilation systems, pneumatic systems, different product pipelines, including those for bulk materials, as well as in fire extinguishing systems. Such pipes can be used in the manufacture of fire extinguishers, containers for paint industry, in the manufacture of cylinders, tubes, receivers and other similar products.

A spirally-welded thin-walled pipe is a pipe manufactured using complex forming and electric welding of sheet rolled metal, which is strip in this case. The basis of the technology of production of spirally-welded pipe consists in producing a weld along a cylindrical spiral along the pipe surface. The use of high-frequency currents can significantly increase the pipe manufacturing speed, however, it is necessary to provide the complexly deforming formation and rotational translational movement of a workpiece welded. To formation both welded billet as well as weld are subjected. 
The spiral weld in such a pipe simultaneously combines the properties of a circumferential and longitudinal weld. Since the weld is produced along a cylindrical spiral, in spirally-welded pipes a favourable uniform distribution of loads to the weld is observed, and the weld metal is partially relieved from radial stresses [4] due to the fact that welds are located at an angle to the forming cylindrical surface of a pipe.

At the E.O. Paton Electric Welding Institute, a high-efficient technology of the high-frequency welding for the manufacture of thin-walled spirally-welded pipes of low-carbon and low-alloy steels was developed. This is a high-frequency welding at pressure with flashing, without flashing and with melting [1-3, 5]. Also, at the E.O. Paton Electric Welding Institute a method of induction press welding with the use of activators in the weld zone and subsequent plastic deformation of the joint zone was developed [1, 2, 6, 7-16]. In 2006, this process of joining metals was introduced into the State Standard of Ukraine [17] under the term braze welding.

The use of activators in the weld zone during their melting allows activating the joining surfaces of the base metal, partially alloying the edges of the metal to be joined, protecting the welding zone from the effects of the atmosphere, reducing the temperature of the welding process. In this case, the formation of the welded joint itself occurs in a solid phase without melting the base metal. The temperature of the process of induction press welding at pressure with use of activators in the weld zone is determined by the melting temperature of the activators, which is lower than the base metal melting temperature. The use of pressure and the subsequent plastic deformation of welded joint allow accelerating the counter diffusion processes in the weld zone, increasing the area of the surface joined in the weld, which contributes to removal of activation products from the weld zone in the form of a thin liquid interlayer, washing the base metal edges, and which is an undesirable component in the formed weld. Thus, the joint forms a refined base metal, which is in the solid state and has a temperature, being somewhat higher than the point $A_{c 3}$ of the steel state diagram.

The work is devoted to development of high-frequency welding technology in the manufacture of thin-walled spirally-welded pipes by applying pressure to the edges welded and, which is innovative, by introducing activators into the weld zone for increase in its strength characteristics. This direction of work is associated with the growing use of foreign low-alloyed and corrosion-resistant steels in the manufac- ture of spirally-welded thin-walled pipes and solves the problem of improving the quality of welded joints while using high-frequency welding.

The basic technological parameters of the process of welding of specimens of thin-walled spirally-welded pipe are welding speed, and accordingly, the upsetting rate associated with it. Also, the basic parameters are the electrical parameters: output voltage and welding current of the high-frequency power source. They determine the heating temperature of the edges welded at the point of their convergence and plastic properties of the weld metal, depending on the grade of metal. An important parameter is the initial value of edges overlapping.

The simultaneous favourable combination of basic parameters of high-frequency welding in the production of specimens of thin-walled spirally-welded pipes allows producing a high-quality welded joint. At the same time, due to the complex process of forming a spirally-welded pipe from a strip and at the same time performing upsetting with a high-frequency welding, where, in addition to the counter deformation of welded edges, their unrolling and decrease in the overlapping thickness to the thickness of the initial material (strip) occurs, the weld from the overlapped one transforms into a bevel butt one.

During the weld formation in producing of specimens of thin-walled spirally-welded pipes, at the point of convergence of edges welded, the concentration of heating, as well as heating of the activators located in the weld zone occurs. As a result of concentrated heating, a transition of activator to the liquid phase, washing and activation of base metal edges welded, being in the solid-plastic state, occurs. At the same time, the processes of mutual diffusion of the activator in the liquid phase into the base metal and vice versa occur. Applying pressure to the edges welded in the form of upsetting intensifies these processes in the weld, and also leads to almost complete removal of reaction products of the activator into the flash and its subsequent crystallization outside the weld.

As a result of upsetting, a plastic deformation of edges welded and a partial squeezing out of plastic metal from the weld zone in the form of flash to the peripheral colder regions of the weld both inside and also outside the pipe with its flattening-out over the pipe surface occur.

The research work was performed in the special equipment S-460, designed at the E.O. Paton Electric Welding Institute, which was previously delivered to the pipe plants and used in the manufacture of thin-walled spirally-welded pipes from low-carbon 
Table 1. Chemical composition of used steels

\begin{tabular}{|c|c|c|c|c|}
\hline \multirow{2}{*}{ Chemical composition [4] } & \multicolumn{5}{|c|}{ Steel grade } \\
\cline { 2 - 5 } & St3sp & $08 \mathrm{kp}$ & S355 & 12Kh18N10T \\
\hline $\mathrm{C}$ & $0.14-0.22$ & $0.05-0.12$ & $0.15-0.2$ & $\leq 0.12$ \\
\hline $\mathrm{Cr}$ & $\leq 0.3$ & $\leq 0.1$ & $\leq 0.3$ & $17-19$ \\
\hline $\mathrm{Fe}$ & 97 & 98 & 96 & $\leq 7$ \\
\hline $\mathrm{Mn}$ & $0.4-0.65$ & $0.25-0.5$ & $\leq 0.3$ & $\leq-11$ \\
\hline $\mathrm{Ni}$ & $\leq 0.3$ & $\leq 0.3$ & $\leq 0.03$ & $\leq 0.035$ \\
\hline $\mathrm{P}$ & $\leq 0.04$ & $\leq 0.035$ & $\leq 0.035$ & $\leq 0.02$ \\
\hline $\mathrm{S}$ & $\leq 0.05$ & $\leq 0.04$ & $0.4-0.6$ & $\leq 0.8$ \\
\hline $\mathrm{Si}$ & $0.15-0.3$ & $\leq 0.3$ & $\leq .008$ & - \\
\hline $\mathrm{N}$ & $\leq 0.008$ & - & $\leq 0.3$ & $\leq 0.3$ \\
\hline $\mathrm{Cu}$ & $\leq 0.3$ & $\leq 0.3$ & $0.02-0.05$ & - \\
\hline $\mathrm{Al}$ & $\leq 0.08$ & - & $\leq 0.12$ & - \\
\hline $\mathrm{V}$ & - & - & - & - \\
\hline $\mathrm{Ti}$ & - & - & & $0.4-0.8$ \\
\hline
\end{tabular}

and low-alloyed steels at the application of high-frequency currents. For heating the edges converging in a spiral, a high-frequency welding generator VChS$160 / 044$ with a power of $160 \mathrm{~kW}$ and a frequency of $440 \mathrm{kHz}$ with contact current supply to the edges welded is used. The main processes of high-frequency welding under pressure in the manufacture of test specimens of spirally-welded pipes of the diameters $D=98,108$ and $152 \mathrm{~mm}$ were carried out on low-carbon steels of grade $\mathrm{St3} 3 \mathrm{sp}$ (killed) $(S=1.0 \mathrm{~mm}$ thickness) and $08 \mathrm{kp}$ (rimmed) of $S=1.0$ and $1.3 \mathrm{~mm}$ thicknesses, low-alloyed steel S355 (analogue of steel $17 \mathrm{G} 1 \mathrm{~S}$ ) with $S=2.0 \mathrm{~mm}$ thickness and corrosion-resistant steel of grade $12 \mathrm{Kh} 18 \mathrm{~N} 10 \mathrm{~T}$ ( $S=0.8$ and $1.0 \mathrm{~mm}$ thicknesses). The chemical composition of the applied steels is given in Table 1.

Figure 1 shows the scheme of the formation of joining of spirally-welded pipe edges during high-frequency pressure welding and the use of activators: $a$ - beginning of the joint formation, 1 - preliminary applied activator on the metal edges to be joined

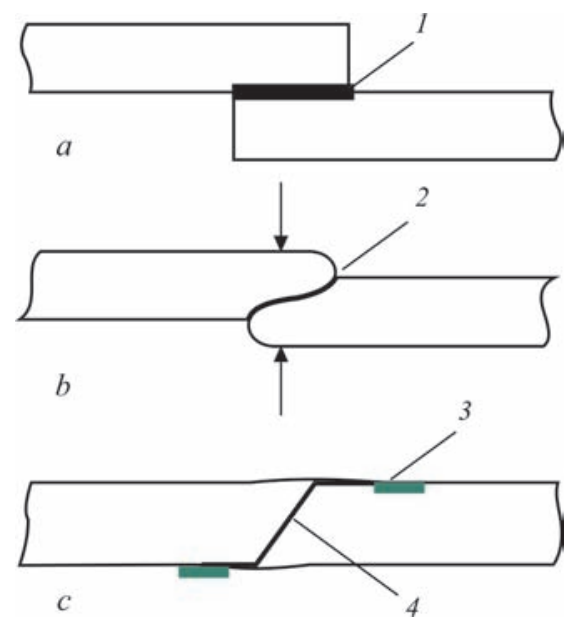

Figure 1. Scheme of forming joint of edges of a spirally-welded pipe (see the description of $a-c$ in the text) (overlapped joint); $b$ - process of upsetting in the form of unrolling the overlapped joint with activator in the weld zone immediately after heating by high-frequency currents, 2 - activator on the metal edges to be joined; $c$ - formed bevel-butt joint of edges, 3 - metal with an activator, squeezed out from the weld, unrolled over the pipe surface; 4 formed weld (with probable inclusions of activator of 0-50 $\mu \mathrm{m}$ thickness).

In producing test specimens of spirally-welded pipes of the mentioned steels, the activators were used, representing a powder mixture of flux PV-201 or PV-209 and a copper-nickel brazing alloy PAN-3 (PD58G32N8S) $(\mathrm{Cu}$ - base $58, \mathrm{Mn}-32, \mathrm{Ni}-8$, $\mathrm{Si}$ - up to $1.5 \%$ ) [18], which was applied by spraying on a thin layer of raw adhesive, with which the welded edges were preliminary greased.

To fix the powdered mixture of the flux and the activator on the welded edges, cyanoacrylate adhesives and BF glue, containing phenol formaldehyde resin and polyvinyl acetal or polyvinyl butyral were used. These adhesives did not leave any undesirable impurities during the welding process.

For test specimens of spirally-welded pipes made of corrosion-resistant steel of grade $12 \mathrm{Kh} 18 \mathrm{~N} 10 \mathrm{~T}$ with a thickness $S=0.8$ and $1.0 \mathrm{~mm}$, the activators were used, representing a powder mixture of flux PV-201 or PV-209 and a powdered brazing alloy $\mathrm{VPr}-1(\mathrm{Cu}-$ the base of $65.7-70.8 \%, \mathrm{Ni}-27-30, \mathrm{Si}-1.5-2.0$, $\mathrm{Fe}-0.1-1.5, \mathrm{~B}-0.1-0.3$, impurities - 0.5) $[18,19]$ or self-fluxing boron-silicon brazing alloy PG-Zh14 ( Fe - base of $43 \%, \mathrm{Ni}-37, \mathrm{C}-1.4, \mathrm{Cr}-14, \mathrm{~B}-$ 2.2, $\mathrm{Si}-2.5$, hardness HRC is 38-45) [20].

It was established that activating powder mixture of components should contain one part of the flux and seven-ten parts of brazing alloy during spraying a powdered mixture of $0.05-0.15 \mathrm{~mm}$ thickness. 
Table 2. Dependence of bending angle and width of heat-affected zone on welding speed applying pressure and activators at different anode voltage

\begin{tabular}{|c|c|c|c|c|c|}
\hline \multirow{3}{*}{ Number } & \multicolumn{5}{|c|}{ Parameters } \\
\hline & \multirow{2}{*}{$\begin{array}{l}\text { Overlap- } \\
\text { ping, mm }\end{array}$} & \multirow{2}{*}{$\begin{array}{l}\text { Welding } \\
\text { speed, } \\
\text { m/min }\end{array}$} & \multicolumn{2}{|c|}{ Bending angle } & \multirow{2}{*}{$\begin{array}{c}\text { Width of } \\
\text { heat- } \\
\text { affected } \\
\text { zone, mm }\end{array}$} \\
\hline & & & I variant & II variant & \\
\hline \multicolumn{6}{|c|}{ Anode voltage $4.0 \mathrm{kV}$} \\
\hline 1 & \multirow{3}{*}{2.0} & 10 & 100 & 60 & 12 \\
\hline 2 & & 15 & 110 & 100 & 10 \\
\hline 3 & & 20 & 180 & 140 & 7 \\
\hline 4 & \multirow{3}{*}{3.0} & 10 & 180 & 150 & 13 \\
\hline 5 & & 15 & 180 & 180 & 11 \\
\hline 6 & & 20 & 180 & 180 & 9 \\
\hline 7 & \multirow{3}{*}{4.0} & 10 & 180 & 180 & 14 \\
\hline 8 & & 15 & 180 & 150 & 12 \\
\hline 9 & & 20 & 180 & 140 & 11 \\
\hline \multicolumn{6}{|c|}{ Anode voltage $5.0 \mathrm{kV}$} \\
\hline 10 & \multirow{3}{*}{2.0} & 15 & 20 & 10 & 10 \\
\hline 11 & & 20 & 70 & 50 & 10 \\
\hline 12 & & 25 & 90 & 40 & 9 \\
\hline 13 & \multirow{3}{*}{3.0} & 15 & 180 & 150 & 11 \\
\hline 14 & & 20 & 180 & 180 & 10 \\
\hline 15 & & 25 & 180 & 180 & 9 \\
\hline 16 & \multirow{3}{*}{4.0} & 15 & 180 & 180 & 12 \\
\hline 17 & & 20 & 180 & 150 & 11 \\
\hline 18 & & 25 & 160 & 140 & 10 \\
\hline \multicolumn{6}{|c|}{ Anode voltage $6.0 \mathrm{kV}$} \\
\hline 19 & \multirow{3}{*}{2.0} & 15 & 50 & 30 & 10 \\
\hline 20 & & 20 & 90 & 80 & 9 \\
\hline 21 & & 25 & 120 & 100 & 8 \\
\hline 22 & \multirow{3}{*}{3.0} & 15 & 160 & 120 & 10 \\
\hline 23 & & 20 & 180 & 180 & 9 \\
\hline 24 & & 25 & 180 & 180 & 8 \\
\hline 25 & \multirow{3}{*}{4.0} & 15 & 180 & 180 & 12 \\
\hline 26 & & 20 & 180 & 180 & 10 \\
\hline 27 & & 25 & 160 & 140 & 9 \\
\hline
\end{tabular}

Figure 2 shows the stages of forming a bevel-butt joint on the specimens of thin-walled spirally-welded pipes. The process of upsetting was carried out in the form of unrolling the overlapped joint immediately after its heating with high-frequency currents applied to the welded edges with an activator. Figure 2, $a$ shows a cross-section of bevel-butt weld at initial stage of its formation.

Figure 2, $b$ shows the outer surface of a specimen of thin-walled spirally-welded pipe with a formed weld (top view) after the upsetting of the overlapped joint edges. A metal is visible, squeezed out from the weld, which is unrolled over the surface of the pipe and a squeezed out activator in the form of a thin film with the products of its reaction removed from the weld zone. Figure 2, $c$ shows a formed cross-section of a bevel-butt at the final stage, in which the thickness $S_{\text {st }}$ is somewhat larger than or equal to the thickness of the strip of the pipe: $S_{\text {st }} \geq S$.

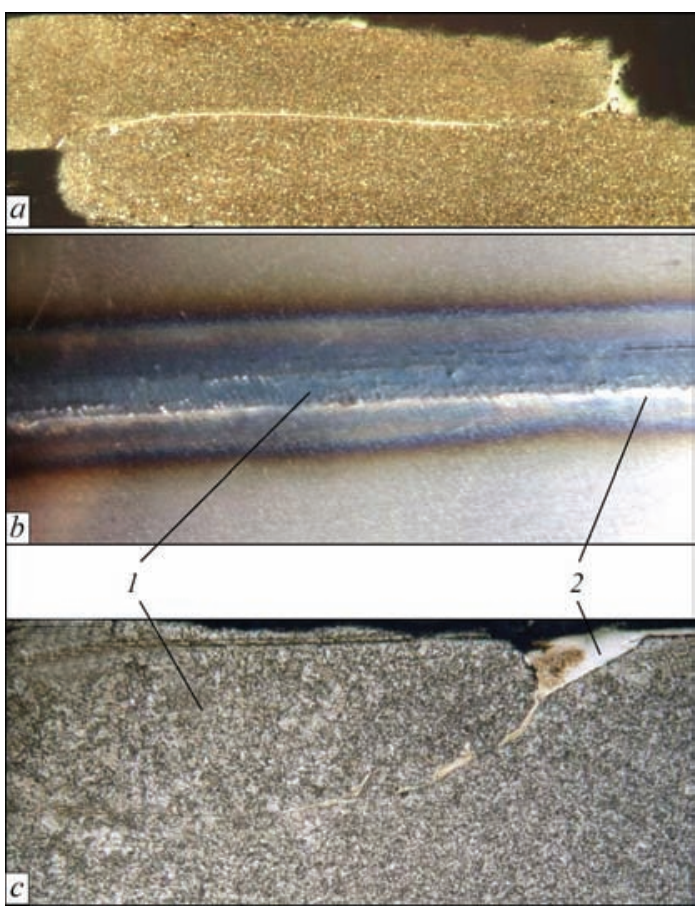

Figure 2. Stages of forming bevel-butt weld on specimens of thinwalled spirally-welded pipes: $a$ - cross-section of the weld at the initial stage of its formation; $b$ - appearance of the formed welded joint (top view); $c$ - cross-section of the formed bevel-butt weld at the final stage; 1 - metal squeezed out from the weld, unrolled over the pipe surface; 2 - activator squeezed out from the weld

Producing welds on specimens of thin-walled spiral welded pipes was carried out in the experimental installation of the E.O. Paton Electric Welding Institute at the speeds of strip movement being 15, 20 and $25 \mathrm{~m} / \mathrm{min}$, at the corresponding values of power from the applied high-frequency generator, being 50, 80 and $110 \mathrm{~kW}$. The length of region of welded edges heating (distance from the place of contact of the current supply of the welding high-frequency generator at the edges welded of the formed spirally-welded pipe billet to the place of point of convergence of edges and their entering the forming rolls) was $35-50 \mathrm{~mm}$. The width of the zone of fixation of traces of the applied activator on the surface of specimens of thinwalled spirally-welded pipes reached $15 \mathrm{~mm}$. The value of edges overlapping was selected at the level of $0.25-2.5 \mathrm{~mm}$ from thickness $S$ of the applied strip, but did not exceed $4.5 \mathrm{~mm}$ for the thickness of the strip $S=2 \mathrm{~mm}$ at the diameter of the pipe $D=152 \mathrm{~mm}$, which allowed producing a reliable welded joint and supporting a stable mode of forming specimens of thin-walled spirally welded pipes. At the same time, after the upsetting by unrolling the thickness of the weld wall $S_{\mathrm{st}}$ in the specimens of thin-walled spirally-welded pipes, almost reached the thickness of the applied strip $S$. 


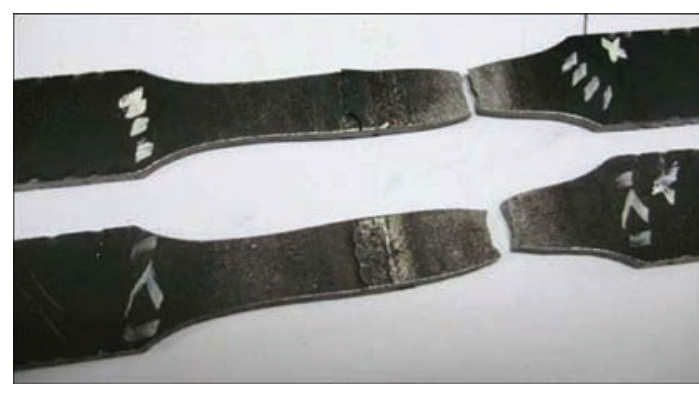

Figure 3. Specimens with weld fragments after mechanical rupture tests. Type of specimens is 8 according to GOST 6996-66

The quality of the weld of experimental thinwalled spirally-welded pipes produced with the use of activators was estimated from the results of mechanical tests of specimens, cut out from these pipes, by such parameters as bending angle and tensile strength. The heat-affected zone was determined by the change in colour and structural analysis of the weld metal and near-weld zone. The presence of scratches was detected visually.

It was established that the electrical properties of high-frequency welding have a significant effect on the weld quality. To produce specimens of thin-walled spirally-welded pipes at different speeds of the strip movement of 15, 20 and $25 \mathrm{~m} / \mathrm{min}$, the values of the anode voltage at the generator tube were changed, affecting the electrical power supplied to the weld zone.

The specimens with weld fragments for mechanical tests were obtained. The test results are given in Table 2.

Table 3 shows the data of the results of mechanical rupture tests of specimens with fragments of a weld of thin-walled spirally-welded pipes of diameter $D=$ $=108 \mathrm{~mm}$ and wall thickness $S=1.3 \mathrm{~mm}$, made of steel 08kp.

Figure 3 presents specimens with fragments of weld after conducting mechanical rupture tests. The specimens is the type 8 according to GOST 6996-66. Ultimate rupture strength is $370-380 \mathrm{MPa}$. The frac-

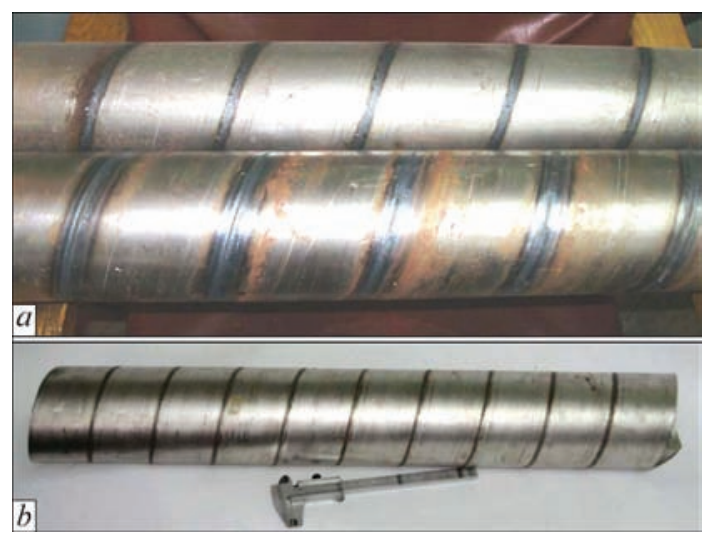

Figure 4. Specimens of thin-walled spirally-welded pipes with welds made applying pressure: $a-$ at the top a pipe of steel $08 \mathrm{kp}$, below - S355; $b-12 \mathrm{Kh} 18 \mathrm{~N} 10 \mathrm{~T}$
Table 3. Dependence of rupture strength of specimens of welds of spirally-welded pipes of $108 \times 1.0 \mathrm{~mm}$ on welding speed applying pressure and activators and overlapping values at different anode voltage and length of heating zone $35 / 50 \mathrm{~mm}$

\begin{tabular}{|c|c|c|c|}
\hline Number & Overlapping, mm & $\begin{array}{l}\text { Welding speed, } \\
\mathrm{m} / \mathrm{min}\end{array}$ & $\begin{array}{c}\text { Rupture strength, } \\
\text { MPa }\end{array}$ \\
\hline \multicolumn{4}{|c|}{ Anode voltage $4.0 \mathrm{kV}$} \\
\hline 1 & \multirow{3}{*}{2.0} & 10 & 40 \\
\hline 2 & & 15 & 90 \\
\hline 3 & & 20 & 340 \\
\hline 4 & \multirow{3}{*}{3.0} & 10 & 360 \\
\hline 5 & & 15 & 380 \\
\hline 6 & & 20 & 380 \\
\hline 7 & \multirow{3}{*}{4.0} & 10 & 350 \\
\hline 8 & & 15 & 380 \\
\hline 9 & & 20 & 380 \\
\hline \multicolumn{4}{|c|}{ Anode voltage $5.0 \mathrm{kV}$} \\
\hline 10 & \multirow{3}{*}{2.0} & 20 & 60 \\
\hline 11 & & 25 & 140 \\
\hline 12 & & 30 & 340 \\
\hline 13 & \multirow{3}{*}{3.0} & 20 & 350 \\
\hline 14 & & 25 & 355 \\
\hline 15 & & 30 & 345 \\
\hline 16 & \multirow{3}{*}{4.0} & 20 & 363 \\
\hline 17 & & 25 & 370 \\
\hline 18 & & 30 & 370 \\
\hline \multicolumn{4}{|c|}{ Anode voltage $6.0 \mathrm{kV}$} \\
\hline 19 & \multirow{3}{*}{2.0} & 15 & 60 \\
\hline 20 & & 20 & 250 \\
\hline 21 & & 25 & 265 \\
\hline 22 & \multirow{3}{*}{3.0} & 15 & 330 \\
\hline 23 & & 20 & 370 \\
\hline 24 & & 25 & 370 \\
\hline 25 & \multirow{3}{*}{4.0} & 15 & 370 \\
\hline 26 & & 20 & 370 \\
\hline 27 & & 25 & 370 \\
\hline
\end{tabular}

ture of specimens occurs on the base metal. At $20^{\circ} \mathrm{C}$ the tensile strength $\sigma_{t}$ for heat-treated steel $08 \mathrm{kp}$, is $310-440 \mathrm{MPa}$. The presented data testify of a high strength of the welded joint produced in a spirally-welded pipe, which is achieved also due to the thermomechanical hardening of the weld as a result of subsequent upsetting in the form of rolling-out overlapped joint of welded edges with applied activator in the weld zone.

In the upper part of Figure 4, $a$ the specimen of thin-walled spirally-welded pipe of diameter $D=$ $=108 \mathrm{~mm}$ and wall thickness $S=1.0 \mathrm{~mm}$ is shown, made of steel $08 \mathrm{kp}$ with a narrow heat-affected zone, in the lower part - a specimen of thin-walled spirally-welded pipe of diameter $D=108 \mathrm{~mm}$ and wall thickness $S=2.0 \mathrm{~mm}$ of steel S355 with a wide heat-affected zone. For the specimen of steel S355, an activator was used in the form of a mixture of brazing alloy PAN-3 and flux PV-201. The difference in the width of the heat-affected zone is determined by a combination of parameters, such as the speed of weld- 
ing, the amount of power introduced into the weld, the chemical composition of steel.

Figure 4, $b$ shows the specimen of thin-walled spirally-welded pipe of diameter $D=98 \mathrm{~mm}$ and wall thickness $S=0.8 \mathrm{~mm}$ of steel $12 \mathrm{Kh} 18 \mathrm{~N} 10 \mathrm{~T}$. While producing this specimen, an activator was used in the form of self-fluxing brazing alloy PG-Zh14. Despite of a rather narrow heat-affected zone, to produce long quality welded joints of specimens of thin-walled spirally-welded pipes of corrosion-resistant steels, it is further necessary to provide a reliable protection of the weld zone with shielding gases from environment effect in the used experimental installation. For the time being, the produced weld is visually different from the base metal: corrosion resistant steel $12 \mathrm{Kh} 18 \mathrm{~N} 10 \mathrm{~T}$.

Figure 5, $a$ shows microsection of the weld of the specimen of a spirally-welded pipe of diameter $D=$ $=108 \mathrm{~mm}$ and wall thickness $S=1.3 \mathrm{~mm}$ of steel $08 \mathrm{kp}$, produced in the process of high-frequency welding using activators: brazing alloy PAN-3, flux PV-201. The weld in the form of a thin residual interlayer of crystallized activator, formed under upsetting pressure and was not completely squeezed out from the joint zone, is clearly visible. The width of the weld (interlayer) does not exceed 4-8 $\mu \mathrm{m}$. At the same time, the chemical composition of the formed weld is enriched with elements of base metal being welded, applied activator, and, partially with the products of surface activation. The structure of metal in the nearweld zone, close to weld, approaches the structure of the base metal.

Figure $5, b$ shows microsection of the steel $12 \mathrm{Kh} 18 \mathrm{~N} 10 \mathrm{~T}$ weld, produced in the process of high-frequency welding using an activator self-fluxing brazing alloy PG-Zh14 without shielding gases. In the place of edges joining, an activator is seen, filling the microscopic nonuniformities of the joint surfaces. The width of the weld is about $1 \mu \mathrm{m}$. The chemical composition of the formed weld is enriched with elements of the welded base metal, however, here there is also a visual difference of the produced weld metal from the base metal.

It is assumed that to produce a stable welded joint of corrosion-resistant and alloyed steels in high-frequency welding as-applied to the production of spiral welds of pipes, it is necessary to protect the zone of the joint formation by neutral gases or to increase the welding speed for the contact between the molten and not yet crystallized activators with the atmosphere of air, which is minimum in time. This is the task of further investigations.
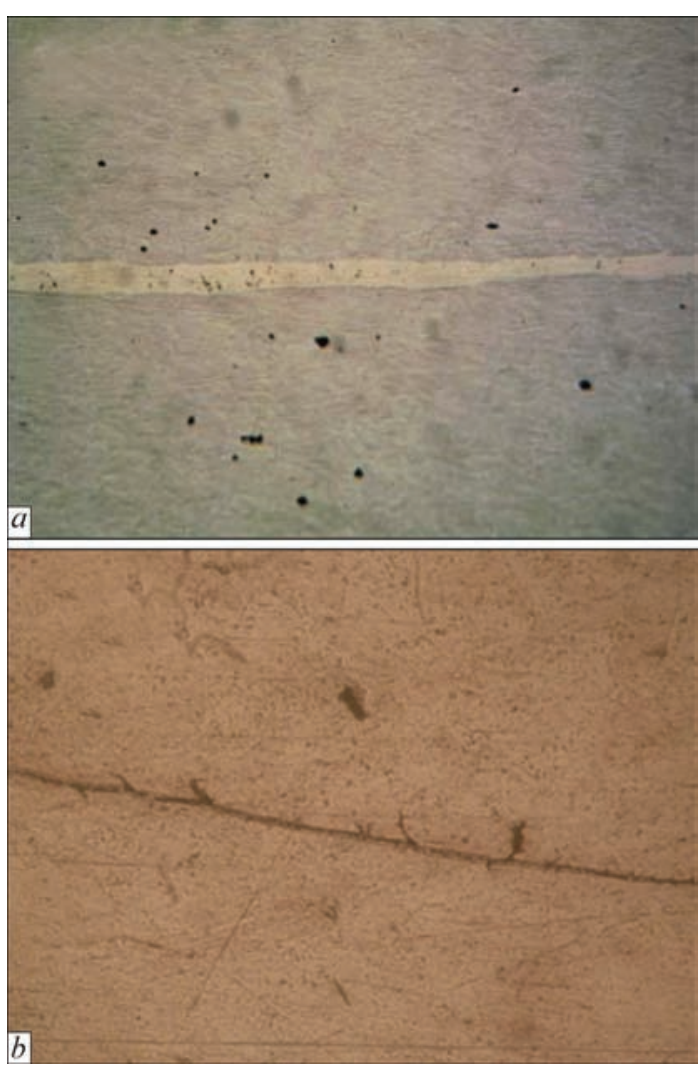

Figure 5. Microsections $(\times 500)$ of specimens of welds of spirally-welded pipes made applying pressure and activators: $a-$ pipe weld of steel 08kp; $b-12 \mathrm{Kh} 18 \mathrm{~N} 10 \mathrm{~T}$

An increase in the welding speed is possible due to an increase in the introduced power of high-frequency generator, which will have a positive effect on the economic indicators of the welding process.

The further investigations should be continued to search the optimal control of the welding process [21] and modernize the equipment, especially in searching a way to protect the zone of welding from weather influence in case of using corrosion-resistant and alloyed steels. However, it is already obvious that this process can become promising in the manufacture of high-quality and inexpensive thin-walled spirally-welded pipes, including the subsequent deposition of protective coatings on them.

\section{Conclusions}

1. The use of high-frequency welding provides a possibility of producing thin-walled spirally-welded pipes of a wide range of diameters, which is relevant for different fields of industry.

2. In case of high-frequency welding of spirally-welded pipes with the application of pressure and the use of activators, the latter provide the binding of surface contaminants and their escape beyond the borders of section welded while applying pressure. As a result, the edges of the purified metal are joined at the temperatures close to the melting temperatures of 
the base metal, at the development of diffusion processes in the metal, and at the final stage the process of joining occurs in the solid phase of the base metal.

3 . The prospects for the application of high-frequency welding technology in the production of thinwalled spirally-welded pipes consist in producing high-quality welds. One of the ways of development is adding activators into the weld zone, which allows producing quality welded joints of low-carbon and low-alloy steels.

1. Pis'menny, A.S. (1997) High-frequency welding of metals. Amsterdam, Harwood Acad. Publ.

2. Pismenny, A.S. (2008) High-frequency welding of metal products. Kiev, PWI [in Russian].

3. Pismenny, A.S., Polukhin, V.V., Polukhin, Vl.V. et al. (2005) Production and application of thin-walled spiral-welded pipes. The Paton Welding J., 9, 29-32.

4. Pismenny, A.S., Prokofiev, A.S., Gubatyuk, R.S. et al. (2012) Increase of strength characteristics of spirally-welded pipes of structural designation. Ibid., 3, 30-34.

5. Lebedev, V.K., Skachko, Yu.N., Polukhin, V.V. et al. (1974) Fusion of edges in high-frequency welding. Avtomatich. Svar$k a, 11,16-19$ [in Russian].

6. Slepak, E.S., Khasnulin, V.S., Kluzhinsky, V.L., Shulman, I.E. (1980) High-frequency welding in power engineering. Moscow, Mashinostroenie [in Russian].

7. Tabelev, V.D., Kareta, N.L., Panasenko, A.I. et al. (1985) Structure and phase composition of welds made by capillary brazing under pressure. Avtomatich. Svarka, 11, 26-29 [in Russian].

8. Tabelev, V.D. (1991) On formation of joints in brazing with plastic deformation of base metal. In: Materials and technology of brazing. Kiev, PWI, 50-54 [in Russian].
9. Lebedev, V.K., Tabelev, V.D., Pismenny, A.S. (1993) Impact strength of butt joints brazed with plastic deformation of base metal. Avtomatich. Svarka, 8, 29-31 [in Russian].

10. Lebedev, V.K., Tabelev, V.D., Pismenny, A.S. (1983) Butt pressure brazing of steel pipelines. Ibid., 9, 25-27 [in Russian].

11. Lebedev, V.K., Pismenny, A.S., Martynova, T.I. (1992) Experience of application of composite filler metal for pressure braze-welding. Ibid., 9-10, 42-43 [in Russian].

12. Pismenny, A.S., Novikova, D.P., Yukhimenko, R.V. et al. (2008) Technology peculiarities of high-frequency seam braze-welding of pipes. The Paton Welding J., 2, 22-25.

13. Pismenny, A.S., Prokofiev, A.S. (2002) Press welding of pipes using activating materials. Ibid., 7, 19-23.

14. Pismenny, A.S., Polukhin, V.V., Prokofiev, A.S. et al. (2002) Express-method for development and verification of pressure brazing technologies. Ibid., 1, 47-50.

15. Prokofiev, A.S., Pismenny, A.S., Bondarev, V.A. et al. (2001) Induction braze-welding of no-accessory T-joints. Ibid., 4, 43-47.

16. Prokofiev, A.S., Pismenny, A.S. (2000) Technology of brazewelding of flanges to tubes. Ibid., 5, 48-50.

17. (1999) DSTU 3761.2-98 (ISO 857:1990): Welding and allied processes. Pt 2: Welding and brazing processes. Terms and definitions. Kyiv, Derzhspozhyvstandart Ukrainy [in Ukrainian].

18. Filler materials. URL:http://termoizolit.ru/pripoi [in Russian].

19. Steels and alloys grades. URL:http://www.splav-kharkov. com/choose type.php [in Russian].

20. Surfacing powder. URL: https://grandlada.com/naplavochniy-poroshok/131 [in Russian].

21. Pantelejmonov, E.A., Samofalov, M.V. (2012) Application of electric parameters of high-frequency welding mode of spirally-welded pipes for organization of management and control processes. Svarshchik, 4, 10-12 [in Russian]. 


\title{
ELECTROSLAG SURFACING OF LAYERS OF DIFFERENT THICKNESS IN STATIONARY CURRENT-SUPPLYING MOULD
}

\author{
Yu.M. KUSKOV, V.G. SOLOVIOV, I.P. LENTYUGOV and V.A. ZHDANOV \\ E.O. Paton Electric Welding Institute of the NAS of Ukraine \\ 11 Kazimir Malevich Str., 03150, Kyiv, Ukraine. E-mail: office@paton.kiev.ua
}

\begin{abstract}
Studied was a nature of change of electrotechnical parameters of process of discrete filler melting in its portion feed and variation of thickness of deposited metal in a stationary current-supplying mould. It is determined that the process of melting in a slag pool is effected by initial values of depth and specific electric conductivity of the slag pool. A concept of averaged heat level of the slag pool was introduced. It characterizes change of physical properties and thermal state of the pool as a result of feed in it of a portion of discrete filler and allows optimizing initial position of deposited surface relatively to current-supplying section of the mould. 5 Ref., 1 Table, 5 Figures.
\end{abstract}

Keywords : electroslag surfacing, stationary current-supplying mould, deposited metal thickness, slag pool depth

One of the main advantages of the electroslag surfacing (ESS) is the possibility of surfacing of large thickness metal without deterioration of quality of deposited metal as well as bimetal joint in whole.

Developed at the E.O. Paton Electric Welding Institute sectional current-supplying mould (CSM) [1-3] allows depositing layers of metal of virtually unlimited thickness. For this relative movement of the product and CSM shall be provided.

In series of cases it is no need to deposit too large thicknesses of metal that allows using CSM in a stationary position. At that maximum thickness of the deposited metal is determined not only by length of mould forming section, but composition of used flux [4].

Application of the stationary CSM considerably simplifies surfacing technology. Thus, mechanical jam of the mould during its movement relatively to deposited billet and spilling of liquid metal (metallic pool) in variations of surfacing mode parameters are eliminated, and it is possible to provide better formation of the deposited layer.

CSM from electrotechnical point of view is a device inside which electroslag process takes place with specific distribution of currents in a melting chamber. The mould walls and bottom plate with located on it deposited product limit the melting chamber itself. It is naturally to suppose that growth of thickness of the deposited layer shall provoke some redistribution of currents relatively to current-supplying section of CSM (Figure 1). This situation can be considered from other point of view, i.e. at what distance from the current-supplying section is it necessary to locate surface being deposited in order to provide optimum heating of the fusion zone and good formation of deposited metal that is also determined by optimum current distribution in slag. In other words, it is necessary to regulate distribution of working current passing vertically down to the product as well as in horizontal direction (horizontal constituent). At that heating of the upper layers of slag pool is provided.

Aim of this work is investigation of current distribution in a slag pool at changing in process of surfacing thickness of deposited layer, qualitatively charac-

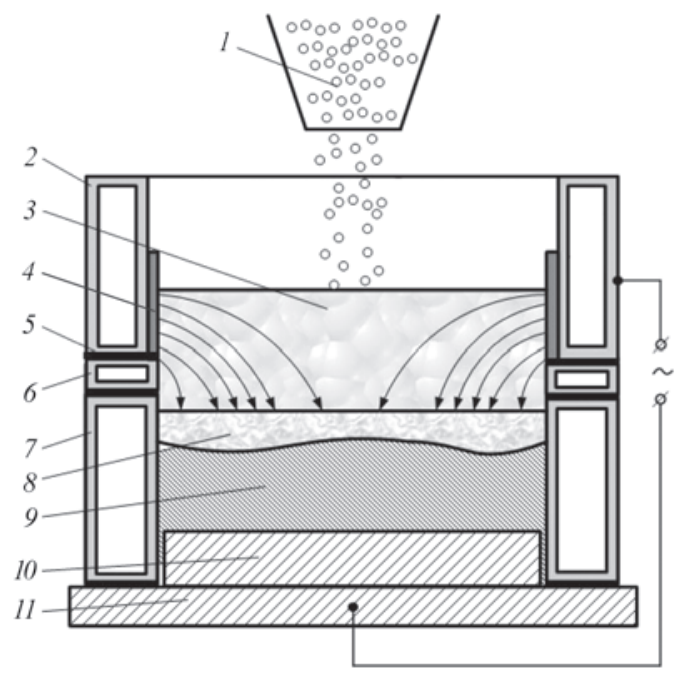

Figure 1. Scheme of distribution of lines of electric current in CSM at ESS of discrete filler: 1 - discrete filler; 2, 6, 7, - current-supplying, intermediate and forming sections of the mould, respectively; 3 - slag pool; 4 - protective lining; 5 - insulating insert; 8 - metallic pool; 9 - deposited metal; 10 - product; 11 - bottom plate 


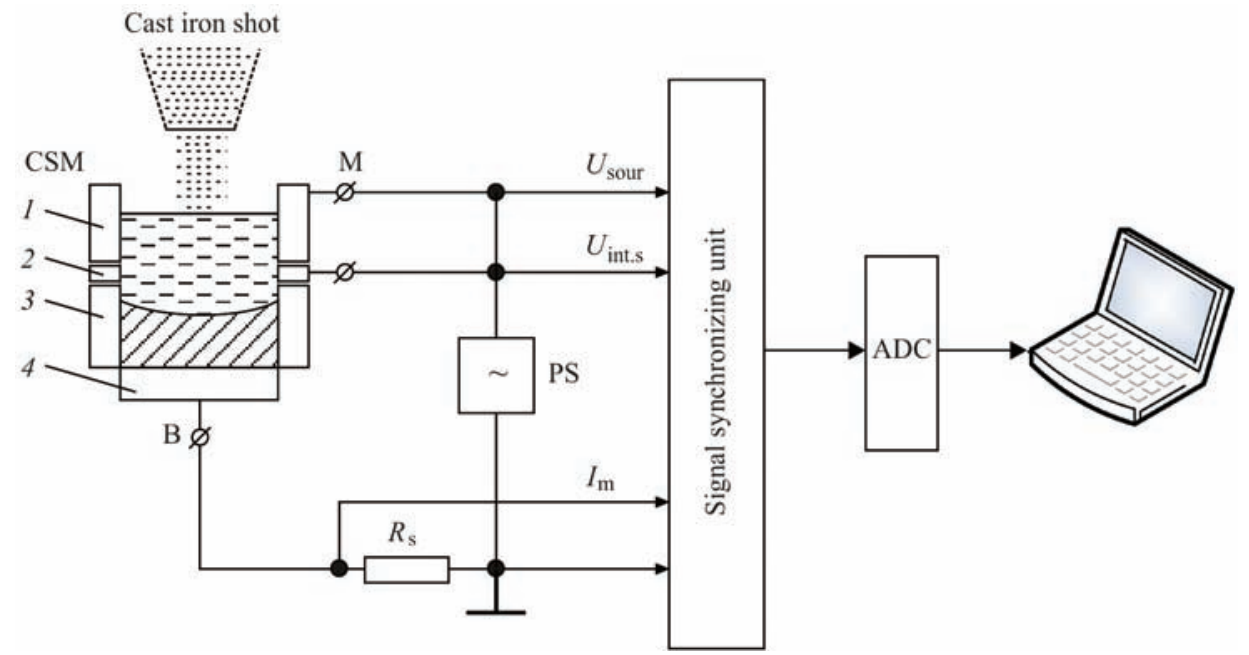

Figure 2. Structural scheme of electric connections in performance of experiments on surfacing: M, B — connection terminals to current-supplying section of mould and bottom plate with product, respectively; PS — power source; $R_{\mathrm{s}}$ - measurement current shunt; $U_{\text {sour, }} U_{\text {int.s }}, I_{\mathrm{m}}$ - signals proportional to power source voltage, potential difference between intermediate section and bottom plate as well as mould current (bottom plate), respectively; ADC — analog-to-digital converter; 1, 2, 3 - current-supplying, intermediate and forming sections of the mould, respectively; 4 - bottom plate with product

terized by variation of specific electric conductivity of the slag pool on its depth.

The most perspective surfacing material, namely discrete filler in form of chipped shot of non-alloy cast iron of approximately $2 \mathrm{~mm}$ diameter was selected as a feed material.

The experiments were carried out on the following procedure. CSM of $180 \mathrm{~mm}$ diameter was filled with molten in graphite crucible slag (flux ANF-29) of volume allowing providing CSM working capacity, i.e. slag pool should wash graphite lining of current-supplying section at approximately $20 \mathrm{~mm}$ height. After stabilizing thermal state of the pool and start of its rotation in a horizontal plane a surfacing shot was fed in CSM of special design by portions (four times by

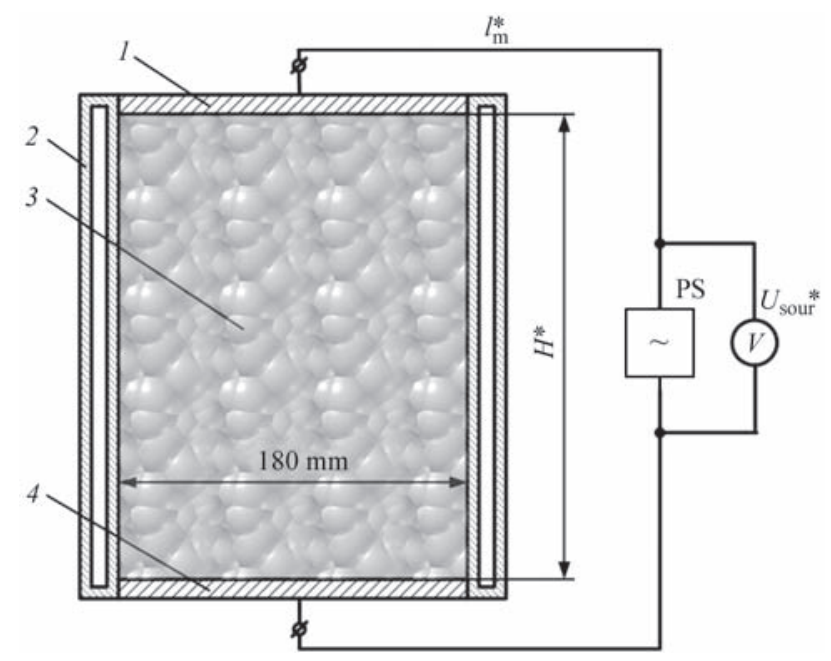

Figure 3. Model of CSM substitution structure: $U_{\text {sour }}^{*}$ - voltage of «model» power source; $I_{\mathrm{m}}^{*}$ — current of mould «model»; $H^{*}$ — height of slag pool of «model»; 1 - upper cylinder current-supplying plate; 2 - water-cooled isolated section; 3 - slag pool; 4 - lower cylinder current-supplying plate
$2 \mathrm{~kg}$ ) with progressive feed of each portion. In melting, a portion of shot transformed in a liquid metal (metallic pool), which later on solidified in form of the deposited layer of approximately $12 \mathrm{~mm}$ thickness. Initially a distance between the lower edge of current-supplying section and bottom plate with product $h_{\mathrm{mp}}$ made $85 \mathrm{~mm}$, then, after filling of each portion of cast iron shot, $h_{\mathrm{mp}}$ reduced by $12 \mathrm{~mm}$. In course of the whole process (including the periods of slag pool stabilizing after pouring the molten slag into the mould, change of its state in shot feed and due to growth of thickness of deposited layer) the measurements of such its electric parameters as mould current $I_{\mathrm{m}}$ and power source voltage $U_{\text {sour }}$ were carried out.

Measurements and record of current as well as voltage were done using universal ADC module E14140, Lenovo notebook (model Ideal Pad 4560 with 64bit operational system) and software «Power Graph». Figure 2 provides the structural scheme of electric connections in performance of the experiments on surfacing. Voltage of the intermediate section was also registered, which allowed controlling and recording difference of potentials between the intermediate section and bottom plate $U_{\text {int.s. }}$ A-622 M transformer was used as a power source in the experiments.

The next electric parameters were calculated for solution of the specified problem:

- conductivity of slag pool $G$ on mould current-supplying section-bottom plate channel;

- specific electric conductivity $\sigma$ before and after filling of the next shot portion for slag pool of a model of CSM substitution structure (Figure 3);

- specific averaged heat level of slag pool $T^{*}$. 
Regarding a heat relationship the local temperature conditions (figuratively speaking «heat layer-cake») are formation after each feed of the portion of filler in the slag pool. It is virtually impossible to register these short-term changes of temperature. Therefore, we have conventionally accepted a calculated averaged (generalized) temperature of slag $T^{*}$, determined by a value of its specific electric conductivity $\sigma$ before and after feed of each portion of the filler.

Figure 4 shows the diagrams of change in time of of difference of potentials between the intermediate section and bottom plate $U_{\text {int.s }}$ as well as conductivity of slag pool $G$. $U_{\text {int.s }}$ voltage shall give an idea on change of the level of metal pool in melting of discrete filler. It was considered that the level of pool approaches to lower edge of the intermediate section of mould at $U_{\text {int.s }}=10-15 \mathrm{~V}$ voltage and it is necessary to finish surfacing process. However, the experiment showed that at uniform increase of the level of metal pool and its approaching to intermediate section (by $12 \mathrm{~mm}$ after filling of each portion of shot) in $t_{1}-t_{2}$ interval $U_{\text {int.s }}$ voltage rapidly decreases, then a drop of $U_{\text {int.s }}$ is delayed and after timing mark $t_{4}$ (see Figure 4) starts step-by-step growth. At that, $U_{\text {sour }}$ voltage drops (Table) with rise of current $I_{\mathrm{m}}$ due to insufficiently rigid characteristic of power source. It is obvious that in this moment there is a redistribution of relationship of conductivities of the circuit sections between the bottom plate and intermediate section as well as between the intermediate section and current-supplying section. Conductivity between the bottom plate and intermediate section fairly shall increase due to decrease of distance between them in rise of level of the metal pool, and conductivity between the intermediate section and current-supplying section shall reduce quicker than conductivity between the bottom plate and intermediate section. Such a situation is possible only at rapid growth of temperature of the slag pool in the interval after $t_{4}$ mark. Electric conductivity of slag pool, which is calculated as $G=I_{\mathrm{m}} / U_{\text {sour }}$ in its essence reflects average (mean-integral) characteristic of the slag pool. Electric conductivity $\mathrm{G}$ over the whole time interval from $t_{1}$ to $t_{5}$ increases with rising speed (see

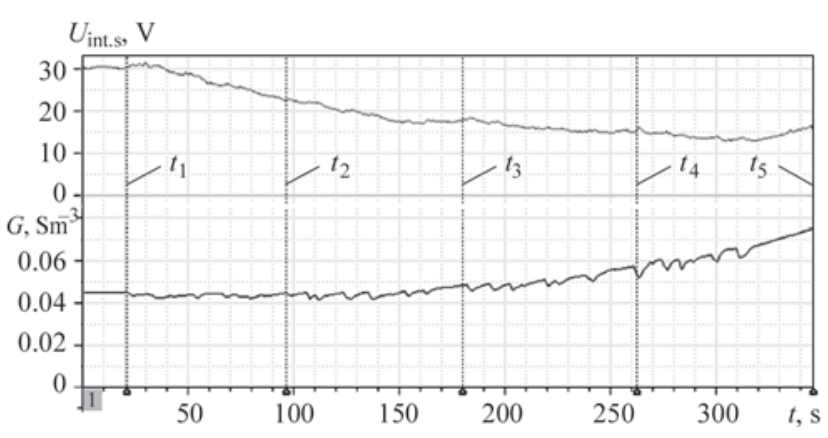

Figure 4. Change in time of difference of potentials between current-supplying section and bottom plate $U_{\text {int.s }}$ and conductivity of slag pool $G ; t_{1}-t_{2}$ - time marks

Table). This parameter indicates that energy level of the process increases, but it is difficult to evaluate change of heat level on it.

To evaluate conventional averaged heat level of the slag pool during the experiment there was calculated a specific electric conductivity $\sigma$ before and after next filling of the shot portion to the slag pool of model of CSM substitution structure (Figure 3). $\sigma$ values calculated at $t_{1}-t_{5}$ time moments were used for calculation of conventional averaged heat level of the slag pool $T^{*}$ on diagram of dependence of electric conductivity of ANF-29 flux on temperature, given in work [5]. This dependence can be well described by expression $T^{*}=230.6 \sigma+991.1$. Calculation of $\sigma$ on the model of CSM substitution structure is based on the fact that «model» has uniform electrostatic field and at equality of the values of real measured voltage of source $U_{\text {sour }}$ and «model» voltage $U_{\text {sour }}^{*}$ as well as at equality of real current $I_{\mathrm{m}}$ and current $I_{\mathrm{m}}^{*}$, specific conductivity $\sigma$ of model and averaged specific conductivity of the real mould will be equal. To get indicated equalities it is necessary to determine height of the slag pool of the model of CSM substitution structure $H^{*}$ at, respectively, equal values of diameters of the mould and «model» $(180 \mathrm{~mm})$. Specific electric conductivity $\sigma$ was calculated as $\sigma=G H^{*} /\left(2 \pi 90^{2}\right)$. $H^{*}$ values are given in the Table.

A conventional averaged heat level of the slag pool $H^{*}$ reduces during filling of the first and second portions of the shot (Figure 5) that corresponds to our understanding since each filled up portion of the shot

Measured and calculation indices of experimental surfacing in CSM

\begin{tabular}{|l|c|c|c|c|c|c|c|c|c|}
\hline \multicolumn{1}{|c|}{ Filling of cast iron shot, time mark } & Time $t, \mathrm{~s}$ & $H_{\mathrm{mp}}, \mathrm{mm}$ & $U_{\text {int.s }}, \mathrm{V}$ & $G, \mathrm{Sm}$ & $I_{\mathrm{m}}, \mathrm{A}$ & $U_{\text {sour }}, \mathrm{V}$ & $H^{*}, \mathrm{~mm}$ & $\sigma, \mathrm{Sm} / \mathrm{m}$ & $T^{*},{ }^{\circ} \mathrm{C}$ \\
\hline Start of $1^{\text {st }}$ portion filling, $t_{1}$ & 21 & 85 & 30.3 & 45.1 & 1926 & 42.7 & 166 & 295 & 1672 \\
\hline Start of $2^{\text {nd }}$ portion filling, $t_{2}$ & 96 & 73 & 22.5 & 44.5 & 1900 & 42.7 & 142 & 249 & 1565 \\
\hline Start of $3^{\text {rd }}$ portion filling, $t_{3}$ & 180 & 61 & 17.7 & 48.1 & 2020 & 42.0 & 119 & 224 & 1509 \\
\hline Start of $4^{\text {th }}$ portion filling, $t_{4}$ & 262 & 49 & 15.0 & 56.6 & 2299 & 40.6 & 101 & 226 & 1512 \\
\hline End of filling of $4^{\text {th }}$ portion, $t_{5}$ & 346 & 37 & 15.8 & 73.9 & 2801 & 37.9 & 91 & 266 & 1604 \\
\hline
\end{tabular}




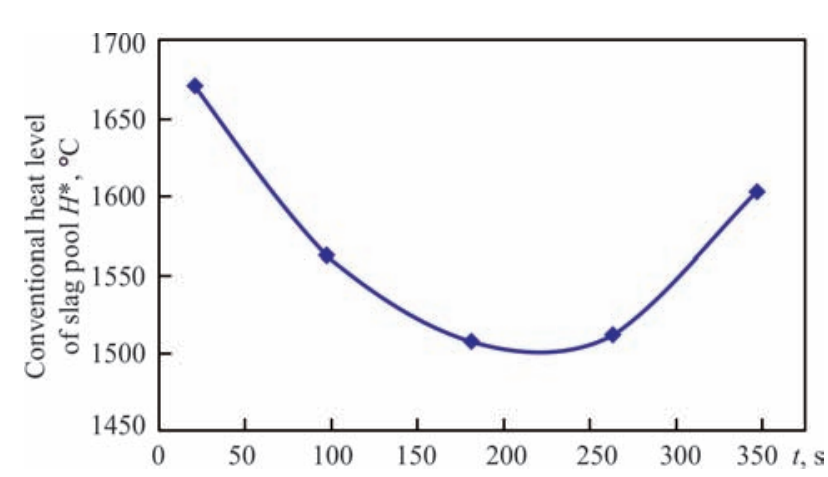

Figure 5. Change of conventional heat level of slag pool depending on time in supply of shot portion

requires heat expenses on its heating and melting, and if electric power is not enough for this then the pool cools down. After the third portion of shot the level of metal pool rises to the height, at which mould current has increased so that heat supply and consumption became equal, temperature was relatively stabilized. After the fourth portion of shot the temperature started rising up, electric conductivity of slag pool demonstrated rapid increase and there was an effect, which resulted in growth of $U_{\text {int.s }}$ (in $t_{4}-t_{5}$ time interval).

From given above it can be concluded that surfacing should be carried out at initial distance between the lower edge of current-supplying section and bottom plate $h_{\mathrm{mp}}=61 \mathrm{~mm}$, i.e. the distance which corresponded the start of filling of the third portion of cast iron in this experiment as well as at calculated value of specific conductivity of the «model» $\sigma=244 \mathrm{~S} / \mathrm{m}$. The value of specific conductivity of the «model» shall be kept during the whole process of surfacing for stabilizing quality characteristics of the deposited product by means of correction of power supply voltage. Besides, it is necessary additionally to study the possibility of evaluation of the level of metal pool on change of voltage between the intermediate section of mould and bottom plate since change of direction of voltage variation $U_{\text {int.s }}$ (increase or decrease of its value) can result in incorrect evaluation by operator of situation during surfacing.

Thus, as a result of carried investigations it was determined that production of quality deposit of a layer of determined thickness in the stationary mould requires consideration of thermophysical characteristics of the used flux and position of the product relatively current-supplying section of the mould.

1. Kuskov, Yu.M. (2003) A new approach to electroslag welding. Welding J., 4, 42-45.

2. Kuskov, Yu.M. (2003) Peculiarities of electroslag surfacing with granular filler material in current-supplying mould. Svarochn. Proizvodstvo, 9, 42-47 [in Russian].

3. Kuskov, Yu.M., Gordan, G.N., Bogajchuk, I.L., Kajda, T.V. (2015) Electroslag surfacing using discrete materials of different methods of manufacture. The Paton Welding J., 5-6, 30-33.

4. Kuskov, Yu.M. (2018) Influence of flux composition on the process of electroslag surfacing of end faces with discrete feeding of filler material. Ibid., 1, 33-37.

5. Latash, Yu.V., Fetisova, T.Ya., Voronin, A.E. (1985) Investigation of electric conductivity and toughness of slags (fluxes) of $\mathrm{CaF}_{2}-\mathrm{CaO}-\mathrm{Al}_{2} \mathrm{O}_{3}-\mathrm{SiO}_{2}$ system used in electroslag technology: Informations. Spetselektrometallurgiya, 58, 11-17 [in Russian]. 


\title{
APPLICATION OF THERMAL SPRAYING METHODS FOR MANUFACTURE OF RESISTIVE COATINGS (REVIEW)
}

\author{
Yu.S. BORISOV, S.G. VOINAROVYCH, O.M. KYSLYTSIA, \\ S.M. KALIUZHNYI and Ie.K. KUZMYCH-IANCHUK \\ E.O. Paton Electric Welding Institute of the NAS of Ukraine
}

11 Kazimir Malevich Str., 03150, Kyiv, Ukraine. E-mail: office@paton.kiev.ua

\begin{abstract}
The review describes the experience of applying thermal spraying methods in manufacture of resistive coatings, as well as the use of appropriate materials containing different alloys and oxides. The positive results of producing resistors by the method of plasma spraying were obtained, providing a service life of more than 10 thou $\mathrm{h}$ at a temperature of $150{ }^{\circ} \mathrm{C}$. The examples of practical application of resistive heating elements directly on the working surfaces of parts, requiring preheating to $400-500{ }^{\circ} \mathrm{C}$, by the methods of thermal spraying were considered. The effective application of thermal spraying of resistive coatings on the products of electronic industry is shown, the specifics of which is associated with providing heating of local areas with a minimal thermal effect on the substrate. The advantages and prospects of developments of thermal spraying technology in producing of resistive coatings in different fields of engineering (electrical engineering, electronics, instrument engineering, etc.) are noted. 17 Ref., 6 Figures.
\end{abstract}

Ke yw ord s: resistive coatings, thermal spraying, resistor, resistive heating element, electronics, electrical engineering

The list of coatings which can be applied using thermal spraying (TS) methods is predetermined by the possibility of heating the materials sprayed to the stage of melting or high plasticity. Up to nowadays, the experience in producing TS coatings from materials with different physicochemical, physicomechanical, thermophysical, electrophysical, optical, and other properties was gained. Due to this, a wide area for functional purpose of thermal coatings is available. They can be wear-resistant, corrosion-resistant, heat-protective, including also those having different electrophysical properties. The development of works in this direction allowed applying these coatings in the field of electrical engineering, electronics, radio and instrument engineering $[1,2]$. The further development of works in this field of engineering is challenging $[3,4]$.

One of the main areas of developments in the field of functional thermal coatings with special electrophysical characteristics is the creation of coatings with resistive properties. To these coatings the corresponding requirements are specified:

- high specific resistivity;

- low temperature coefficient of thermal expansion;

- ability of long-time operation at elevated temperatures, maintaining the properties;

- stable phase composition;

- minimum porosity;

- uniformity of coating across the thickness;

- high adhesion strength with the base.

Considering the experience of developments related to the formation of thermal coatings with resistive properties, a group of works is distinguished related to the application of the alloy Kh20N80 as a material for spraying, known for its resistive properties, to determine the degree of meeting the abovementioned requirements of these materials in the state of sprayed coating.

The first works in this direction were carried out in 1976 at the Drexel University (USA) with measurement of influence of the size of sprayed particles on specific resistance of plasma-sprayed coatings of powder $\mathrm{NiCr}$ [5].

The staff scientists of the State University of New York at Stony Brook (USA) carried out works on manufacture of resistive heating elements (RHE) for kitchen electric cookers, the possibility of heating to $600{ }^{\circ} \mathrm{C}$ for $1 \mathrm{~min}$ and the stability of the specific resistance of the RHE of $\mathrm{NiCr}(80 / 20)$ to $900{ }^{\circ} \mathrm{C}$ is shown [6].

The results of the investigation of the process of producing and properties of RHE in the form of strips, where the deposition of Ni20Cr layer was carried out using the methods of atmospheric plasma (APS), vacuum plasma (VPS), high-velocity oxygen fuel spraying (HVOF), were presented by the Massachusetts Institute of Technology (USA) [7]. On the strip base an insulating ceramic layer was deposited, and then a resistive coating of 75-300 $\mu \mathrm{m}$ thick was sprayed. The advantage of methods VPS and HVOF was shown in connection with more dense, uniform across the thickness and pure microstructure of coating.

A detailed investigation of properties of the resistors produced by the methods of plasma and high-velocity oxygen fuel spraying using $\mathrm{Ni}$ and $\mathrm{Ni} 20 \mathrm{Cr}$ powders was carried out at the Modena University (Italy) [8]. The effect of cyclic heating and cooling on the stability of characteristics of these resistors was established.

A comprehensive complex of investigations on the application of composite thermal coatings as functional ones in the manufacture of film heaters 


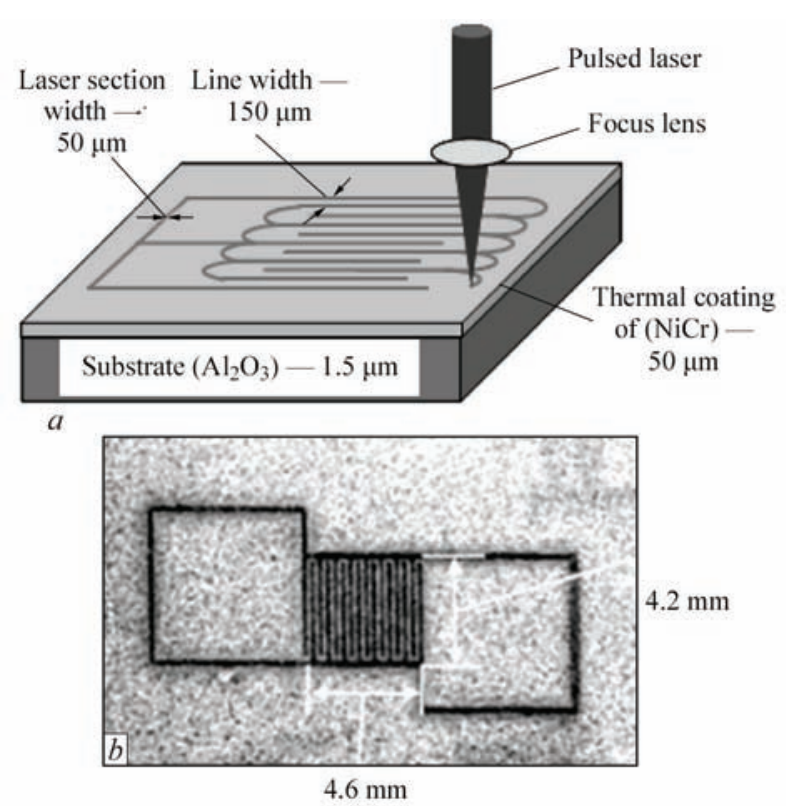

Figure 1. Scheme of producing high-definition sensors applying thermal coating of $\mathrm{NiCr}$ with the following flashing by CAD-laser: $(a)$ and example of microheating element sensor $(b)$

was performed at the University of Stuttgart (Germany) [9]. Spraying of coatings from the powders and wires NiCr, Fe13Cr, FeCrAl was carried out using the methods APS, HVOF and electric arc spraying. The investigation of the relationship between the electrical properties and service life of heaters and the structure and properties of sprayed layers was carried out.

The development of TS technology in the manufacture of resistive sensors for control of temperature of gas turbine blades was carried out by the Siemens Power Generation (Germany) and MesoScribe Technologies (USA) [10, 11]. The NiCr-based sensors,

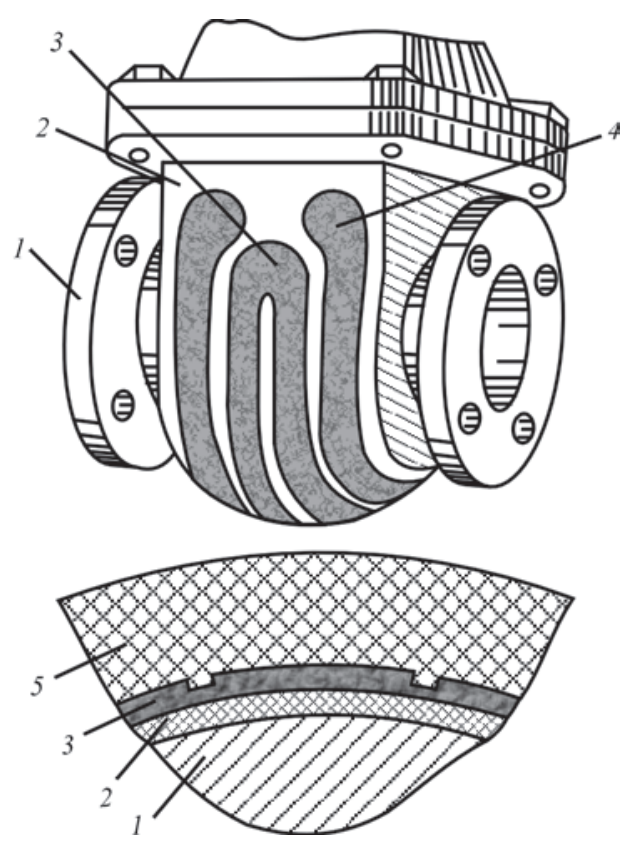

Figure 2. Casing of stop valve with sprayed heating element [12] 1 - casing; 2 - electrical insulating layer; 3 - resistive track; 4 - supplying electrical contact; 5 - additional external electrical insulating layer placed directly on the working surfaces of the blades, provide a constant temperature monitoring of their condition (Figure 1).

Deposition of heating element by thermal methods directly onto the working surface provides a significant increase in heat transfer efficiency up to $96 \%$. The I.N. Frantsevich Institute for Problems in Materials Science of the NAS of Ukraine developed at the time such RHE, which were deposited by the TS method [12]. The composite RHE consisted of an electrical insulating coatings based on aluminum oxide or magnesium aluminate spinel of 300-600 $\mu \mathrm{m}$ thickness depending on operating conditions and a resistive heating layer based on nichrome powders, nickel and their alloys of 100-200 $\mu \mathrm{m}$ thickness. The RHE can be operated up to the heating temperatures of $400-500{ }^{\circ} \mathrm{C}$. An example of the Du- 100 valve is given, installed in the sulphur transportation line with an operating temperature of $180{ }^{\circ} \mathrm{C}$ (Figure 2).

Such RHE sprayed on the surface of valves, stop valves, provide stable, high operating characteristics during outdoor installing and operation under unfavourable conditions. The use of resistive material $\mathrm{NiO} / \mathrm{Fe}_{3} \mathrm{O}_{4}$ with a good stability of electrical properties at elevated temperatures allows manufacturing resistors using the method of plasma spraying for a whole number of products in the electronic industry [13]. The results of duration of stable operation of resistors, produced by the method of plasma spraying from the mixture $\left(\mathrm{NiOFe}_{3} \mathrm{O}_{4}\right.$ 55/45) during 10 thou $\mathrm{h}$ spent in air at $150{ }^{\circ} \mathrm{C}$, and for resistors with a resistance value of $340 \mathrm{Ohms}$ are shown in the form of a histogram (Figure 3). The Figure shows, that the change in resistance is always less than $10 \%$ and the average deviation for most resistors is equal to $5 \%$, which corresponds to the technical specifications: $2 \%$ for $1000 \mathrm{~h}$ of operation. The change in the composition of powder and the film thickness allows withstanding the value of thermal expansion coefficient in the range of $200 \cdot 10^{-6} \mathrm{Ohm} /{ }^{\circ} \mathrm{C}$, which corresponds to the value for resistors produced by screen printing.

The advantage of TS when applying resistive coatings consists in the high mechanical strength of coatings, produced by plasma spraying, as well as the ability of reducing the production costs due to the use of inexpensive substrates and coating materials in the manufacture of resistive films for integrated circuits, the resistance of which can vary from tenths of Ohms to several MOhms. Other advantages of TS over the method of screen printing with paste application, where the firing procedure leads to increase in labour intensity and limits the selection of bases with the requirement of using expensive refractory ceramics, allow plasma spraying as a method of manufacturing thick-film coatings for microelectronics to significantly expand the practical use of electronic voltage regulators. In particular, the use of resistive coatings in the 


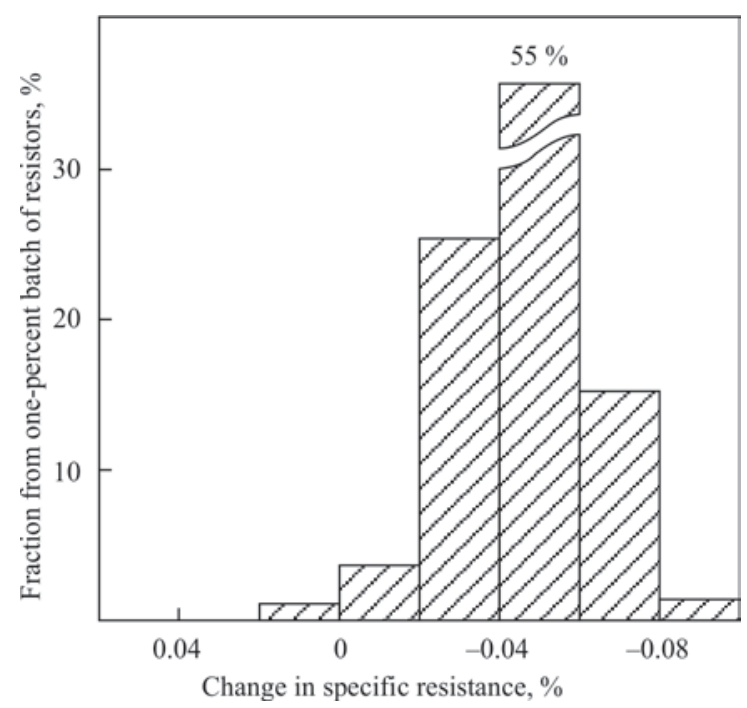

Figure 3. Change in specific resistance of batch of resistors after 10 thou h of operation at $150{ }^{\circ} \mathrm{C}$ in air

automobile industry requires accounting for the operating conditions: environmental temperature range from -40 to $110{ }^{\circ} \mathrm{C}$ with sharp temperature fluctuations; change in humidity; vibration forces of up to 30 $\mathrm{g}$; resistance to a whole number of polluting materials, including gasoline, diesel fuel, detergents, antifreeze, dust, salt; abrasive influence of sand; fungi. In this regard, the use of plasma spraying in the manufacture of microcircuits significantly allows increasing the reliability of their operation under the conditions of vibrations, temperature and humidity fluctuations, which will allow using them in the automobile industry (creating electronic speed controllers, windscreen wiper control, systems of fuel injection and ignition).

At the Fraunhofer Institute for Ceramic Technologies and Systems (Germany), RHE of $\mathrm{TiO}_{2}$ were produced, applying the methods of HVOF and APS at a thickness of resistive coating from 100 to $200 \mu \mathrm{m}$ in the form of a plane and tubular heater with a heating temperature of $300{ }^{\circ} \mathrm{C}$ (Figure 4) [14]. The electrical insulation properties were obtained by applying a deposited spinel layer with a thickness of up to $300 \mu \mathrm{m}$.

According to the work results the conclusions were made concerning the further development of the investigation with the spraying of coatings with resistive properties of $20 \% \mathrm{Cr}_{2} \mathrm{O}_{3}-\mathrm{TiO}_{2}$ mixture to increase the operating temperature of heating over $300^{\circ} \mathrm{C}$.
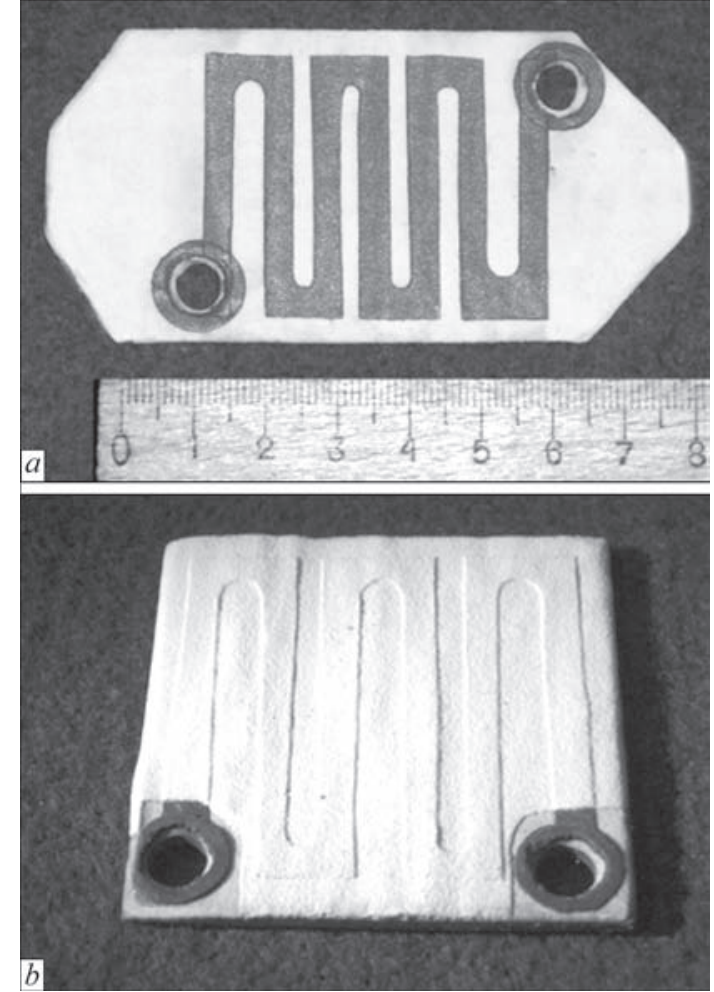

Figure 5. Resistive heating element: $a, b$ - respectively, two-layer and three-layer coating of $\mathrm{Al}_{2} \mathrm{O}_{3}$ and $\mathrm{TiO}_{2}$

At the E.O. Paton Electric Welding Institute the specimens of RHE from multilayer coatings were produced, applied on a steel base by microplasma spraying method (Figure 5) [15].

To form narrow resistive tracks, the powder $\mathrm{TiO}_{2}$ with particles size of 15-40 $\mu \mathrm{m}$ was used. For electrical insulation of resistive tracks from the steel base, a sublayer of the powder $\mathrm{Al}_{2} \mathrm{O}_{3}$ with particles size of $-40 \mu \mathrm{m}$ was preliminarily applied to the latter. The carried out tests of resistive heating elements showed their serviceability up to a temperature of $230{ }^{\circ} \mathrm{C}$ at a specific power of $75 \mathrm{~W}$ (Figure 6).

Using plasma spraying method, the State Scientific and Production Powder Metallurgy Association (Republic of Belarus) manufactured RHE applying lanthanum chromite $\left(\mathrm{LaCrO}_{3}\right)$ coatings [16]. This material allows increasing the operating temperature of the RHE to $1800^{\circ} \mathrm{C}$. With RHE of $\mathrm{LaCrO}_{3}$ the electric furnaces for testing and treatment of ceramic products of refractory metals were equipped, which allowed
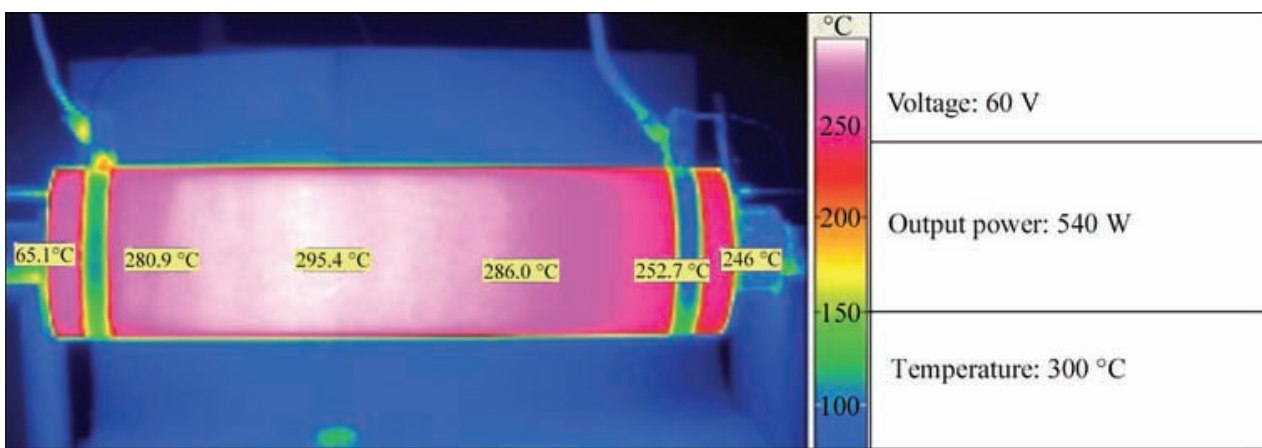

Figure 4. Heat distribution of temperature of heated tubular RHE [14] 


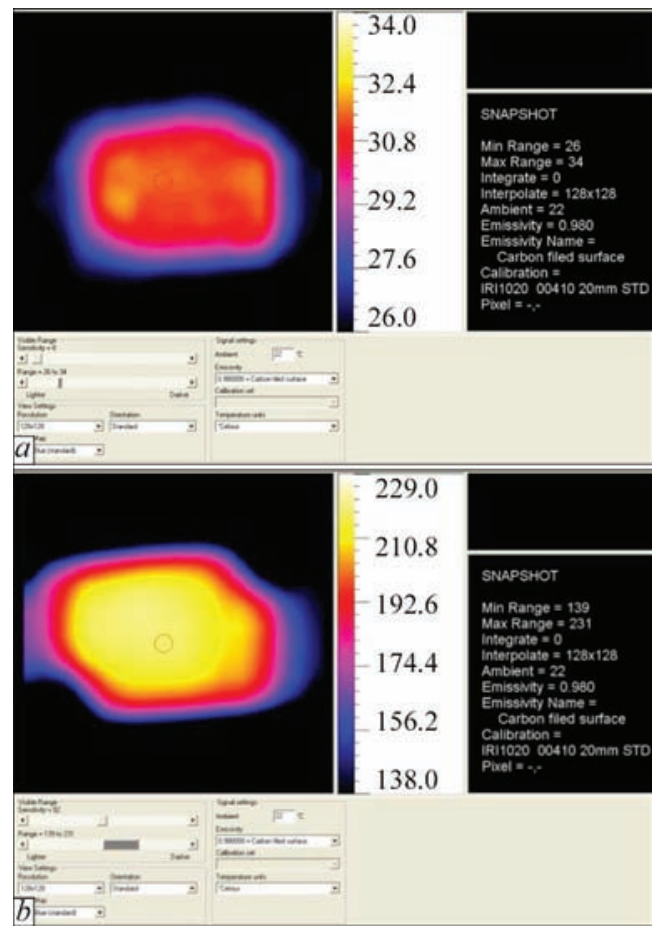

Figure 6. Heat distribution over resistive tracks of $\mathrm{TiO}_{2}$ depending on time ( $a$ - initial heating temperature; $b$ - final temperature)

not only achieving higher heating temperatures, but also replacing RHE of silicon carbide with multiple prolongation of their service life in electric furnaces with the heating temperature to $1450{ }^{\circ} \mathrm{C}$ [17].

\section{Conclusions}

1. For thermal application of resistive coatings the methods of atmosphere (APS) and vacuum (VPS) plasma, high-velocity oxygen fuel spraying (HVOF) were used. The best results on the quality and service life of such resistive coatings were obtained in case of using VPS and HVOF due to the formation of a denser and purer microstructure of sprayed layers.

2. As materials for spraying of resistive coatings, the powders of alloys $\mathrm{NiCr}$, NiAl, FeCr, FeCrAl were used. The most widespread is producing a resistive coating of the alloy $\mathrm{Kh} 20 \mathrm{~N} 80$. The list of applied ceramic materials includes $\mathrm{Al}_{2} \mathrm{O}_{3}, \mathrm{MgAl}_{2} \mathrm{O}_{3}$ - for deposition electric insulating coatings, $\mathrm{TiO}_{2}, \mathrm{LaCrO}_{3}$, $\mathrm{MoSi}_{2}, \mathrm{SiC}$ - for manufacturing heaters, $\mathrm{NiO} / \mathrm{Fe}_{3} \mathrm{O}_{4}$, spinel $\mathrm{Mn}-\mathrm{Co}-\mathrm{Ni}-\mathrm{O}$ - for elements of microcircuits.

3 . The practical purpose of thermal spraying of resistive coatings consists in manufacture of heaters and components of microcircuits (resistor, thermistor, posistor), as well as sensors of different functional purposes.

4. The examples of tested practical application of thermal spraying of resistive coatings are the spraying of a resistive heating element on the working surface of the heating unit, instrument, device, which provides an improvement in heat transfer efficiency up to $96 \%$; manufacture of plane and tubular heaters, manufacture of microcircuits with improved mechanical strength, in particular, for challenging application in the automobile industry as electronic speed controllers, fuel injection and ignition systems, etc. The application of thermal spraying in manufacture of resistive films for integrated circuits will allow reducing production costs, costs for substrates and coating materials.

1. Borisov, Yu.S., Borisova, A.L. (1986) Plasma powder coatings. Kiev, Tekhnika [in Russian].

2. Lyasnikov, V.N., Ukrainsky, V.S., Bogatyryov, G.F. (1985) Plasma spraying of coatings in production of electronic engineering products. Saratov, Sarat. Un-t [in Russian].

3. Sanjay Sampath (2010) Thermal spray applications in electronics and sensors: past, present, and future. J. Thermal Spray Technol., 19(5), 921-949.

4. Vardelle, A., Moreau, C. et al. (2016) The 2016 Thermal Spray Roadmap. Ibid., 25(8), 1376-1440.

5. Smyth, R.T., Andersen, J. C. (1976) Electronic circuit production by arc plasma spraying. In: Proc. of Int. Thermal Spray Conf., American Welding Society, Miami, FL, 456-463.

6. Mac Crone, R. K., Herman, H. (1984) Thermal spray fabrication of electrical conductor. Insulator Systems, Rensselaer Polytechnic and State University of New York at Stony Brook.

7. Michels, D., Hadeler, J., Lienhard, J. H. (1998) High-heatflux resistance heaters from VPS and HVOF thermal spraying. Exp. Heat Transfer, 11, 341-359.

8. Prudenziati, M., Gualtieri, M. L. (2008) Electrical properties of thermally sprayed $\mathrm{Ni}$ - and $\mathrm{Ni} 20 \mathrm{Cr}$-based resistors. J. Thermal Spray Technol., 17(3), 385-394.

9. Killinger, A., Gadow, R. (2006) Thermally sprayed coating composites for film heating devices. Adv. Sci. Technol., 45, 1230-1239.

10. Mitchell, D., Kulkarni, A., Roesch, E. et al. (2008) Development and F-class industrial gas turbine engine testing of smart components with direct write embedded sensors and high temperature wireless telemetry. In: Proc. of ASME Turbo Expo 2008: Power for Land, Sea and Air (June 9-13 Berlin 2008, Germany), GT2008-51533.

11. Liang, S., Ravi, B. G., Sampath, S., Gambino, R. J. (2006) Microstructure and electrical characteristics of plasma sprayed thick film Mn-Co-Ni oxide thermistor. In: Proc. of Materials Research Symposia of State University of New York at Stony Brook, 900E, 0900-006-41.1-6.

12. Griffen, L.A., Dyadechko, A.G. et al. (1990) Heating elements for fittings produced by thermal powder spraying. Poroshk. Metallurgiya, 5, 102-104 [in Russian].

13. Smyth, R. T., Anderson J. C. (1976) Electronic circuit production by arc plasma spraying. In: Proc. ITSC 8th Int. Thermal Spraying Conf. (September 28-October 1, Miamie Beach), 456-463.

14. Scheitz, S., Toma, F.-L., Berger, L.-M. et al. (2011) Thermally sprayed multilayer ceramic heating elements. Thermal Spray Bull. 4(2), 88-92.

15. Borisov, Yu.S., Vojnarovich, S.G., Kislitsa, A.N. et al. (2018) Application of the method of microplasma spraying for manufacturing resistance heating element. The Paton Welding J., 2, 33-37.

16. Dostanko, A.P., Kundas, S.P., Bordusov, S.V. et al. (2001) Plasma processes in manufacturing of electronic engineering products. In: 3 Vol. Vol. 3: Ed. by A.P. Dostanko, P.E. Vityaz. Minsk, FU Ainform, 175-177 [in Russian].

17. Barykin, B.M., Gordon, V.G., Romanov, A.I. et al. (1980) Investigation of ceramic heating elements based on alloyed lanthanum chromite. Elektrotekhnich. Promyshl. Elektrotekhn. Mat-ly, 2(11B), 6-8 [in Russian]. 


\section{INTERNATIONAL CONFERENCE «MATHEMATICAL MODELLING AND INFORMATION TECHNOLOGIES IN WELDING AND RELATED PROCESSES»}

IX International Conference «Mathematical modelling and information technologies in welding and related processes» - MMITWRP-2018 was held on September 10-14, 2018 in Odessa at «Kurortnyi» hotel.

The Conference was organized by the International Association «Welding».

This Conference has become traditional starting from 2002 and every two years gathers the specialists in the field of mathematical modelling of physical processes taking place in welding from different countries of the world.

45 scientists and specialists from Ukraine and Belarus as well as specialists from Germany with remote participation took part in the Conference work, which was organized in form of sessions of plenary and poster presentations.

The Conference was opened by the head of the Program Committee Prof. I.V. Krivtsun. In his speech he fixed on the problems, possibilities and tasks of mathematical modelling and theoretical analysis of the physical processes in the field of welding and related technologies.

Let's note some presentations, which give an idea of the discussed Conference topics:

- «Effect of current and arc length on characteristics of arc discharge in nonconsumable electrode welding», Krivtsun I.V., Demchenko V.F., Krikent I.V., Kovalenko D.V., E.O. Paton Electric Welding Institute (PWI);

- «Modelling of residual stresses in welded joint of header to nozzle of steam generator PG-1000M», Makhnenko O.V., Muzhichenko A.F., Saprykina G.Yu., PWI;

- «Mathematical modelling of heat, electro- and hydrodynamic processes in ESK of forging ingots of alloyed steels», ${ }^{1}$ Sibir A.V., ${ }^{2,3}$ Medovar L.B., ${ }^{1}$ Gubinsky M.V., ${ }^{2}$ Polishko A.A., ${ }^{2,3}$ Stovpchenko A.P., ${ }^{2}$ Kolomiets D. $V$., ${ }^{1}$ National Metallurgical Academy of Ukraine, Dnepr, ${ }^{2} \mathrm{PWI},{ }^{3}$ «Elmet-Roll», Kyiv;

- «Calculaed estimation of thermal cycles in friction welding of dissimilar nickel alloys», Zyakhor I.V., Velikoivanenko E.A., Rozynka G.F., Zavertanny M.S., PWI;

- «Nonstationary processes in arc plasma and welded metal in TIG welding with high-frequency current modulation», Demchenko V.F., Krivtsun I.V., Krikent I.V., Abdulakh V.M., PWI;

- «Effect of preheating on thermal cycle of argon-arc welding of sparsely-doped titanium alloys», Akhonin S.V., Belous V.Yu., Selin R.V., PWI;

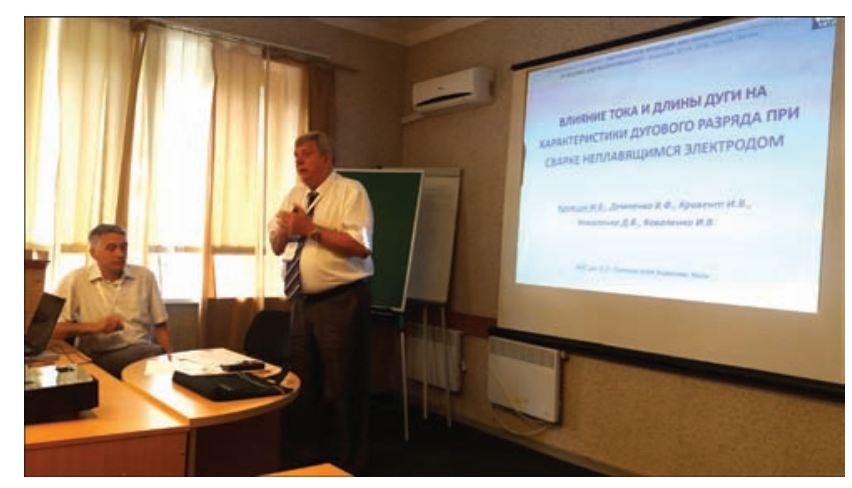

Presentation of Prof. I.V. Krivtsun

- «Complex mathematical model of the process of plasma-induction growing of single-crystals of refractory metals», Gnizdylo A.N., Shapovalov V.A., Yakusha V.V., PWI;

- «Investigation of thermal fields in reaction brazing under conditions of local heating of joint zone» ${ }^{1}$ Kulinich M.V., ${ }^{2}$ Zaporozhets T.V., ${ }^{2}$ Gusak A.M., ${ }^{1}$ Ustinov A.I., ${ }^{1}$ Kosintsev S.G., ${ }^{1} \mathrm{PWI},{ }^{2}$ Bogdan Khmelnytsky National University of Cherkassy;

- «Modelling of thin-wall cylinder shells produced by additive method», Kostin V.A., PWI;

- «Effect of residual welding stresses on evaluation of fracture resistance of elements of WWER1000 reactor internals for substantiation of operation extension», Makhnenko O.V., Kandala S.M., Savitskaya E.M., PWI;

- «Shape of welding current pulses optimum by force action», ${ }^{1}$ Demchenko V. F., ${ }^{1}$ Krivtsun I.V., ${ }^{2}$ Nomirovsky D.A., ${ }^{1} \mathrm{PWI},{ }^{2}$ Taras Shevchenko National University of Kyiv;

- «Effect of mode of arc welding on formation of metastable phases in weld metal and HAZ of highstrength pseudo $\beta$-titanium alloy VT19», Belous V.Yu., Kostin V.A., Grigorenko G.M., Selin R.V., Grigorenko S.G., PWI;

- «Effect of technological parameters of submerged-arc surfacing of anticorrosive layer in nozzle zone of WWER-1000 RV on distribution of residual stresses», Makhnenko O.V., Kostenevich E.S., PWI;

- Mathematical modelling of wire melting and detachment of drops in arc welding», ${ }^{1} O$. Semenov, ${ }^{1}$ I. Krivtsun, ${ }^{2} U$. Reisgen, ${ }^{2} A$. Schiebahn, ${ }^{2} O$. Mokrov, ${ }^{2} M$. Simon, ${ }^{2}$ R. Sharma, ${ }^{2}$ P. Lozano, ${ }^{2}$ S. Mann, ${ }^{1} \mathrm{PWI},{ }^{2}$ Institute of Welding and Joining, RTWH, Aachen, Germany; 
- «Prediction of microstructure and mechanical properties in layer-by-layer formation of products from titanium alloy VT6 using EBW», ${ }^{1}$ Makhnenko O.V., ${ }^{1}$ Kandala S.M., ${ }^{1}$ Ananchenko N.S., ${ }^{2}$ Kovalchuk D.V., ${ }^{1} \mathrm{PWI}$, JSC «Chervona Hvilya», Kyiv;

- «Mathematical modelling of combined process of ESR + CC for production of high-quality rail steel», ${ }^{1}$ Sibir A.V., ${ }^{2,3}$ Medovar L.B., ${ }^{1}$ Gubinsky M.V., ${ }^{1}$ Polishko A.A., ${ }^{2,3}$ Lebed V.A., ${ }^{1}$ National Metallurgical Academy of Ukraine, Dnepr, ${ }^{2} \mathrm{PWI},{ }^{3}$ «Elmet-Roll», Kyiv;

- «Mathematical modelling of process of formation of stress-strain state in laser treatment», Devojno O.G., Kardapolova M.A., Pilipchuk A.P., Belarusian National Technical University, Minsk;

- «Structural transformations in welded joints of HPP steam lines», Dmitrik V.V., Glushko A.V., NTU «Kharkiv Polytechnic Institute»;

- «Prediction of peculiarities of kinetics of thermodeformed state of compact specimens of different geometry in their layer-by-layer forming on xBeam 3D Metal Printer equipment», Makhnenko O.V., Milenin A.S., Velikoivanenko E.A., Rosynka G.F., Pivtorak N.I., Kozlitina S.S., Dzuybak L.I., Kovalchuk D.V., PWI;

- «Physical modelling of processes of melting, hydrodynamics and metal solidification in electroslag technologies», Protokovilov I.V., Porokhonko V.B., PWI;

- «Modelling of processes of external electromagnetic effect in underwater welding», ${ }^{1}$ Maksimov S.Yu., ${ }^{1}$ Prilipko E.A., ${ }^{2}$ Krazhanovsky D.M., ${ }^{2}$ Vinnichuk S.D., ${ }^{1} \mathrm{PWI},{ }^{2} \mathrm{Pukhov}$ Institute for Modelling in Energy Engineering, Kyiv.

A round-table «Processes of welding and related technologies: theoretical investigations, mathematical modelling, calculation experiment» (moderators Acad. of the NAS of Ukraine I.V. Krivtsun and Prof. V.F. Demchenko) was held during the Conference.

In his speech I.V. Krivtsun noted that one of the key problems of modern industrial production is improvement of existing and development of new high-performance technologies of joining and processing of metallic materials. Among them there are, for example, such technological processes as fusion welding, surfacing, coating spraying, heat treatment of surface, arc refining of steels. At current stage of development of welding and related technologies solution of this problem is impossible without detailed investigation of collection of physical phenomena (heat, diffusion, gas-, hydrodynamic, electromagnetic, optical, etc.), taking place at interaction with welded or treated material of different sources of heat energy. This is gas-discharge, first of all arc, plasma, electromagnetic, in particular, laser radiation or their combination.

Experimental investigation of physical nature of such multifactor interaction is connected with sig- nificant difficulties, caused by high values of plasma temperature and surface of material being treated in a zone of effect of heat source, small geometry sizes of the indicated zone, high rates of investigated processes and series of other circumstances. Besides, received experimental data, as a rule, reflect cumulative result of effect of the whole complex of physical processes taking place in a system «heat source-material being treated» at that to detect a role of each of them in formation of resulting effect appears to be sufficiently difficult problem. Therefore, in the recent decades the methods of theoretical investigation, including development of mathematical models, as well as appearing with development of computer engineering numerical methods and packets of application programs for complex computer modelling of physical processes in welding and material processing attract more and more attention of the specialists. Such an approach allows significantly reducing the expenses connected with performance of large amount of expensive full-scale experiments, since provides the possibility of sufficiently quick and relatively cheap qualitative and quantitative analysis of the processes taking place in the considered system, for wide range of conditions and parameters of mode of welding or treatment, characteristics and properties of welded or treated material. Besides, what is particularly important, numerical modelling allows investigating the effect on a predicted result of the technological process of each of considered by model physical phenomena separately and, thus, determining the optimum ways and methods of improvement of technology and equipment under study for its realization.

V.F. Demchenko stopped on those tendencies, which take place in the field of mathematical modelling of welding and related processes in the recent years. In particular, he noted that there is increase of number of researches using standard packets of the application programs for integration of mathematical physics equations.

Proceedings of MMITWRP-2018 Conference will be published till the end of 2018. These proceedings as well as proceedings of the previous eight International Conferences MMITWRP can be ordered in the editorial board of «The Paton Welding Journal» or get in e-form in open access on website of the Paton Publishing House http://patonpublishinghouse.com/rus/ proceedings/mmw.

The next, X International Conference «Mathematical modelling and information technologies in welding and related processes» is planned to be carried out in Odessa in September 2020. 


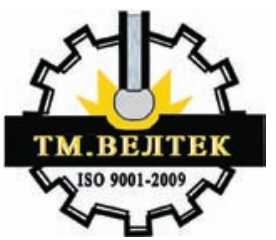

\section{LLC «TM.WELTEK»: 25 Years in the World of Flux-Cored Wires}

In 1993 the staff of the E.O. Paton Electric Welding Institute organized an enterprise, the objective of which was restoration of flux-cored wire production in Ukraine. The new enterprise rented an unused shop on flux-cored wire production at OJSC «Dneprometiz» (City of Dniepr), which was put into operation already in 1964.

Owing to the efforts of engineering-technical personnel and workers of the shop, production was restored and manufacturing of a large range of new modern grades of flux-cored wires was mastered. Here, the physical and moral wear of the equipment was a bottleneck, leading to high cost of labour and material resources, increasing the consumption of materials and cost of flux-cored wire manufacture, and did not ensure the required labour efficiency. The main shop equipment (4/250 drawing mills) was designed for producing flux-cored wires of $2.5-3.6 \mathrm{~mm}$ diameter, that did not meet the modern industry needs.
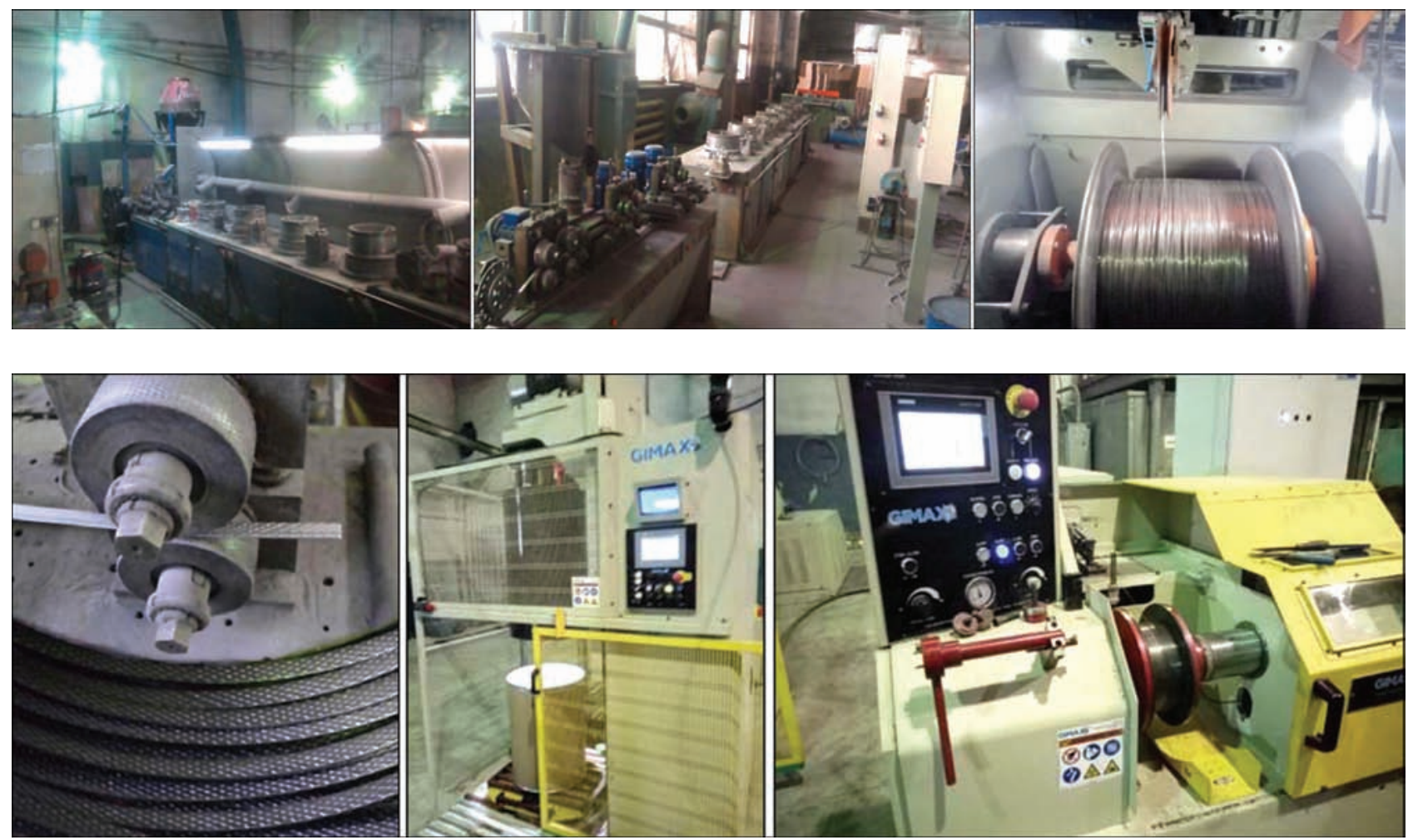

For this reason, the enterprise implemented a set of measures for repair and upgrading of old equipment and purchase of new equipment, in particular, lines for flux-cored wire production, including double mill 2/500 for producing large diameter wires $(4.0-6.0 \mathrm{~mm})$, two six high mill 6/250 and eight high mill $8 / 250$. All these mills are fitted with improved forming devices and storages. Production of flux-cored strips was restored. Furnaces for drying raw materials and flux-cored wire baking and, packing complex were purchased, and charge preparation compartment was upgraded.

Availability of such equipment allowed optimizing the technology of producing flux-cored wires of 1.0 up to $6.0 \mathrm{~mm}$ diameters, developing and producing a number (more than 90 grades) of modern, often unique domestic welding and surfacing flux-cored wires, including those for spraying. 

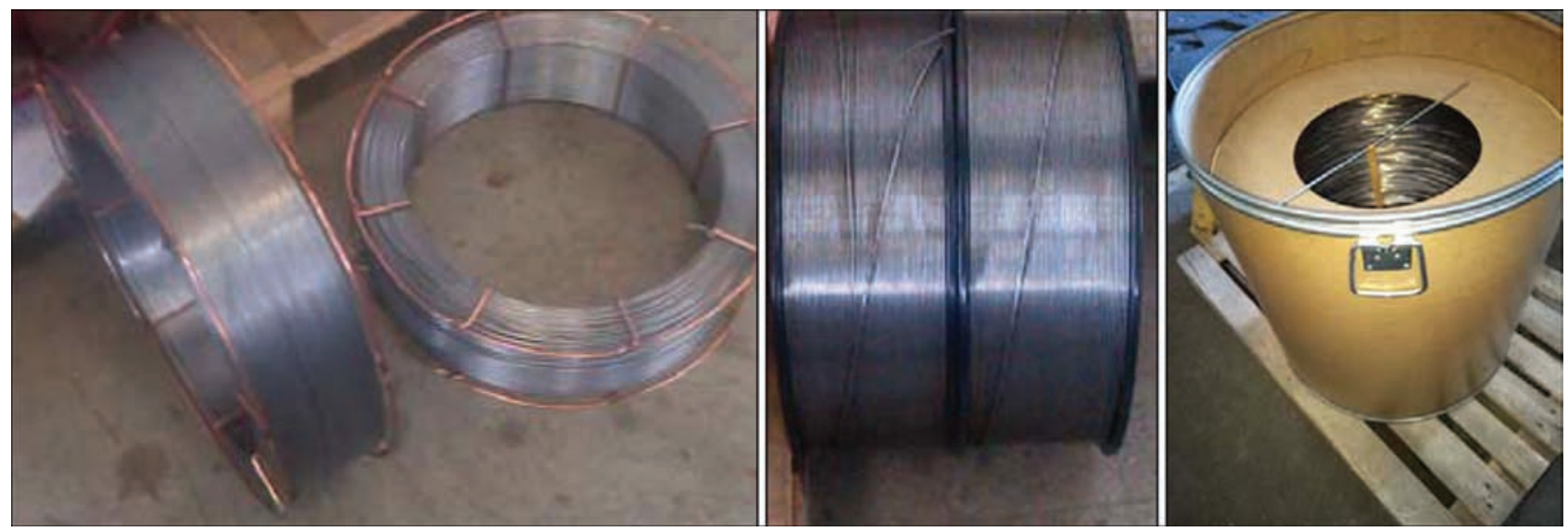

Modern forms of product delivery to DSTU ISO 544 have been mastered by now: cardboard drums with packed wire weight of 150-300 kg; frame drums R 415 an R 435; plastic spools S 200 and S 300 and a number of specific variants of packing, made by customer request.

As to their purpose and technical characteristics, the flux-cored wires of WELTEK grade are not inferior to products of leading foreign companies that is confirmed by their acceptance by many enterprises in Ukraine and abroad. For instance, flux-cored welding wire designed for welding low-carbon and low-alloyed structural steels has passed testing in keeping with European Directive No.305/2011 (System 2+) in the field of building components and received CE marking. Testing was performed by TUF Division Rheinland Industrie Service GmbH (Germany).

Controlling bodies of Ukraine on ecology, fire safety, labour safety, etc. issued permission documents for conducting the production activity of the enterprise.

Flux-cored wires of WELTEK trade mark are used in the most diverse sectors of industry: in railway enterprises, works of mining-metallurgical complex, plants producing metal structures, machine-building plants, in shipbuilding, etc.

A.A. Golyakevich
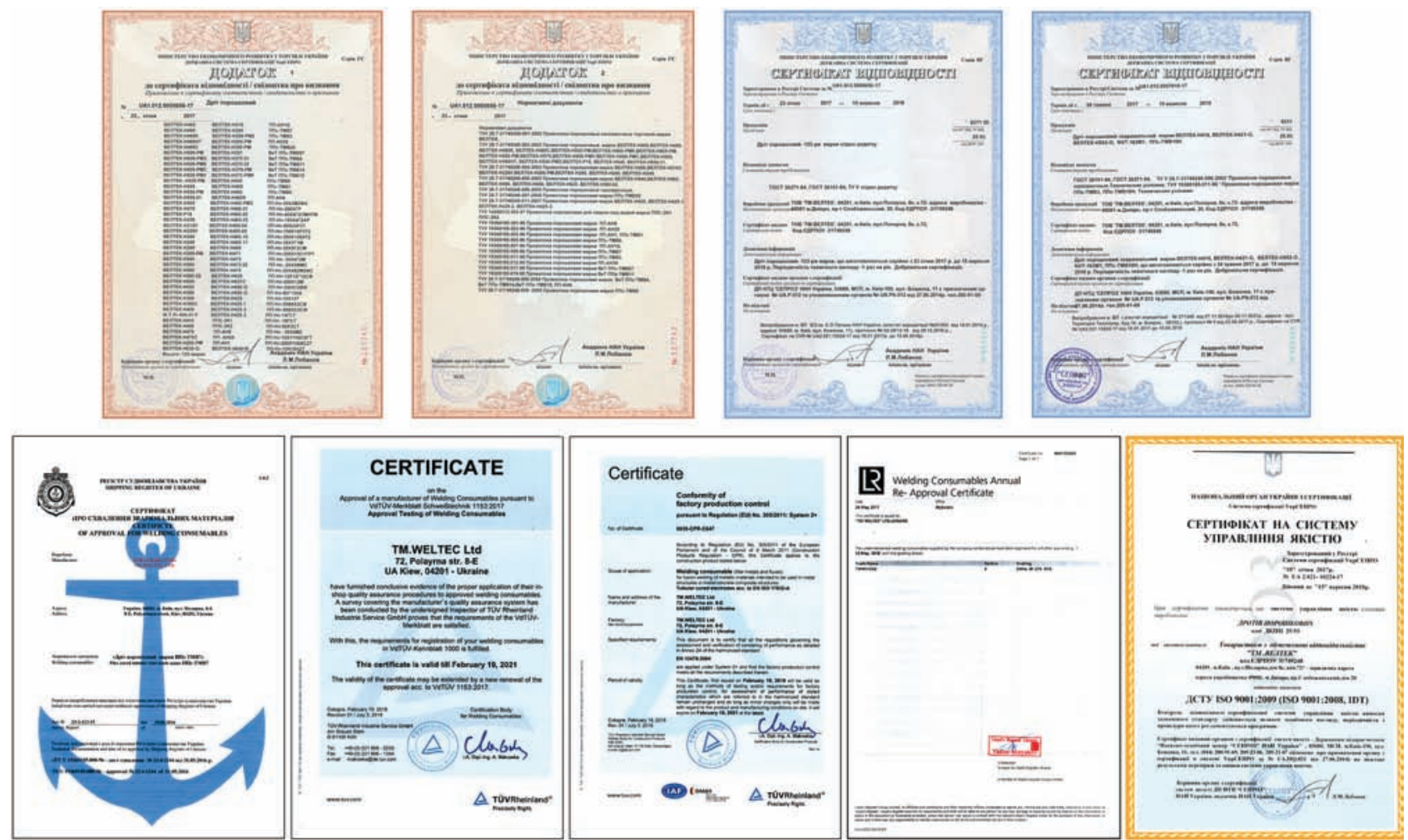